\title{
Assessment of management information system [MIS] of national program for family planning and primary health care [LHW Program]
}

Arshad Mahmood

Population Council

Syeda Saman Naz

Follow this and additional works at: https://knowledgecommons.popcouncil.org/departments_sbsr-rh

Part of the Health Policy Commons, and the International Public Health Commons

How does access to this work benefit you? Let us know!

\section{Recommended Citation}

Mahmood, Arshad and Syeda Saman Naz. 2012. "Assessment of management information system [MIS] of national program for family planning and primary health care [LHW Program]." Islamabad: Population Council. 


\section{Assessment of}

Management Information System [MIS] of National Program for Family Planning and Primary Health Care [LHW Program]

Authors:

Arshad Mahmood Ph.D.

Syeda Saman Naz 


\section{Assessment of \\ Management Information System [MIS] of \\ National Program for Family Planning and \\ Primary Health Care [LHW Program]}

Authors:

Arshad Mahmood Ph.D.

Syeda Saman Naz

(f) Population Council 


\section{Population Council}

The Population Council, an international, non-profit, non-governmental organization established in 1952, seeks to improve the well-being and reproductive health of current and future generations around the world and to help achieve a humane, equitable, and sustainable balance between people and resources.

The Council analyzes population issues and trends; conducts research in the reproductive sciences; develops new contraceptives; works with public and private agencies to improve the quality and outreach of family planning and reproductive health services; helps governments design and implement effective population policies; communicates the results of research in the population field to diverse audiences; and helps strengthen professional resources in developing countries through collaborative research and programs, technical exchange, awards, and fellowships.

The Population Council reserves all rights of ownership of this document. No part of this publication may be reproduced, stored or transmitted in any form by any means-electronic, photocopying, recording or otherwise-without the permission of the Population Council.

For inquiries, please contact:

Population Council

Add: $\quad 7$, Street 62, F-6/3, Islamabad, Pakistan

Tel: $\quad 92518445566$

Fax: $\quad 92512821401$

Email: info.pakistan@popcouncil.org

Web: http://www.popcouncil.org

http://www.falah.org.pk

Layout and Design: Ali Ammad

Published: March, 2012

Disclaimer

"This study/report is made possible by the generous support of the American people through the United States Agency for International Development (USAID). The contents are the responsibility of the Population Council, Islamabad and do not necessarily reflect the views of USAID or the United States Government." 


\section{Table of contents}

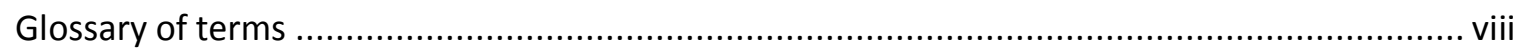

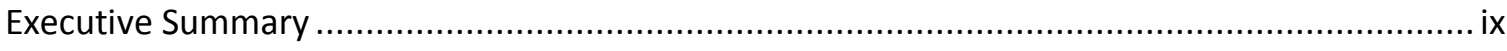

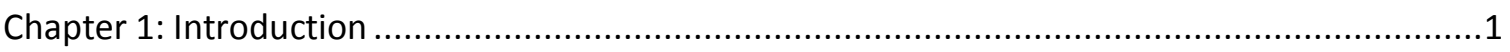

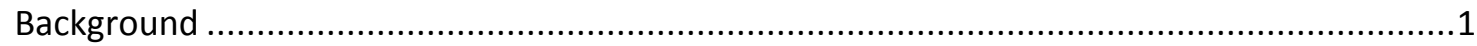

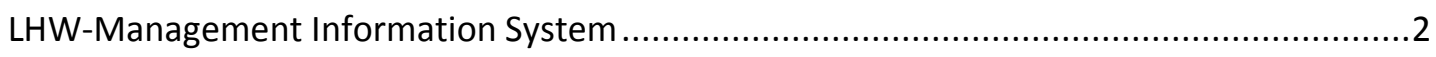

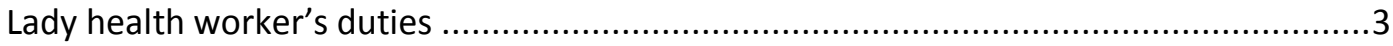

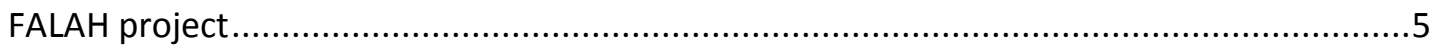

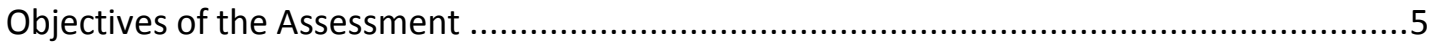

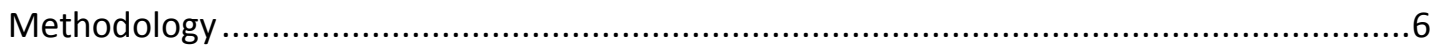

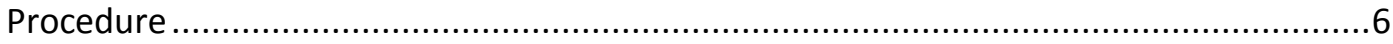

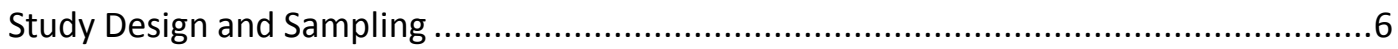

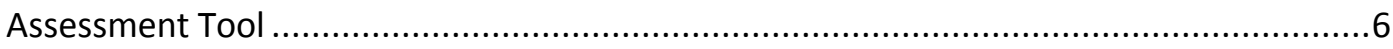

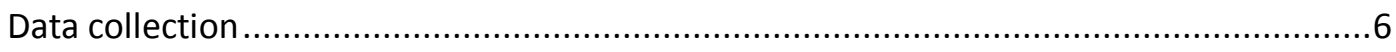

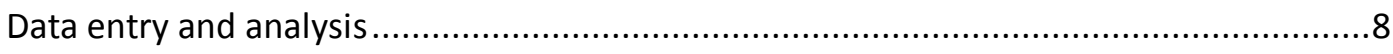

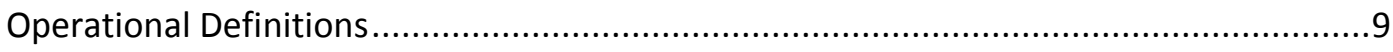

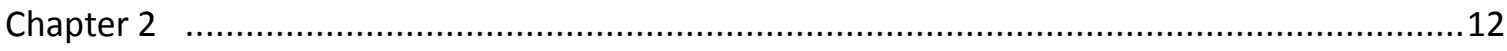

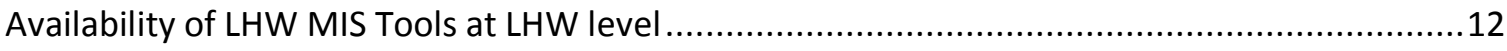

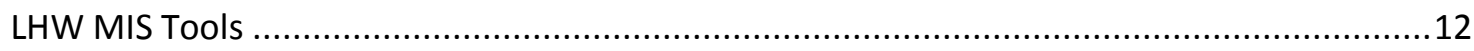

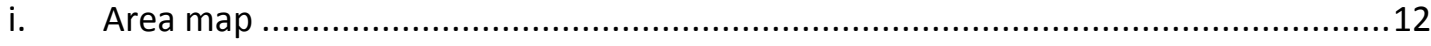

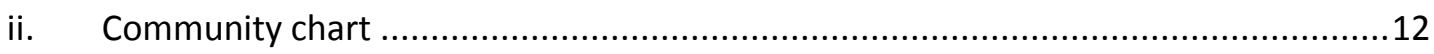

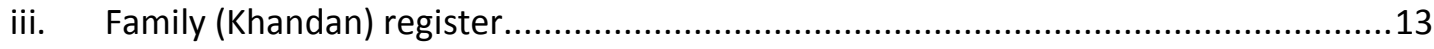

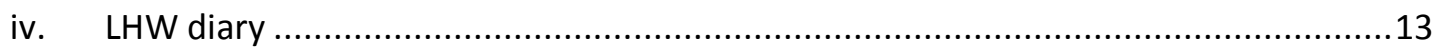

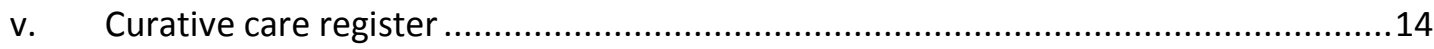

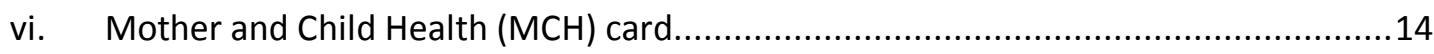

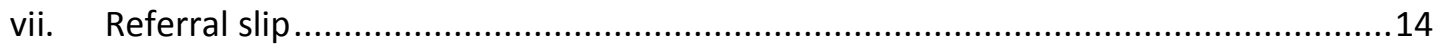

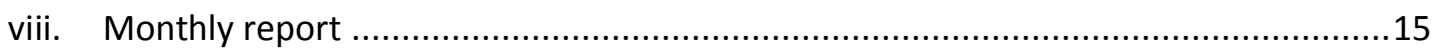

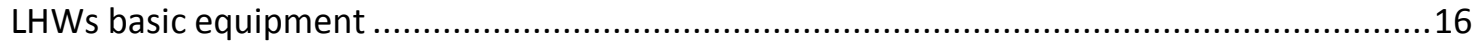

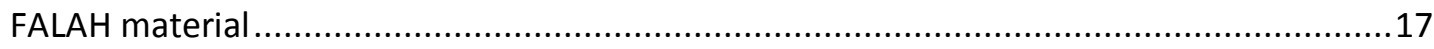

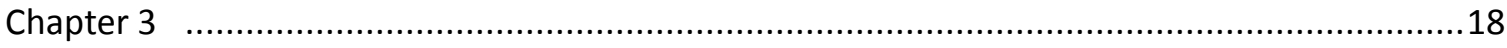

Comparison of LHW monthly report with corresponding MIS tools......................................18

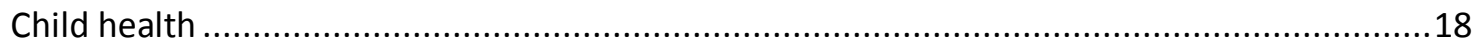

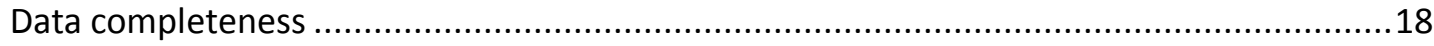

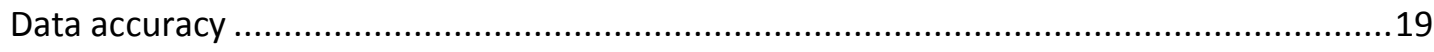

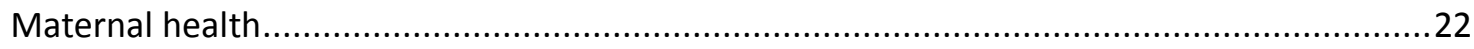

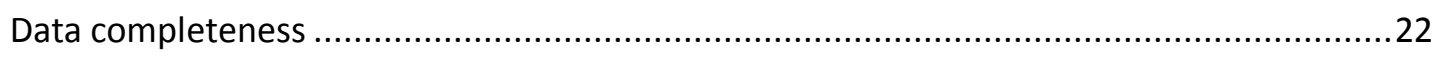

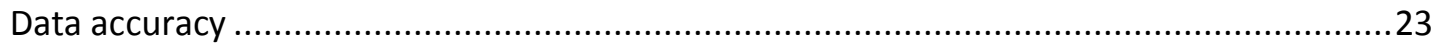

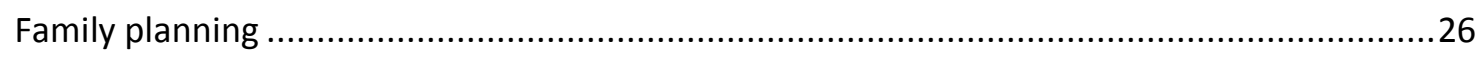

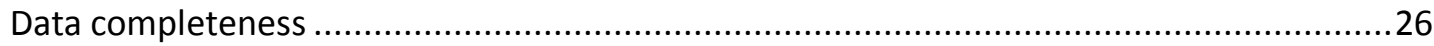




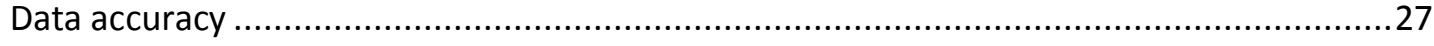

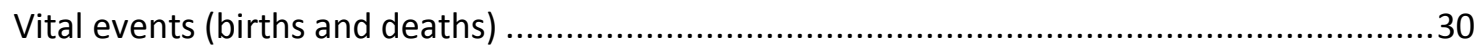

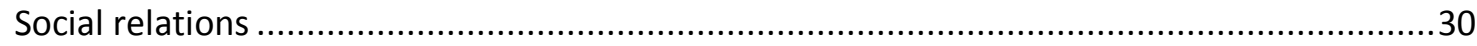

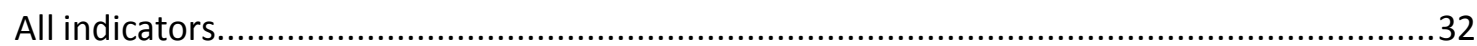

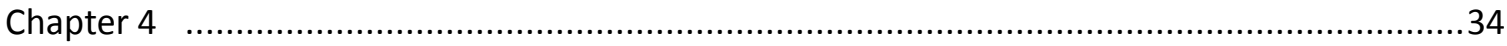

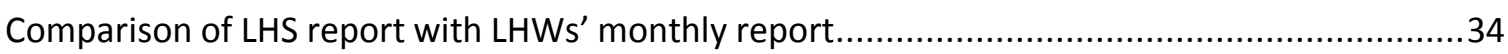

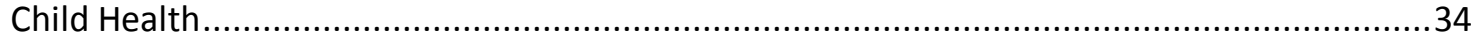

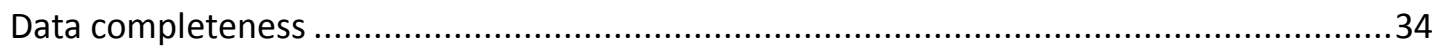

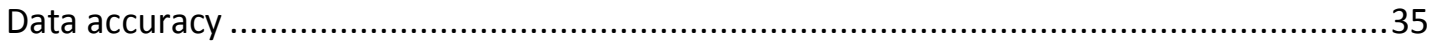

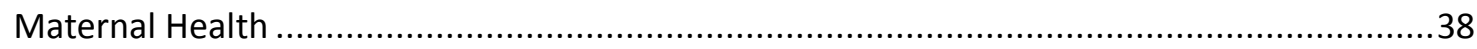

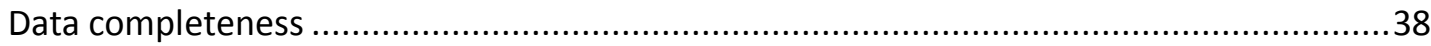

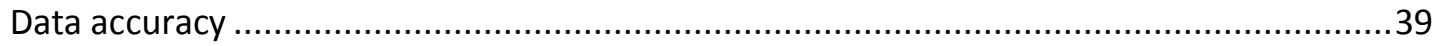

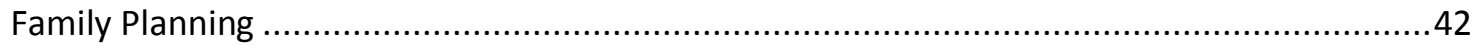

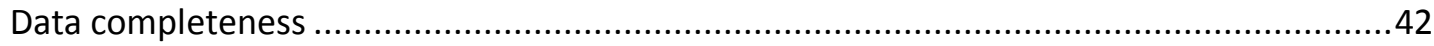

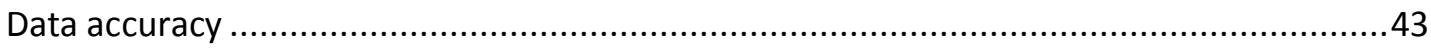

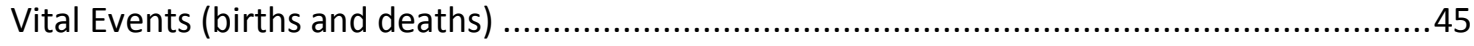

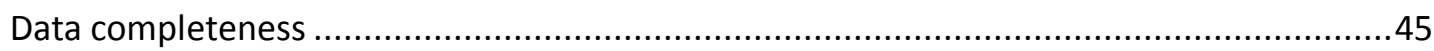

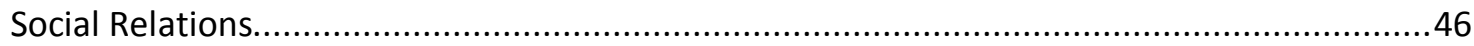

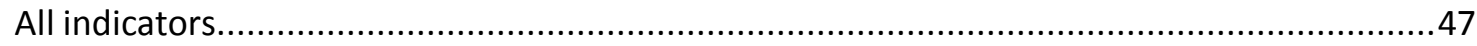

Chapter 5

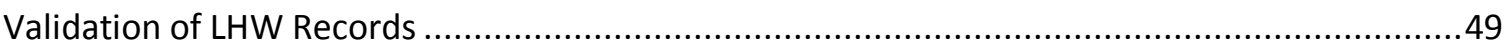

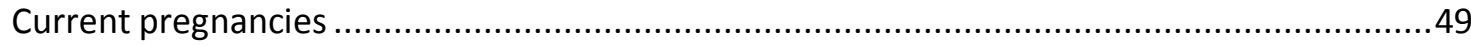

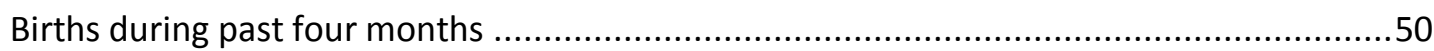

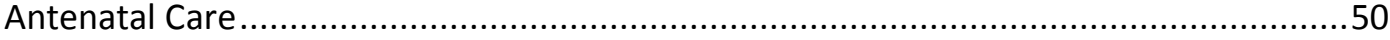

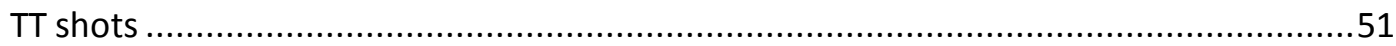

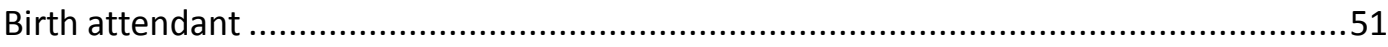

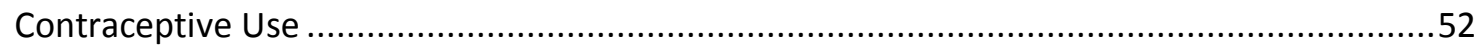

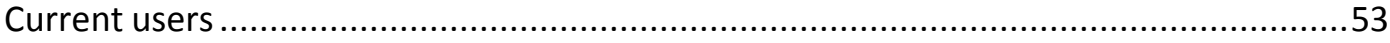

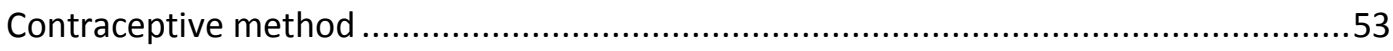

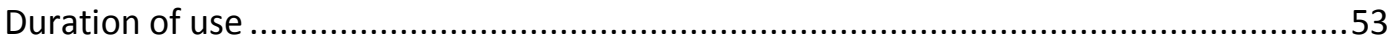

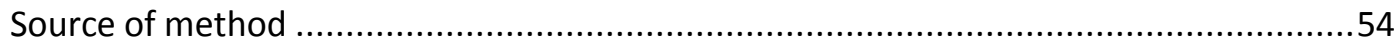

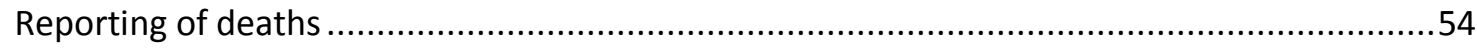

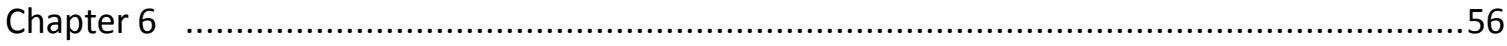

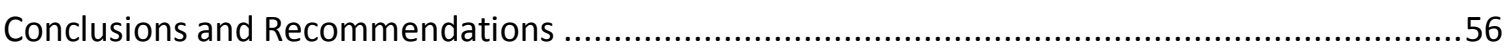

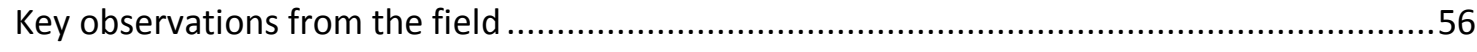

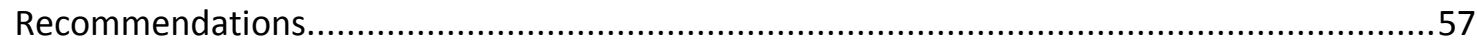

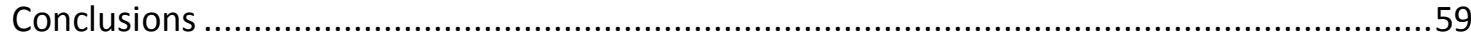

Annex 


\section{List of Figures}

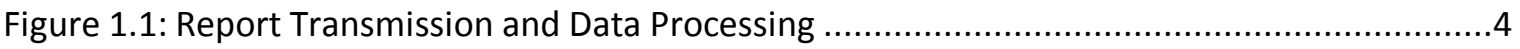

Figure 2.1: Availability of various LHW MIS tools at LHW level ................................................16

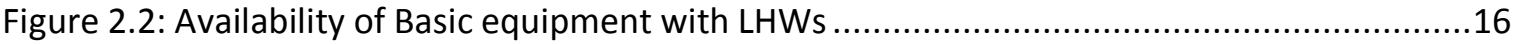

Figure 2.3: Availability of Tiahrt Chart and CCA Manual at LHW level .....................................17

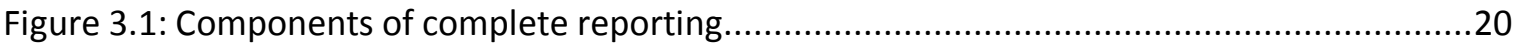

Figure 3.2: Percentage of LHWs reported Correct Information from the Record for the Month of May 2010 in Selected BHUs, Neonatal and Child Health Indicators ........................21

Figure 3.3: Components of complete reporting (maternal health indicators) ............................24

Figure 3.4: Percentage of LHWs Reported Correct Information from the Record for the Month of May 2011 in Selected BHUs, Maternal Health Indicators ....................................25

Figure 3.5: Components of complete reporting (family planning indicators) .............................28

Figure 3.6: Percentage of LHWs Reported Correct Information from the Record for the Month of May 2011 in Selected BHUs, Family Planning Indicators .....................................29

Figure 3.7: Components of complete reporting (vital events) ...............................................30

Figure 3.8: Percentage of LHWs with correct reporting according to available record and

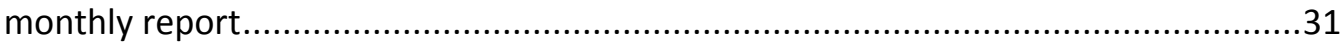

Figure 3.9: Components of complete reporting (social events) ...............................................31

Figure 3.10: Percentage of correct indicators reported by the BHU.........................................33

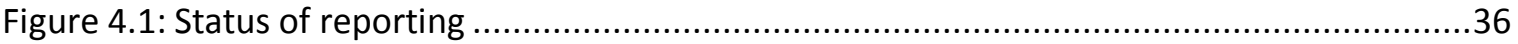

Figure 4.2: Percentage of LHSs reported Correct Information from the Record for the Month of May 2011 in Selected BHUs, Child Health Indicators...........................................37

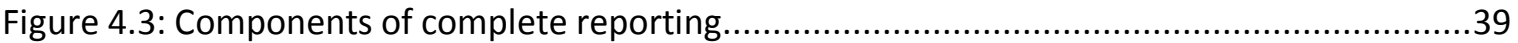

Figure 4.4: Percentage of LHSs reported Correct Information from the Record for the Month of May 2011 in Selected BHUs, Maternal Health Indicators ....................................41

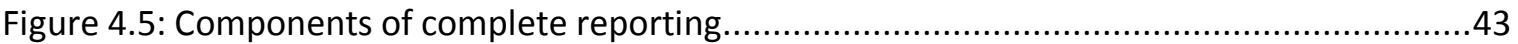

Figure 4.6: Percentage of LHSs reported Correct Information from the monthly report of LHW for the Month of May 2011 in Selected BHUs, Family Planning Indicators ................45

Figure 4.7: Percentage of LHSs reported Correct Information from the monthly report of LHW for the Month of May 2011 in Selected BHUs, vital events ........................................46

Figure 4.8: Percentage of LHSs with correct reporting according to available record and

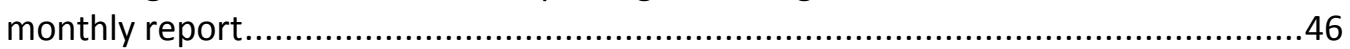

Figure 4.9: Components of complete reporting (social events) ...........................................47

Figure 4.10: Percentage of correct indicators reported by the BHU...........................................48

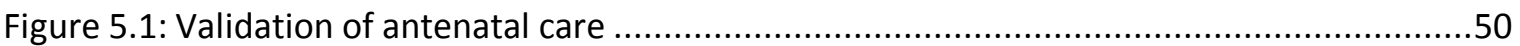


Figure 5.2: Validation of TT shots.

Figure 5.3: Validation of birth attendant....

Figure 5.4: Validation of contraceptive use 53

Figure 5.5: Validation of current contraceptive method 53

Figure 5.6: Validation of current contraceptive method... 53

Figure 5.7: Validation of current contraceptive method..... .53

Figure 5.8: Validation of deaths at household level.... .54 


\section{List of Tables}

Table 1.1: Sample and interview status of the LHWs and their clients ---------- 7

Table1.2: Reference LHW MIS tools for each indicator --- 11

Table 3.1: Percent distribution of LHWs with incompleteness of data either in records or the monthly report by each child health indicator -------------------------------------------- 19

Table 3.2: Percent distribution of LHWs with accurate reporting according to available record and monthly report (variables $=9$ )----

Table 3.3: Percent distribution of LHWs with incompleteness of data either in the records or

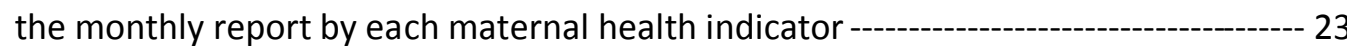

Table 3.4: Percent distribution of LHWs with accurate reporting according to available record and monthly report (variables $=9$ )--- 24

Table 3.5: Percent distribution of LHWs with incompleteness of data either in the records or the monthly report by each family planning indicator ---

Table 3.6: Percent distribution of LHWs with accurate reporting according to available record and monthly report (indicators = 15) ---------------------------------------------------- 29

Table 3.7: Percentage distribution of number of correctly reported indicators by LHWs (Total variables = 43) --- 32

Table 4.1: Percent distribution of LHWs with incomplete reporting in either of the LHW report or the LHS report by each child health indicator ------------------ 35

Table 4.2: Percent distribution of LHSs with accurate reporting according to available record and monthly report (variables $=9$ )

Table 4.3: Percent distribution of LHWs with incomplete reporting in either of the LHW report or the LHS report by each maternal health indicator------------- 38

Table 4.4: Percent distribution of LHWs with accurate reporting according to available record and monthly report (indicators $=9$ ) -------------------------------------------------- 40

Table 4.5: Percent distribution of LHWs with incomplete reporting in either of the LHW report or the LHS report by each family planning related indicators ---

Table 4.6: Percent distribution of LHWs with accurate reporting according to available record

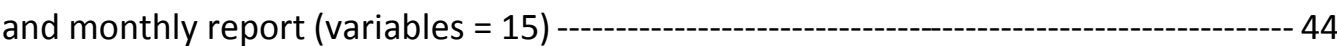

Table 4.7: Percentage distribution of number of correctly reported indicators by LHSs (Total

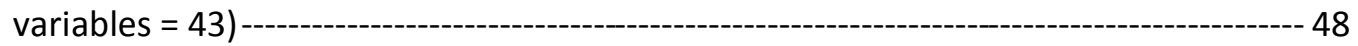

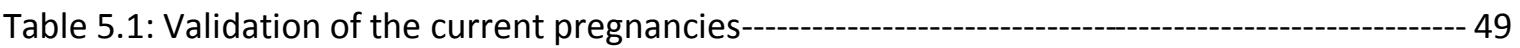

Table 5.2: Validation of the births 50 


\begin{tabular}{|c|c|}
\hline FALAH & Family Advancement for Life and Health \\
\hline FLCF & First Level Care Facility \\
\hline $\mathrm{BHU}$ & Basic Health Unit \\
\hline EDO & Executive District Officer \\
\hline FP & Family Planning \\
\hline HANDS & Health and Nutrition Development Society \\
\hline IUD & Intra Uterine Device \\
\hline KP & Khyber Pakhtunkhwa \\
\hline LHS & Lady Health Supervisor \\
\hline LHW & Lady Health Worker \\
\hline $\mathrm{MCH}$ & Maternal and Child Health \\
\hline MIS & Management Information System \\
\hline NP & National Program \\
\hline $\mathrm{PHC}$ & Primary Health care \\
\hline PIU & Project Implementation Unit \\
\hline $\mathrm{RHC}$ & Rural Health Center \\
\hline RSPN & Rural Support Program Network \\
\hline SBA & Skilled Birth Attendant \\
\hline TT & Tetanus Toxoid \\
\hline USAID & United States Agency for International Development \\
\hline VHC & Village Health Committee \\
\hline WHC & Woman Health Committee \\
\hline
\end{tabular}




\section{Executive Summary}

This assessment is based on a random sample of 154 LHWs from 9 BHUs of 4 districts across three provinces of Pakistan: Jhelum and D.G.Khan (Punjab), Mardana (KPK) and Sukkur (Sindh). The aim is to strengthen the routine LHW-MIS in the districts so that it can contribute to the improvement of the district health system by providing reliable evidence. Further, based on the findings of the current assessment, the districts managers/ decision makers should be able to continuously improve the LHW-MIS through applying a problem solving approach.

The data were collected from three difference sources: Women in the community (LHW's clients), LHW, and from LHS. Client level information was collected to validate the information, provided by the clients, with the LHW's records. Whereas data collected from rest of the sources were used to assess the accuracy of data transferring from records to reports and the completeness of the reports.

Results show that a substantial majority of the LHWs (between 90 percent to 97 percent LHWs) have maintained the basic MIS tools (LHW diary, family register, curative care register and monthly report). However, most of the LHWs did not have the $\mathrm{MCH}$ card, referral slips and area maps. Less than half of the LHWs had the LHW basic equipment available to them, with an exception of the LHW kit bag (86 percent).

This report is based on 43 key indicators from the LHW monthly report. The comparison of LHW level recording and reporting of the key indicators shows that data completeness was high, however, the accuracy of the indicators was low. The findings also show that data incompleteness was higher in recording of these indicators as compared to reporting. Data completeness was highest for the following five indicators: "number of children aged $<3$ years" (95 percent), "number of children aged 12-23 months" (95 percent), "number of registered eligible couples" (93 percent), "number of total registered pregnant women" (93 percent), and the "number of children 12-23 months with complete vaccination" (92 percent). Results show that the main reason for the incompleteness of the indicators is the unavailability of MIS tools to the LHWs.

The most accurate reporting at the LHW level was of the indicators: "number of total registered pregnant women" (58 percent), "number of deliveries assisted by SBA" (58 percent), "number of pregnant women who completed TT vaccine" (55 percent), and the "number of registered pregnant women" (53 percent). Moreover, all of the indicators pertaining to the number of births and deaths had a high level of accuracy. District wise comparison shows that LHWs from district 
D.G. Khan had the most accurate reporting followed by district Jhelum, Mardan and Sukkur in that order.

The comparison of LHS and LHW level monthly reporting shows that the proportion of completeness was higher in the family planning related indicators as compared to the maternal and child health indicators. Data completeness was highest for the following three indicators: "number of registered eligible couples", "number of total registered pregnant women" and the "number of total users of Pills" (97 percent each). The most accurate reporting was of the indicators: "number of total registered eligible couples" (78 percent), "number of users of traditional methods" (77 percent) and the "number of meetings with VHC" (92 percent). Further, our findings show that LHSs working in district Jhelum have reported more accurately than LHSs working in other three districts.

The household validation, of the LHW records, shows that out of the total 154 LHWs, 73 percent had correctly reported the current pregnancies in their community, whereas 82 percent of them had correctly recorded the births. However, only 65 percent had correctly reported whether the women in their community were current contraceptive users. Findings also show that 94 percent of the LHWs had correctly reported the deaths that occurred in six months prior to the survey in their catchment area. 


\section{Chapter 1: Introduction}

\section{Background}

The National Program for Family Planning and Primary Health Care (NP for FP\&PHC) also known as the Lady Health Workers' Program (LHW Program) was launched by the Ministry of Health, Government of Pakistan in 1994. It was initiated in response to the need to serve the underserved and poor communities of the rural and semi urban areas of Pakistan. The aim of the NP for FP \& PHC is to bring community participation through creation of awareness and bring about changes in attitude regarding basic issues of health and family planning by establishing a comprehensive grassroots level effective system for provision of FP and PHC.

The rationale for this initiative was:

- High maternal and children mortality rates;

- Comparatively slow demographic transition due to high fertility;

- High proportion of vulnerable population; and

- Low utilization of static health care facilities.

It is a countrywide program for provision of FP and PHC services with community participation. The program regularly recruits women and trains them to provide family planning and primary health care services in their own communities. These women known as lady health workers (LHWs) are the frontline of primary health care in many low-income communities of Pakistan. One LHW is responsible for approximately 1,000 residents, or 150 households, and she visits 5 to 7 households per day. The scope of work and responsibility of LHWs includes health education regarding antenatal care, vaccination and support to community mobilization, provision of contraceptives and basic curative care.

The health services provided by the LHWs are through monthly household visits and visitation by clients at the static health houses established within the LHWs residence. She is supported by a health committee and a women's group that are voluntary boards formulated by her for assisting her to provide health services as required. The program also hires Lady Health Supervisors (LHSs) who monitor the LHWs and provide supervision support to them. Following is the scope of work of LHWs:

- Mobilization of community;

- Liaison between formal health system and community; 
- Health education messages;

- Registration of all families;

- Provision of family planning services;

- Contribution in improving skilled birth attendant cover;

- Support other vertical programs (nutrition, immunization, TB, Malaria, and others);

- Prevention and treatment of minor ailments; and

- Initiate information sheet about her area.

\section{LHW-Management Information System}

Sustainability of a successful PHC program is an important issue and research has shown that an efficient and cost-effective Management Information System (MIS) is one of the important tools for strengthening, planning and management of PHC. It assists mid and senior health managers in making informed and evidence based decisions. Further, the effective planning depends on the correct and timely information on various health issues. The LHW program has developed its own management information system (LHW-MIS). The LHWs are accountable for maintaining comprehensive records for all patients under their charge by updating family register at the Health Houses to reflect medical histories and health conditions of each member. Moreover, each LHW also prepares a detailed monthly report containing information about indicators of maternal and child health, FP utility and basic curative care of her own community. Hence, both the meticulous record keeping and management Information system tools allow the LHWs to keep track of individuals in order to proactively provide services. There are three main purposes of the LHW-MIS:

- To help LHW keep track of the health status of her community, specially about mothers' and children's health;

- To provide a source to the health officials to evaluate the performance of LHWs;

- To attach the information gathered under LHW-MIS with the first level care facility (FLCF) information.

At present the Program has a well established network of MIS and LHWs that are using MIS tools to collect the basic information regarding maternal and child health and contraceptive usage in their own communities. This is shown in Figure 1. The information from these tools has been computerized at the district level. There are nine instruments that are used for LHW-MIS to collect required information. These instruments are:
1. Area map
2. Community chart 
3. Family register

4. Curative care and family planning register

5. Referral slip

6. LHW diary

7. Mother and child health card

8. Monthly report for LHW

9. Monthly report for the health center

\section{Lady health worker's duties}

The LHW visits all households of her community at least once in a month. During these visits she keeps her registers and monthly report with her and records the required information. At the end of each month, LHW submits the monthly report that she prepares throughout the month at her affiliated health center (Basic Health Unit). The lady health supervisor (LHS) at the health center prepares the summary report from the monthly reports of the LHWs and sends that to district coordinator by the end of second week of the preceding month. This same report reaches the provincial coordinator and national coordinator by the end of third and fourth week of the same month respectively. 
Figure 1.1: Report Transmission and Data Processing

Computer Transmission

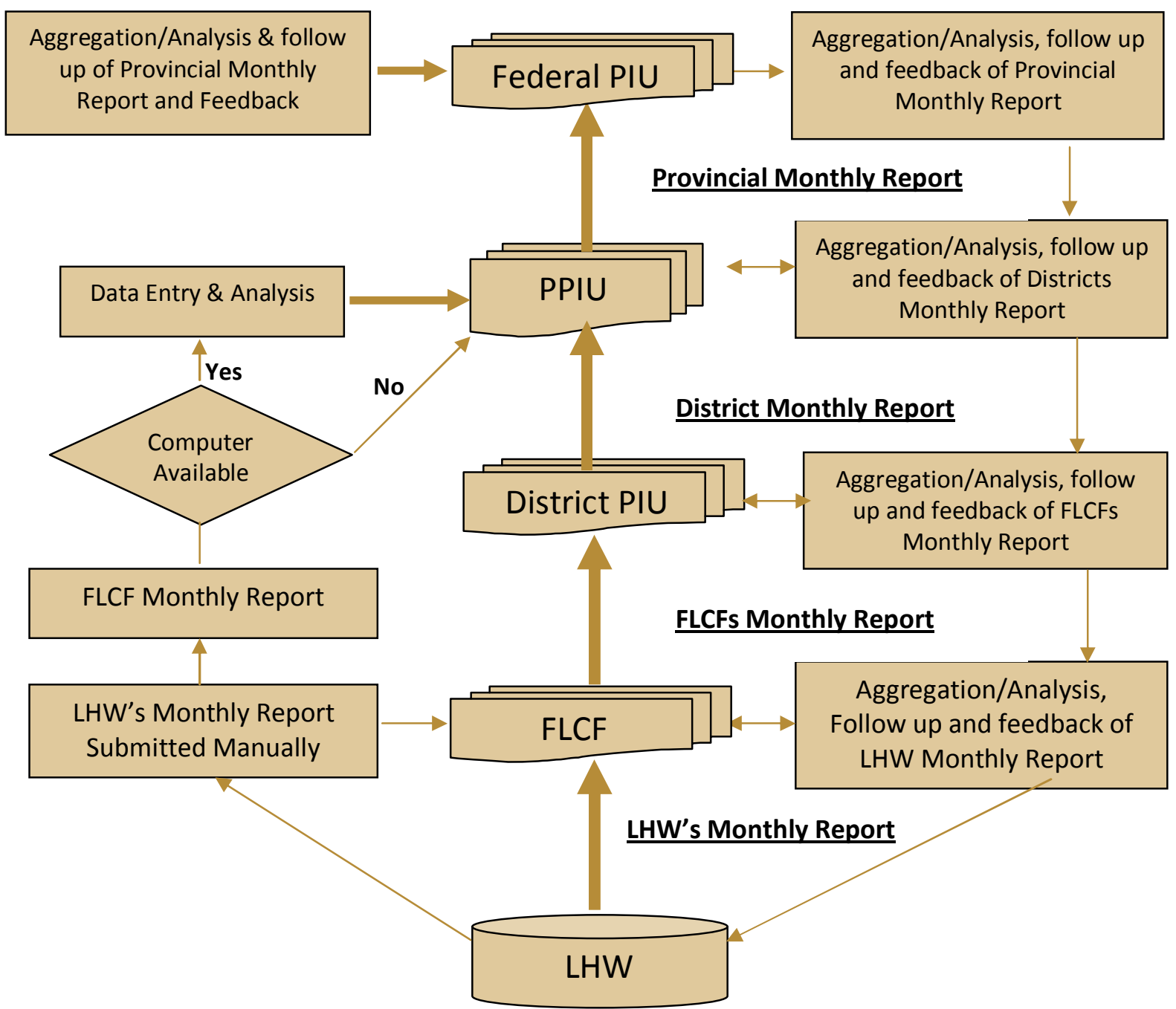

All reports are to be transmitted through regular line management channels: from LHWs to FLCF, then to district, then to division and province and ultimately to federal level. Timetables for transmission have been agreed upon.

LHW Prepares on daily basis and submits to FLCF in the $1^{\text {st }}$ week of every month.

FLCF LHW Monthly Report arrives at FLCF at the latest before end of $1^{\text {st }}$ Week

DISTRICT Aggregated report of FLCF arrives at the District at the latest before $2^{\text {nd }}$ Week of same month PROVINCE Aggregated report of District arrives at the Province at the latest before $3^{\text {rd }}$ Week of same month FEDERAL Aggregated report of Province arrives at the Federal PIU at the latest $1^{\text {st }}$ Week of next month 


\section{FALAH project}

The Family Advancement for Life and Health (FALAH) is a five-year project funded by the United States Agency for International Development (USAID) focusing on twenty districts across the four provinces of Pakistan. Population Council (PC) Pakistan was the lead partner along with a consortium of a number of national and international implementing and technical partners. Partners include: Greenstar Social Marketing, Health and Nutrition Development Society (HANDS), JHPIEGO, Mercy Corps, Rural Support Program Network (RSPN), and Save the Children USA. The consortium works under the guidance/umbrella of the Government, particularly the Ministries of Population Welfare and Health, and involves both public and private sectors extensively. The consortium's blend of skills, expertise, and geographic spread is ensure complementary and comprehensive coverage of the technical issues and targeted geographic areas. The goal of the project is to increase the use of methods of family planning and birth spacing in Pakistan through removing barriers, improving understanding of the value of family planning for family health and well-being, increasing knowledge of all methods of birth spacing, and improving access to and quality of care in both the public and private sectors.

Population Council through the FALAH project has made a strong professional partnership with the NP for FP\&PHC. FALAH has shared efforts for improving the functioning of the LHW-MIS for efficient management of health services at the community level through production of quality data and its continuous use for evidence based decision-making. National program requested FALAH management to assess the quality of data which is transmitted every month by the LHWs through their MIS.

\section{Objectives of the Assessment}

The goal is to strengthen the routine LHW-MIS in the districts so that they can contribute to the improvement of the district health system by providing reliable evidence. Further, based on the findings of the current assessment, the districts managers/decision makers should be able to continuously improve the LHW-MIS through applying a problem solving approach.

The primary foci of the current LHW-MIS assessment were the completeness and accuracy of the data and the level of use of information generated through the routine LHW-MIS at the LHW, LHS and district level. One commonly mentioned reason of low performance of LHW-MIS is the lack of printed MIS tools at LHW level. Thus, assessment of the level of MIS resources/tools was also part of the current assessment. 


\section{Methodology}

\section{Procedure}

In this assessment, Lady Health Workers Program Management Information System (LHW-MIS), universally implemented at the LHW level, was assessed.

Population Council in collaboration with NP for FP \& PHC carried out the assessment of LHW-MIS. Before conducting this exercise, EDOs (Health) of the selected districts were informed in writing followed by telephonic discussions about the objectives and the specific filed activities to be taken in their districts. EDOs (Health) were briefed about the methodology and outcome of the assessment of LHW-MIS. In each district a team of two female interviewers was formed to visit and assess quality and completeness MIS data at the LHW and LHS level.

\section{Study Design and Sampling}

The LHW-MIS assessment was a cross-sectional study that was carried out in four selected districts - Sukkur (in Sindh), Mardan (In KP), D.G Khan, and Jhelum (In Punjab) during the months of April-June, 2011. A sample of two BHUs was randomly selected from each district, except Mardan where three BHUs were selected due to the small number of LHWs in the initially selected sample of two BHUs. All the LHWs attached to selected BHUs were visited at their health houses and interviewed to observe the overall reporting quality. Selection of the health facilities (BHUs and RHCs) was done from the list of health facilities using random numbers. In total 9 health facilities were included in four FALAH districts.

\section{Assessment Tool}

Two separate questionnaires were developed for the current study. One questionnaire was for the LHWs and the other for the women in the community. The 'Diagnostic Tools' were used for assessing the levels of MIS resources, accuracy of data transferring from records to reports and the completeness of the reports. The accuracy and completeness of the last monthly reports submitted by the LHW using the entire data item from each report were assessed.

\section{Data collection}

Four teams, (one per district) each comprising of two female interviewers and one researcher from the FALAH project, Population Council, were constituted for the assessment. A two day training on how to fill out the assessment tools, methodology of the study and explanation of various MIS tools of NP for FP\&PHC was given to the team members prior to the fieldwork. A 
field data collection plan was prepared to complete the field work. The Health Houses of the LHWs were visited to cross-match data from her records and monthly reports. The reports prepared and submitted by the LHS were also collected from the district offices.

Table 1 given below shows the selected sample of LHWs and their clients. It shows that all of the selected LHWs were interviewed except for two LHWs in Sukkur district who could not be located in their catchment area; even the people in their community were not familiar with them to help the survey team locate them. Another three LHWs in Sukkur district did not provide their monthly report to the survey team; therefore they were eliminated from the LHW level analysis.

Table 1.1: Sample and interview status of the LHWs and their clients

\begin{tabular}{l|r|r|r|r|r}
\hline LHW interviews & Jhelum & D.G. Khan & Mardan & Sukkur & Total \\
\hline Total sampled & 47 & 35 & 36 & 38 & 156 \\
\hline Not available for interview & 0 & 0 & 0 & 2 & 2 \\
\hline Did not provide monthly report & 0 & 0 & 0 & 3 & 3 \\
\hline Complete interviews & 47 & 35 & 36 & 72 & 308 \\
\hline Client interviews & 94 & 70 & 72 & 72 & 308 \\
\hline $\begin{array}{l}\text { Currently pregnant women } \\
\text { Mothers of under 4 months old } \\
\text { children }\end{array}$ & 94 & 70 & 72 & 72 & 308 \\
\hline \begin{tabular}{l} 
Current contraceptive users \\
\hline
\end{tabular}
\end{tabular}

In order to assess if the LHWs were maintaining their records about the current situation of the women's health in their community, three main indicators were chosen for the purpose of validation. These three indicators include 'information about the currently pregnant women', 'women with children under 4 months' and 'current family planning users'. For the purpose of validation, two women for each indicator were randomly selected and interviewed from the LHWs' catchment area. The information provided by these women was then validated by matching with the LHW's records. This method of interviewing the women first and then checking the LHW records help to indentify if the LHW has accurately reported these indicators.

On average, an LHW interview took 90 minutes and a client interview was 15 minutes long. Almost all of the LHWs were very cooperative in providing the information to the enumerators. 


\section{Data entry and analysis}

Data from the filled questionnaires were entered into SPSS software. All the analysis was done by using SPSS software at Population Council, Islamabad. The analysis of the current study was conducted to examine:

a. Level of data completeness

b. Level of data accuracy.

\section{Level of Data Completeness}

Data completeness determines the quality of data. Incomplete LHW monthly report loses its value and definitely affects aggregate reports at the facility as well as at the district level. This ultimately minimizes the use of the data produced at the facility level as well as questions its quality. If data completeness is weak, this is also indicative of weak or no training of data reporting personnel on the LHW-MIS. For this assessment the instructional manual on LHW-MIS of the NP for FP\&PHC, Government of Pakistan, 2006 (Revised Edition) was followed.

The data completeness was assessed by examining the number of cells in the LHW monthly reports that were left blank, i.e., neither even filled with " 0 " nor crossed-out as "Not Applicable (N/A)". Since the LHW was not asked to fill-in the cells in the monthly MIS report for calculating percentages, these cells were excluded from the assessment.

\section{Level of Data Accuracy}

Data accuracy means that the data recorded on different instruments (registers) is consistent with the LHW monthly report. Data accuracy is the most important determinant of data quality. To prepare monthly reports at the LHW-level, information has to be transferred from the various LHW-MIS tools including Family register, mother and child health card to the monthly reporting formats. During the survey, the level of data accuracy was assessed by cross-matching the available information on the LHW monthly reports with that of the various LHW-MIS tools/ registers (called as records).

\section{Correct reporting}

To analyze the data accuracy, we compared the reporting of an indicator at one level with that of the same indicator to the previous level of recording and/or reporting. If the number against an indicator was same at the two simultaneous levels of reporting we labeled it as correct reporting.

\section{Fallse reporting (under/over reporting)}

If the numbers against the same indicator did not match at the different levels of reporting, it was considered as "false reporting". If the numbers on the second level of information exceeded the 
information at the first level, it was labeled as over reporting. Similarly it was labeled as under reporting if it was less than the first level information. For instance while comparing the same indicator at LHW level reporting with that of the recordings in the registers, if the reporting of the indicator was higher than it was depicted in the recordings of the registers, it was labeled as over reporting. Likewise while comparing the LHW and LHS level reporting the entries on LHW level reporting were considered as base and an indicator is considered as under reported if it had a lower number at the LHS level reporting than the corresponding LHW level reporting.

\section{No information}

To analyze the data completeness we counted the number of indicators against which the LHW and/or LHS did not report any numbers and left them empty. The proportion of such categories in the indicators was labeled as "no information".

\section{Radar chart/Spider chart}

This report uses the radar/spider charts to graphically depict the level of accurate recording and reporting of the indicators by the LHW. It gives a comparison between the accurate data reporting of same indicators in different districts along with identifying the gaps between accurate data reporting of different indicators. This chart displays the important categories of performance and makes visible concentrations of strengths and weaknesses.

On comparing the Facility wise accuracy of reporting in indicators, a facility that has a wider circle on the radar chart showed a better monthly reporting by the LHWs than the facility that made a circle which was concentrated in the center of the chart. Similarly an indicator that was concentrated to the borders of the chart displayed a better reporting by the LHW.

\section{Operational Definitions}

\section{Recording of indicators}

The term "recording of indicators" is used in this report to refer to the information that LHW enters in her MIS tools other than the monthly report. These tools mainly include the family register, LHW's diary and register curative care. The table below shows the reference tool of each indicator for the recording.

\section{LHW level reporting}

The term "LHW level reporting" refers to the information that is extracted from the monthly report of LHW. Each LHW records the relevant information regarding members of her community in her registers on daily basis and by the end of the month, she compiles the monthly report by 
aggregating the information that she records in those registers. This report is then submitted to the LHS on monthly basis.

\section{LHS level reporting}

The term "LHS level reporting" refers to the data that were gathered from the monthly reports of the lady health supervisors. The LHS compiles this report based on the monthly reports of the LHWs in her area. 
Table1. 1: $\quad$ Reference LHW MIS tools for each indicator

\begin{tabular}{|c|c|}
\hline Indicator & Reference in the LHW records \\
\hline \multicolumn{2}{|l|}{ Child health } \\
\hline No. of neonates weighted within one week of birth & $\mathrm{MCH}$ card \\
\hline No. of underweight neonates & $\mathrm{MCH}$ card \\
\hline No. of neonates who breastfed within 24 & $\mathrm{MCH}$ card \\
\hline No. of neonates who were started vaccination & List of children under three years of age (LHW diary) \\
\hline No. of children aged $12-23$ months & List of children under three years of age (LHW diary) \\
\hline No. of children $12-23$ months with complete vaccination & List of children under three years of age (LHW diary) \\
\hline No. of children aged $<3$ years & List of children under three years of age (LHW diary) \\
\hline No. of children $<3$ yrs who were assessed for their growth & $\mathrm{MCH}$ card \\
\hline No. of underweight children $<3$ yrs & $\mathrm{MCH}$ card \\
\hline \multicolumn{2}{|l|}{ Maternal health } \\
\hline No. of pregnant women registered this month & List of pregnant women (LHW diary) \\
\hline No. of total registered pregnant women & List of pregnant women (LHW diary) \\
\hline No. of total pregnant women checked this month & $\mathrm{MCH}$ card or list of pregnant women \\
\hline No. of pregnant women provided iron tablets & Register curative care \\
\hline No. of abortions (within 7 months of pregnancy) & List of pregnant women (LHW diary) \\
\hline No. of women who visited $4 />4$ times to skilled provider & List of pregnant women (LHW diary) \\
\hline No. of women who completed TT vaccine before delivery & List of pregnant women (LHW diary) \\
\hline No. of deliveries assisted by SBA & List of pregnant women (LHW diary) \\
\hline No. of women checked up within 24 hours of delivery & $\mathrm{MCH}$ card \\
\hline \multicolumn{2}{|l|}{ Family planning } \\
\hline No. of registered eligible couples & List of current FP users (LHW diary) \\
\hline No. of couples started any FP method this month & List of current FP users (LHW diary) \\
\hline No. of current users given follow up & List of current FP users (LHW diary) \\
\hline No. of total users of modern methods & List of current FP users (LHW diary) \\
\hline No. of total users of condom & List of current FP users (LHW diary) \\
\hline No. of total users of pills & List of current FP users (LHW diary) \\
\hline No. of total users of injectables & List of current FP users (LHW diary) \\
\hline No. of total users of IUD & List of current FP users (LHW diary) \\
\hline No. of total users of female sterilization & List of current FP users (LHW diary) \\
\hline No. of total users of Other modern methods & List of current FP users (LHW diary) \\
\hline No. of total users of traditional methods & List of current FP users (LHW diary) \\
\hline No. of couples referred to health facility/FP center & List of current FP users (LHW diary) \\
\hline No. of clients provided condom by LHW & List of current FP users (LHW diary) \\
\hline No. of clients provided pills by LHW & List of current FP users (LHW diary) \\
\hline No. of clients provided injectables by LHW & List of current FP users (LHW diary) \\
\hline \multicolumn{2}{|l|}{ Vital events } \\
\hline No. of live births & List of children $<3$ years of age and list of pregnant women (LHW diary) \\
\hline No. of still births & List of pregnant women (LHW diary) \\
\hline No. of total deaths & Family register \\
\hline No. of neonatal death within one week of births & Family register and list of children under three years of age \\
\hline No. of infant deaths (age above one week $\&<1$ year) & Family register and list of children under three years of age \\
\hline No. of child deaths (age above one year and $<5$ years) & Family register and list of children under three years of age \\
\hline No. of maternal deaths & Family register and list of pregnant women (LHW diary) \\
\hline \multicolumn{2}{|l|}{ Social relations } \\
\hline No. of health talks/ gatherings in local school & LHW diary \\
\hline No. of meetings with $\mathrm{VHC}$ & LHW diary \\
\hline
\end{tabular}




\section{Chapter 2 \\ Availability of LHW MIS Tools at LHW level}

Availability of MIS tools to the LHW is very critical for the accurate and timely recording and reporting of the necessary indicators. Lack of availability of these tools will not only result in under/over reporting of these indicators but will also influence the quality and coverage of services that LHW provides. The current chapter is divided into two subsections. The first section provides a brief description of each LHW MIS tool and the current status of its availability at LHW level. The second section describes the current status of availability of various LHW equipments.

\section{LHW MIS Tools}

\section{i. $\quad$ Area map}

The LHW is required to make a map of her community (covered area) and identify the main places, such as schools, mosques, main roads etc and the health house on the map. The map helps the LHW to effectively work in her catchment area. The LHW is required to display the map in her health house.

Out of 154 interviewed LHW, only 62 percent LHWs reported that they had prepared the area map whereas only half of the LHWs (52 percent) were able to show the maps to the survey team.

\section{ii. Community chart}

The main purpose of the LHW's community chart is to display a summary of demographic indicators and other basic information about the LHW area. The community chart is updated on monthly basis. It includes information on the total population of the area, number of children under one year and three years of age, number of women aged 15 to 49 years, number of married couples, number of current contraceptive users, number of live births, number of new arrivals (via migration or births) and migration and total deaths. The community chart, along with the names of the members of the health and women committees also shows the number of families by the source of drinking water and type of toilet facility. 
Figure 2.1 shows that almost three in four LHWs (76 percent) had the community chart whereas slightly over two third of the LHWs (68 percent) provided their community chart to the survey team for physical verification.

\section{iii. Family (Khandan) register}

LHW's family register contains a list of all the families living in the LHW area along with the names of each member of the family and their basic demographic information. LHW also records important events, for instance, births, deaths and migration in her family register. Family register gives a correct number about the population and the number of families living in her catchment area.

Results show that a substantial majority of LHWs (97 percent) reported that they have maintained the family registers. Moreover, 91 percent LHWs presented their family registers to the survey team for physical verification.

\section{iv. LHW diary}

LHW prepares a monthly planner for herself which she prepares using the LHW diary. The diary also contains a list of the population that needs special care from LHW. Following are the components of LHW diary:

- LHW's monthly planner

- Health committee meeting report

- Women committee meeting

- List of under three years old children

- List of pregnant women

- List of married couples of age 15-49 years and their contraceptive use

- Visitor's remarks

- LHW monthly score chart

The LHW diary is one of the very important MIS tools which reflect her monthly performance. According to the survey 94 percent of the LHWs reported that they had their diaries whereas 88 percent LHWs were able to provide their diaries to survey team for physical verification. 


\section{v. Curative care register}

The LHW's curative care register is used to document the patients, who are treated by the LHW, along with the detail of the treatment that LHW provides them. LHW also keeps the record of those patients whom she refers to the health facilities.

Results show that 90 percent of the LHWs had their curative care register with them, whereas 84 percent of the LHWs presented their register to the survey staff for physical verification.

\section{vi. Mother and Child Health (MCH) card}

One side of the LHW's MCH card is "mother's health card" which contains information on a routine checkup of woman (during pregnancy, delivery and right after the delivery) to monitor the health status of the mother so that in case of any danger sign she is provided with the necessary care. The other side is "child health card" which is prepared for the children under three years of age to monitor their growth and health status so that in case of any problem the child could be provided with necessary health care.

The LHW prepares the $\mathrm{MCH}$ card for all pregnant women in her community and visits the pregnant woman every month during the second and third trimester. While visiting the woman LHW keeps this card with her and fills in the given information at every visit. After the childbirth, LHW flips the card and starts observing the health and growth of the child until he/she is three years old. Hence availability of this card is very important to have complete record of pregnancy (including complications), delivery and post delivery status, as well as the health and well being of the child till the age of 3 years.

The findings show that less than a third of the total women had the supply of $\mathrm{MCH}$ cards, whereas only 28 percent LHWs could show the MCH cards to the survey team. Many of the LHWs who were able to present their $\mathrm{MCH}$ cards to the survey team complaining that they had photo copied of the $\mathrm{MCH}$ cards from their own pocket because of the unavailability of the $\mathrm{MCH}$ cards. It was also observed that although a third of the LHWs reported that they had at least one MCH card, a majority was not filling these cards to monitor the health status of the pregnant women and children.

\section{vii. Referral slip}

One of the scopes of LHWs' work is to improve referral pathways to clinical care. Whenever needed, LHW refers the patients/clients to the nearest health facility. For this purpose LHW uses the referral/feedback slip. While referring to the health facility, LHW fills out the referral slip and gives the filled referral slip to the patient/ client. The health facility staff after providing the 
necessary treatment fills out the feedback form and gives it back to the patient/ client. The patient/ client on her returns back to home, submits the referral slip to the LHW. The unavailability of the referral slips to the LHW might create a problem for the patients/ clients to smoothly receive the care from the health facility.

Results show that only two fifths (41 percent) of the LHWs had the referral slips with them, whereas slightly more than a third (36 percent) of the LHWs presented at least one referral slip to the survey staff for physical verification.

\section{viii. Monthly report}

LHW's monthly report is one of the most important MIS tools. This report reflects the important events in the community that occurred in one month period such as births, deaths and maternal deaths, information on the medicines and contraceptives provided and number of the pregnancies, deliveries, child immunization, contraceptive users and other related information.

LHW submits this report to the lady health supervisor (LHS) on the first of every month. LHS then compiles the monthly report for health facility based on the monthly reports from all the LHWs working in her supervision. The LHS then submits her monthly report to the district coordinator of the LHW program who forwards it to the provincial coordinator.

The results of the survey show that a great majority of LHW, 97 percent of the LHWs had the monthly reports of previous month with them. The rest of the three LHWs who could not provide their monthly report to the survey team, are eliminated from further analysis performed in this report. 
Figure 2.1: Availability of various LHW MIS tools at LHW level

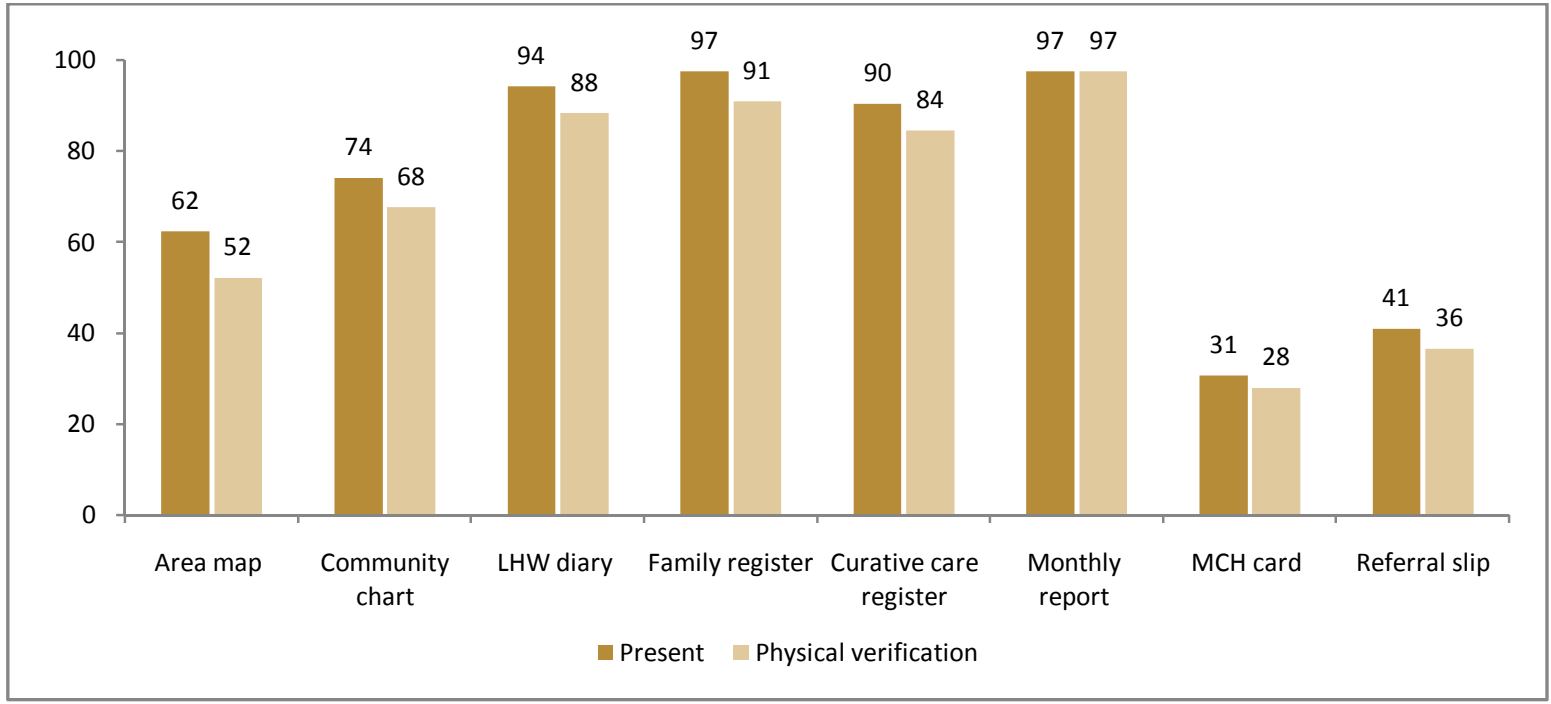

\section{LHWs basic equipment}

Results show that a substantial majority of LHWs had a shortage of the basic equipment. Only two thirds of them had their kit bags in functional form. Half of the LHWs had a weighing scale whereas only about two-fifths of the LHWs had scissors, thermometers and weighing scales in a functional form. Less than a quarter of the LHWs reported that their torch is in functional form.

Figure 2.2: Availability of Basic equipment with LHWs

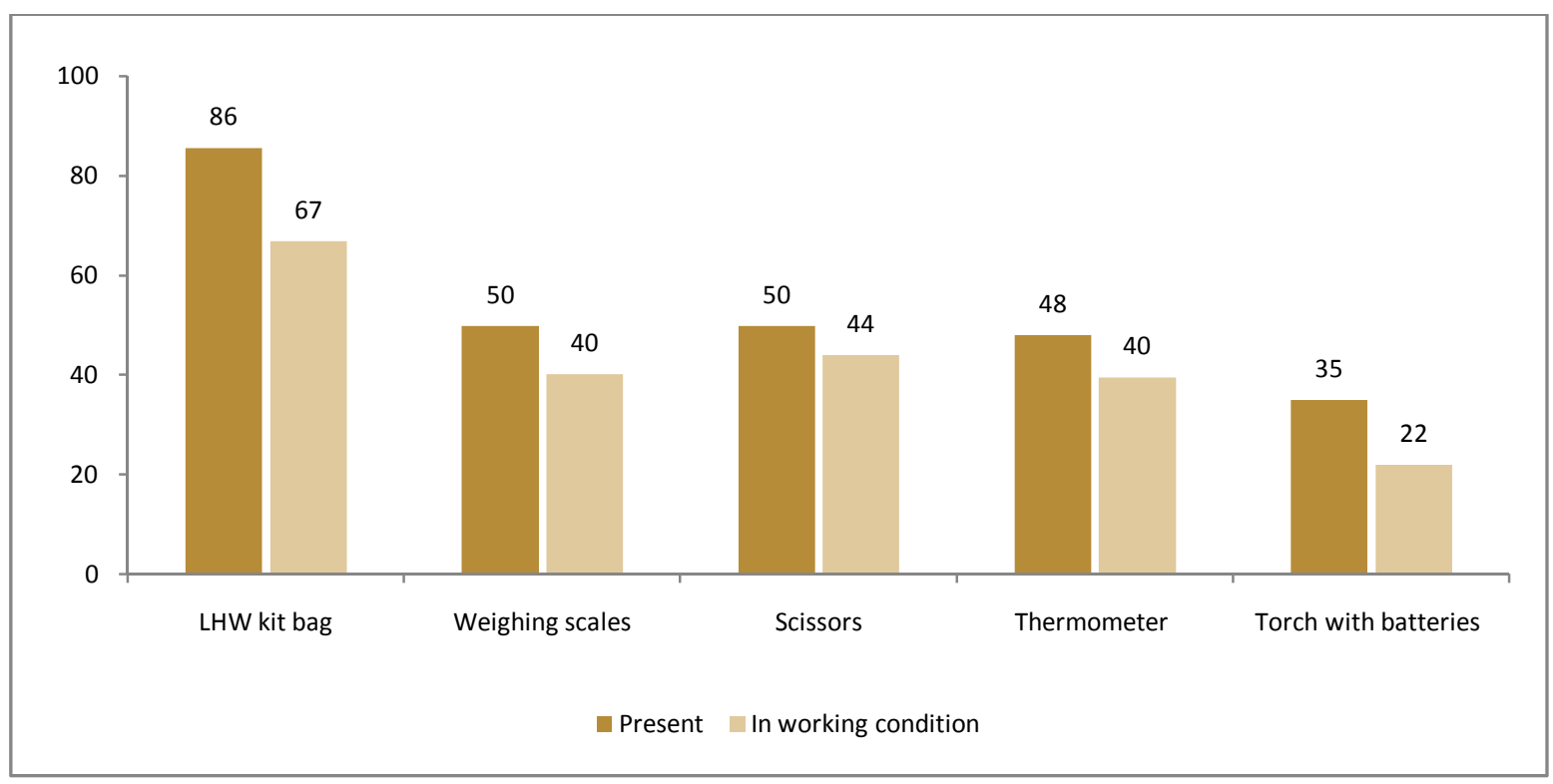




\section{FALAH material}

All of the LHWs were given training on client centered approach in FALAH project districts. After this training along with other material the LHWs were given the manual on client centered approach (CCA) and the Tiahrt chart. In this survey the LHWs were also asked if they received this material. Under three quarters of the LHWs presented their Tiahrt chart and CCA manual to the survey team.

Figure 2.3: Availability of Tiahrt Chart and CCA Manual at LHW level

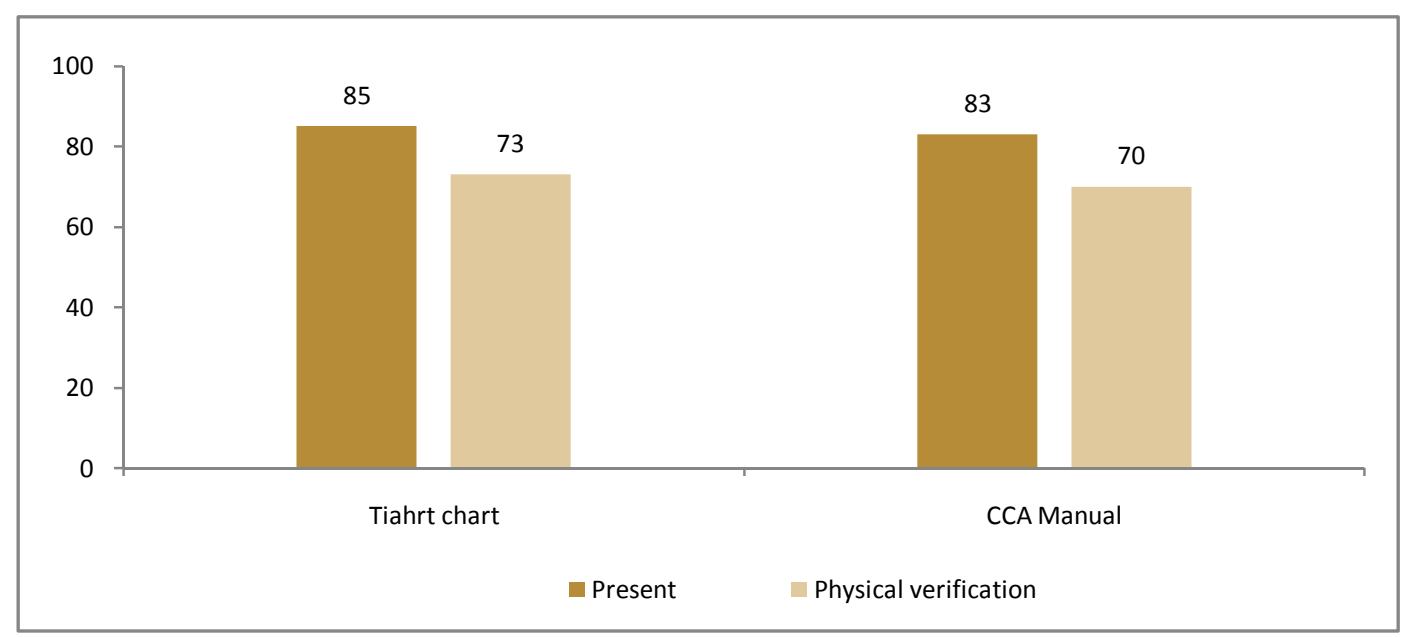




\section{Chapter 3 \\ Comparison of LHW monthly report with corresponding MIS tools}

This chapter presents the findings of comparison of LHW monthly report with corresponding MIS tools. Further, in the current chapter the discrepancies between the recording and LHW level monthly reporting of the main indicators that LHW uses to depict her activities and the health status of the population in her community are presented. The numbers against each indicator that LHW recorded in her registers (family register, LHW diary, and register curative care) and the same indicators from her monthly report were collected for this purpose. This data is then explored first for data completeness and later on for data accuracy to check the extent to which the data is completed at the two levels of reporting and whether the same information against these indicators matched at the two different levels of reporting.

\section{Child health}

\section{Data completeness}

LHW reports nine indicators related to the child health in her monthly report. Table 3.1 gives an overview of the data completeness in the reporting and recording of the child health indicators. The term 'complete reporting' here shows the percentage of the LHWs who had both reported and recorded that particular indicator. The most complete reporting was for the "number of children aged less than 3 years" (95 percent), and the "number of children aged 12-23 months"(95 percent) followed by the "number of children 12-23 months with complete vaccination" (92 percent). Only 6 percent of the LHWs reported the "number of underweight neonates" and the "number of neonates who were breastfed within 24 hours of birth". Similarly only 5 percent of the LHWs reported the "number of underweight children (<3 years)".

Our findings show that a higher number of LHWs did not provide information in recording of the indicators as compared to reporting. It also tells that although some LHWs had not recorded the 
indicators they still reported the numbers in their monthly reports against these indicators. The observation during the data collection phase was that for many of the indicators LHWs do not keep the records they only maintain the data on their monthly report. Further, data shows that only 28 percent (Figure 2.1) of the LHWs had the MCH card available to them which is the main reason for the incompleteness of the indicators which are to be recorded on the $\mathrm{MCH}$ card.

Table 3.1: Percent distribution of LHWs with incompleteness of data either in records or the monthly report by each child health indicator

\begin{tabular}{|c|c|c|c|c|c|c|c|}
\hline \multirow[b]{2}{*}{ Indicator } & \multirow[b]{2}{*}{$\begin{array}{l}\text { Completenes } \\
\mathrm{s} \text { in data }\end{array}$} & \multirow[b]{2}{*}{$\begin{array}{l}\text { Incompletene } \\
\text { ss in data }\end{array}$} & \multirow[b]{2}{*}{ Total } & \multirow[b]{2}{*}{$\mathbf{N}$} & \multicolumn{3}{|c|}{ Breakdown of incompleteness in data } \\
\hline & & & & & $\begin{array}{l}\text { No } \\
\text { information } \\
\text { in recording }\end{array}$ & $\begin{array}{l}\text { No } \\
\text { information } \\
\text { in reporting }\end{array}$ & $\begin{array}{c}\text { No } \\
\text { information } \\
\text { in both* }\end{array}$ \\
\hline $\begin{array}{l}\text { No. of neonates } \\
\text { weighted within one } \\
\text { week of birth }\end{array}$ & 27.2 & 72.8 & 100.0 & 151 & 49.0 & 0.0 & 23.8 \\
\hline $\begin{array}{l}\text { No. of underweight } \\
\text { neonates }\end{array}$ & 6.0 & 94.0 & 100.0 & 151 & 60.9 & 0.0 & 33.1 \\
\hline $\begin{array}{l}\text { No. of neonates who } \\
\text { breastfed within } 24\end{array}$ & 6.0 & 94.0 & 100.0 & 151 & 80.8 & 0.7 & 12.6 \\
\hline $\begin{array}{l}\text { No. of neonates who } \\
\text { were started } \\
\text { vaccination }\end{array}$ & 72.8 & 27.2 & 100.0 & 151 & 8.6 & 11.3 & 7.3 \\
\hline $\begin{array}{l}\text { No. of children aged } \\
12-23 \text { months }\end{array}$ & 94.7 & 5.3 & 100.0 & 151 & 2.6 & 2.0 & 0.7 \\
\hline $\begin{array}{l}\text { No. of children } 12-23 \\
\text { months with complete } \\
\text { vaccination }\end{array}$ & 92.1 & 7.9 & 100.0 & 151 & 3.3 & 3.3 & 1.3 \\
\hline $\begin{array}{l}\text { No. of children aged }< \\
3 \text { years }\end{array}$ & 95.4 & 4.6 & 100.0 & 151 & 1.3 & 2.6 & 0.7 \\
\hline $\begin{array}{l}\text { No. of children }<3 \text { yrs } \\
\text { who were assessed for } \\
\text { their growth }\end{array}$ & 29.1 & 70.9 & 100.0 & 151 & 39.1 & 0.0 & 31.8 \\
\hline $\begin{array}{l}\text { No. of underweight } \\
\text { children }<3 \text { yrs }\end{array}$ & 5.3 & 94.7 & 100.0 & 151 & 64.2 & 0.0 & 30.5 \\
\hline
\end{tabular}

\section{Data accuracy}

Figure 3.1 shows the accuracy and the components of complete reporting. Our findings show that a lower proportion of the LHWs for all the child health indicators who recorded and reported the 
completed data reported it correctly, whereas the proportion of over and under reporting varies by the type of indicator. Half of the LHWs correctly reported the indicator 'number of neonates who were started vaccination' (50 percent). However, the proportion of over reporting was higher for indicators 'number of children aged less than three years' and for 'children between 12-23 months who completed vaccination'. The proportion of under reporting was higher for indicators 'number of children aged 12-23 months' and for 'number of children less than 3 years'.

Figure 3.1: Components of complete reporting

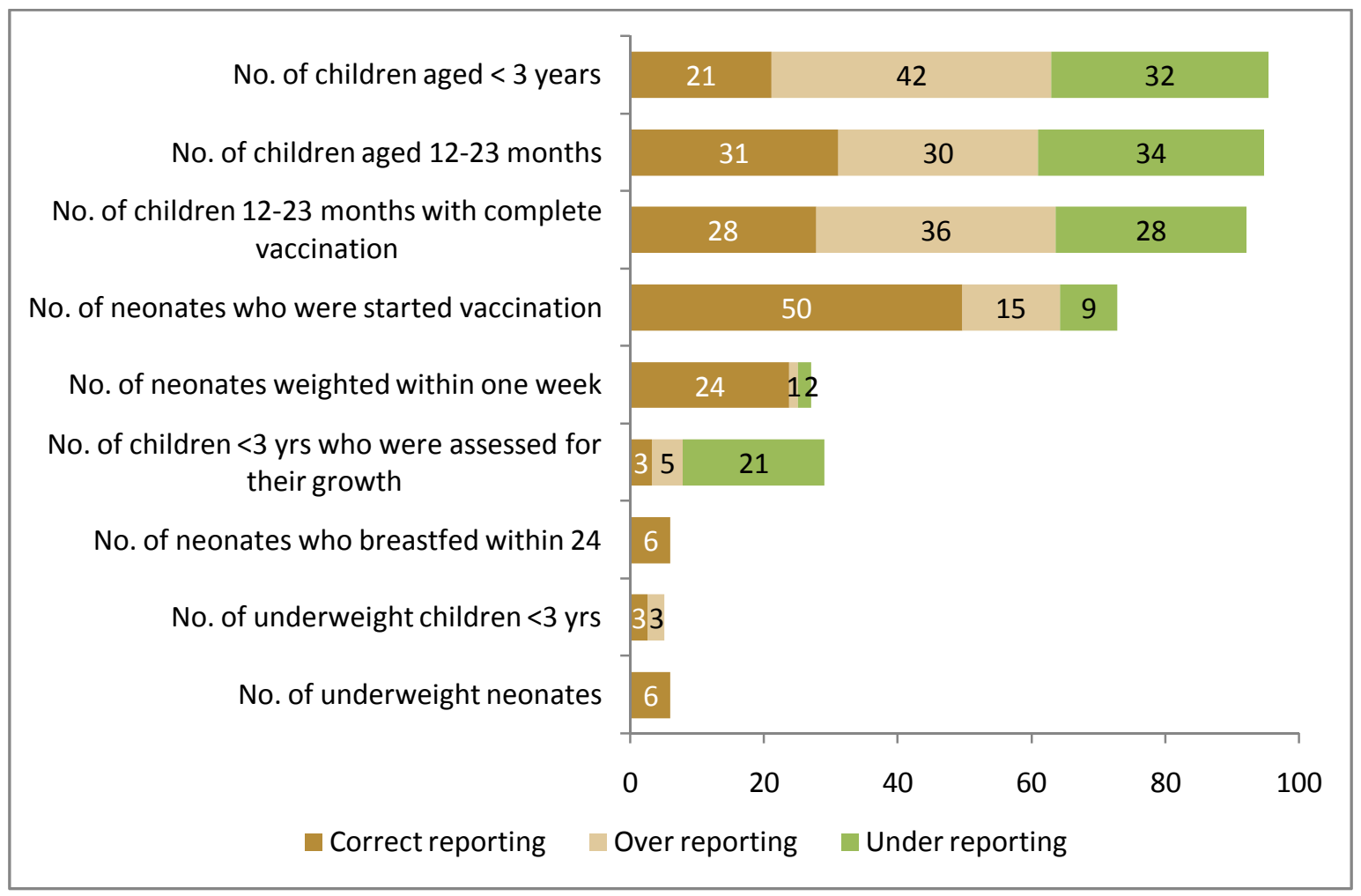

Table 3.2 shows the accuracy of reported data in LHWs monthly report for the child health indicators. . There are nine child health indicators in LHW monthly report. Our findings show that overall none of the 151 LHWs correctly reported all the nine child health indicators in their monthly report. District wise analysis shows a better data reporting in district D.G. Khan district compared to other three selected districts where the median number of correctly reported indicators was 4. In Mardan and Sukkur districts the median number of correctly reported indicators was only one, while for Jhelum it was two indicators. 
Table 3.2: Percent distribution of LHWs with accurate reporting according to available record and monthly report (variables $=9$ )

\begin{tabular}{l|r|r|r|r|r}
\hline No. of indicators & Jhelum & D.G. Khan & Mardan & \multicolumn{1}{|c}{ Sukkur } & Total \\
\hline $\mathbf{0 - 2}$ & 55.3 & 22.8 & 86.1 & 81.8 & 60.9 \\
\hline $\mathbf{3 - 5}$ & 42.5 & 45.7 & 13.9 & 18.2 & 31.1 \\
\hline $\mathbf{6 - 8}$ & 2.1 & 31.4 & 0 & 0 & 7.9 \\
\hline Total & $\mathbf{1 0 0 . 0}$ & $\mathbf{1 0 0 . 0}$ & $\mathbf{1 0 0 . 0}$ & $\mathbf{1 0 0 . 0}$ & $\mathbf{1 0 0 . 0}$ \\
\hline Median & $\mathbf{2}$ & $\mathbf{4}$ & $\mathbf{1}$ & $\mathbf{1}$ & $\mathbf{2}$ \\
\hline $\mathbf{N}$ & $\mathbf{4 7}$ & $\mathbf{3 5}$ & $\mathbf{3 6}$ & $\mathbf{3 3}$ & $\mathbf{1 5 1}$ \\
\hline
\end{tabular}

Figure 3.2: Percentage of LHWs reported Correct Information from the Record for the Month of May 2010 in Selected BHUs, Neonatal and Child Health Indicators

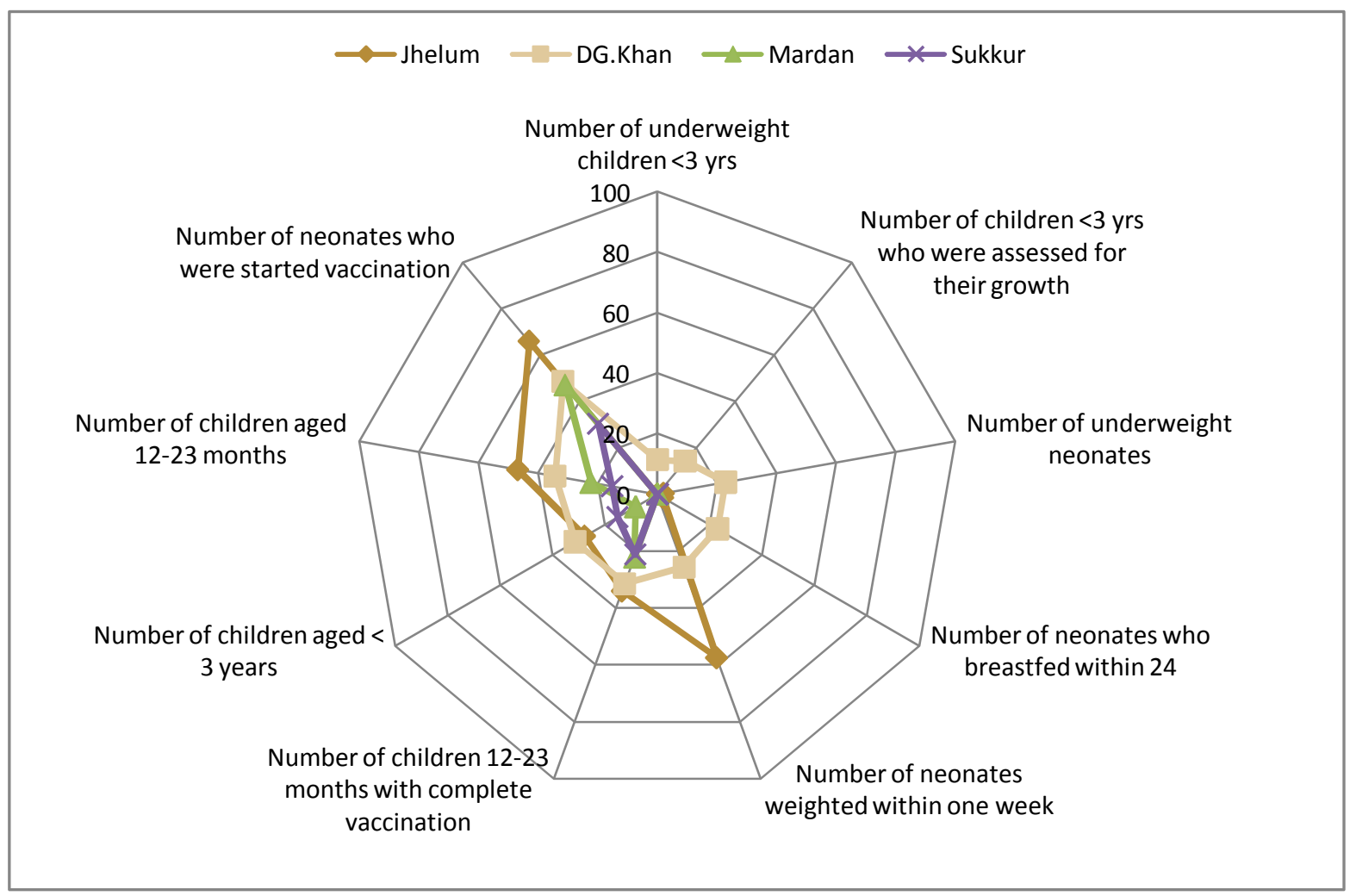

Figure 3.2 gives a snapshot of the accuracy of reported data for child health indicators by district. It shows that for some indicators, D.G. Khan and Jhelum had a better reporting of accurate data than Jhelum, Mardan and Sukkur districts. 
It is pertinent to mention here that, apart from D.G. Khan, none of the LHWs correctly reported the child growth related indicators. In D.G. Khan district only under 30 percent of the LHWs reported those indicators correctly, whereas three of the indicators (number of neonates weighed within one week, number of children aged 12-23 months, number of neonates who were started vaccination) in district Jhelum were more accurately reported compared to any other district. The indicator 'number of children under 3 years' was reported correctly by 30 percent of LHWs in district D.G. Khan and Jhelum, while, in district Mardan and Sukkur this number was under 10 percent. In district Mardan the most accurately reported indicator was the 'number of neonates who were started vaccination' (47 percent).

\section{Maternal health}

\section{Data completeness}

LHW reports nine indicators relating maternal health in her monthly report. Table 3.3 gives an overview of the data completeness in the reporting and recording of these indicators. The most complete data was about the number of registered pregnant women (93 percent). The second most complete data was about the number of women who received TT vaccine and the number whose deliveries were assisted by SBA. The most incomplete reporting was in the number of women who were checked up within 24 hours of delivery.

If we explore the incomplete reporting, we see that a higher number of LHWs did not provide information in recording of the indicators as compared to the reporting. It also tells that although some LHWs had not recorded the indicators they still reported the numbers in their monthly reports against these indicators. 
Table 3.3: Percent distribution of LHWs with incompleteness of data either in the records or the monthly report by each maternal health indicator

\begin{tabular}{|c|c|c|c|c|c|c|c|}
\hline \multirow[b]{2}{*}{ Indicator } & \multirow[b]{2}{*}{$\begin{array}{l}\text { Completeness } \\
\text { in data }\end{array}$} & \multirow[b]{2}{*}{$\begin{array}{l}\text { Incompletenes } \\
\text { s in data }\end{array}$} & \multirow[b]{2}{*}{ Total } & \multirow{2}{*}{$\mathbf{N}$} & \multicolumn{3}{|c|}{ Breakdown of incompleteness in data } \\
\hline & & & & & $\begin{array}{l}\text { No } \\
\text { information } \\
\text { in recording }\end{array}$ & $\begin{array}{l}\text { No } \\
\text { information } \\
\text { in reporting }\end{array}$ & $\begin{array}{c}\text { No } \\
\text { informatio } \\
\mathrm{n} \text { in both* }\end{array}$ \\
\hline $\begin{array}{l}\text { No. of pregnant women } \\
\text { registered this month }\end{array}$ & 71.5 & 28.5 & 100.0 & 151 & 16.6 & 6.0 & 6.0 \\
\hline $\begin{array}{l}\text { No. of total registered } \\
\text { pregnant women }\end{array}$ & 92.7 & 7.3 & 100.0 & 151 & 4.0 & 1.3 & 2.0 \\
\hline $\begin{array}{l}\text { No. of total pregnant } \\
\text { women checked }\end{array}$ & 49.0 & 51.0 & 100.0 & 151 & 46.4 & 2.0 & 2.6 \\
\hline $\begin{array}{l}\text { No. of pregnant women } \\
\text { provided iron tablets }\end{array}$ & 64.2 & 35.8 & 100.0 & 151 & 16.6 & 12.6 & 6.6 \\
\hline $\begin{array}{l}\text { No. of abortions (within } \\
7 \text { months of pregnancy) }\end{array}$ & 60.9 & 39.1 & 100.0 & 151 & 6.0 & 21.2 & 11.9 \\
\hline $\begin{array}{l}\text { No. of women who } \\
\text { visited } 4 />4 \text { times to } \\
\text { skilled provider }\end{array}$ & 68.2 & 31.8 & 100.0 & 151 & 17.2 & 11.9 & 2.6 \\
\hline $\begin{array}{l}\text { No. of women who } \\
\text { completed TT vaccine } \\
\text { before delivery }\end{array}$ & 75.5 & 24.5 & 100.0 & 151 & 9.3 & 12.6 & 2.6 \\
\hline $\begin{array}{l}\text { No. of deliveries assisted } \\
\text { by SBA }\end{array}$ & 70.9 & 29.1 & 100.0 & 151 & 11.9 & 13.2 & 4.0 \\
\hline $\begin{array}{l}\text { No. of women checked } \\
\text { up within } 24 \text { hours of } \\
\text { delivery }\end{array}$ & 25.8 & 74.2 & 100.0 & 151 & 57.0 & 9.9 & 7.3 \\
\hline
\end{tabular}

\section{Data accuracy}

Figure 3.3 shows the accuracy of reported data in LHWs monthly report for the maternal health indicators., Our findings show that overall a lower proportion of the LHWs who recorded and reported the completed data reported it correctly, whereas the proportion of over and under reporting varies by the type of indicator. The most accurately reported indicators were the 'number of pregnant women', 'number of abortions' and for the 'number of deliveries assisted by SBA' (58 percent each). The proportion of over reporting was highest for the two indicators; 'number of pregnant women provided iron tablets' and the 'number of pregnant women checked'. This shows that LHW over reports the indicators that reflect her performance. The proportion of under reporting was highest for the 'number of registered pregnant women'. 
Figure 3.3: Components of complete reporting (maternal health indicators)

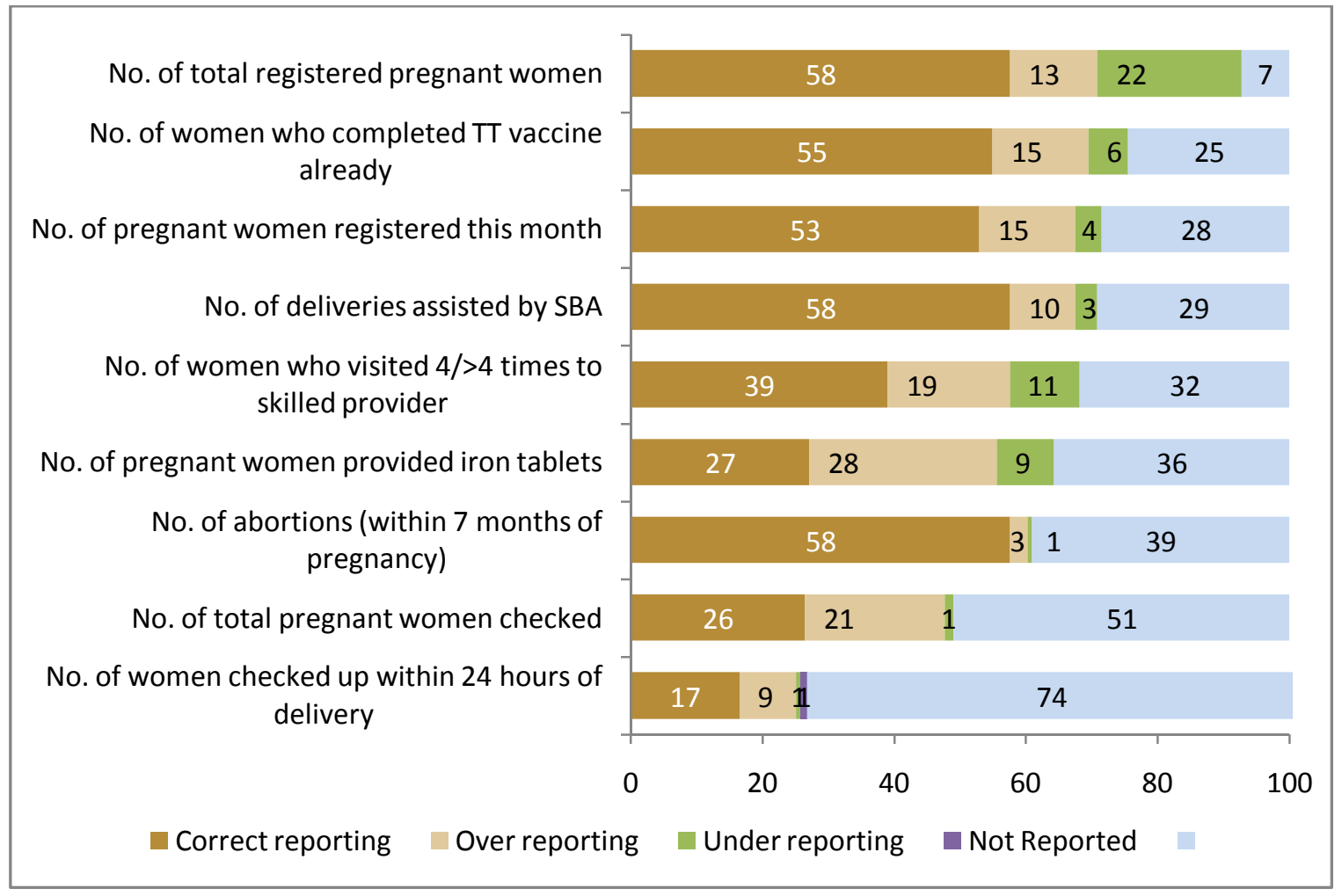

Table 3.2 depicts the accuracy of reported data for maternal health indicators. Our findings show that overall only 5 percent of the LHWs accurately reported all the nine maternal health indicators. Results show a better data reporting in district D.G. Khan than other three selected districts. The median number of correctly reported indicators in D.G. Khan was 6, while it was 5, 4 and only one in Jhelum, Mardan and Sukkur respectively.

Table 3.4: Percent distribution of LHWs with accurate reporting according to available record and monthly report (variables $=9$ )

\begin{tabular}{l|r|r|r|r|r}
\hline No. of indicators & \multicolumn{1}{|c|}{ Jhelum } & D.G. Khan & Mardan & Sukkur & Total \\
\hline $\mathbf{0 - 2}$ & 12.7 & 2.9 & 38.9 & 78.8 & 31.1 \\
\hline $\mathbf{3 - 5}$ & 63.8 & 40.0 & 44.5 & 18.2 & 43.7 \\
\hline $\mathbf{6 - 8}$ & 23.4 & 34.3 & 16.7 & 3.0 & 19.8 \\
\hline $\mathbf{9}$ & 0.0 & 22.9 & 0.0 & 0.0 & 5.3 \\
\hline Total & 100.0 & 100.0 & 100.0 & 100.0 & 100.0 \\
\hline Median & 5 & 6 & 4 & 1 & 4 \\
\hline $\mathbf{N}$ & 47 & 35 & 36 & 33 & 151 \\
\hline
\end{tabular}


Figure 3.4 gives an overall picture of the accuracy of reported data for the maternal health indicators by district. It shows that district Sukkur had the poorest accuracy of reported data for maternal health indicators compared to the remaining three districts. The LHWs in district D.G. Khan had the most accurately reported data for maternal health indicators compared to other selected districts accept for the three indicators; 'number of abortions', 'number of deliveries assisted by SBA' and 'number of pregnant women who completed TT vaccine during pregnancy'. All these three indicators were reported more accurately in Jhelum district.

It is pertinent to mention here that one indicator; 'number of women checked up within 24 hours of delivery' apart from district D.G Khan, had almost 100 percent inaccurate reporting in all of the districts. One of the major reason for this variation among the selected districts was the provision of $\mathrm{MCH}$ card, as LHWs working in district D.G Khan were using the $\mathrm{MCH}$ cards while no cards were available in other three districts.

Figure 3.4: Percentage of LHWs Reported Correct Information from the Record for the Month of May 2011 in Selected BHUs, Maternal Health Indicators

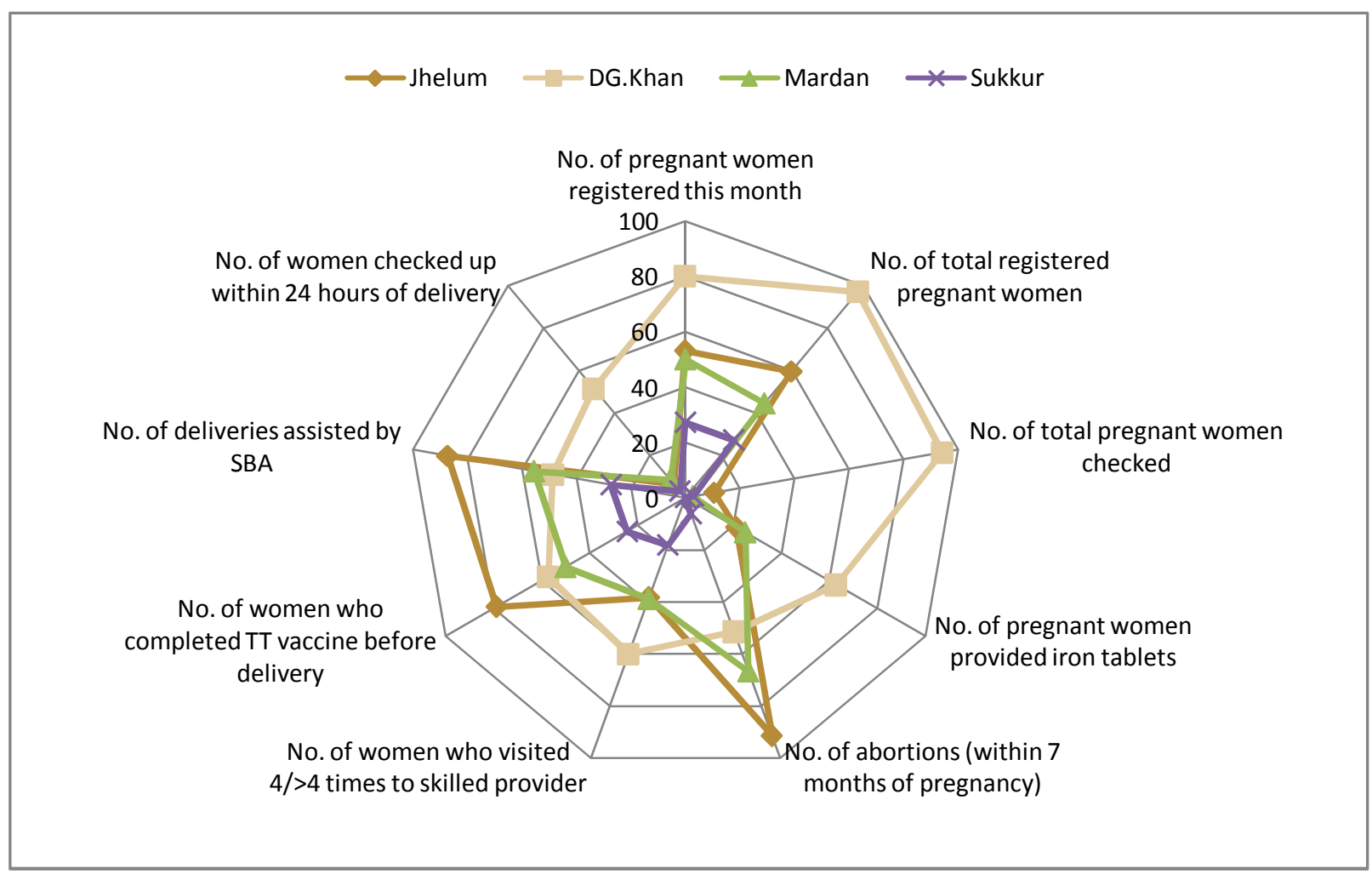




\section{Family planning}

\section{Data completeness}

In LHW monthly report there are 15 indicators relating to family planning. Table 3.5 gives an overview of the data completeness in the reporting and recording of these indicators by LHWs. Our findings show that the data completeness for the reporting of the number of different family planning users ranges from 85 percent to 87 percent. The most incomplete reporting was for indicators 'number of users provided condom', 'injectables by the LHW' and for 'number of couples referred to health facility by the LHW'.

As opposed to other sections, where a higher proportion of LHWs had more incomplete data in recording than reporting, for most of the family planning indicators the LHW had more incompleteness in reporting than the recording. This might be due to the arduous effort that is required to count the numbers from the list of FP users and fill in the monthly report. 
Table 3.5: Percent distribution of LHWs with incompleteness of data either in the records or the monthly report by each family planning indicator

\begin{tabular}{|c|c|c|c|c|c|c|c|}
\hline \multirow[b]{2}{*}{ Indicator } & \multirow[b]{2}{*}{$\begin{array}{l}\text { Completeness } \\
\text { in data }\end{array}$} & \multirow[b]{2}{*}{$\begin{array}{l}\text { Incompleteness } \\
\text { in data }\end{array}$} & \multirow[b]{2}{*}{ Total } & \multirow[b]{2}{*}{$\mathrm{N}$} & \multicolumn{3}{|c|}{ Breakdown of incompleteness in data } \\
\hline & & & & & $\begin{array}{l}\text { No } \\
\text { information } \\
\text { in recording }\end{array}$ & $\begin{array}{c}\text { No } \\
\text { information } \\
\text { in reporting }\end{array}$ & $\begin{array}{c}\text { No } \\
\text { information } \\
\text { in both* }\end{array}$ \\
\hline $\begin{array}{l}\text { No. of registered eligible } \\
\text { couples }\end{array}$ & 93.4 & 6.6 & 100.0 & 151 & 1.3 & 4.6 & 0.7 \\
\hline $\begin{array}{l}\text { No. of couples started any } \\
\text { FP method this month }\end{array}$ & 64.9 & 35.1 & 100.0 & 151 & 19.2 & 7.3 & 8.6 \\
\hline $\begin{array}{l}\text { No. of current users given } \\
\text { follow up }\end{array}$ & 82.1 & 17.9 & 100.0 & 151 & 1.3 & 9.9 & 6.6 \\
\hline $\begin{array}{l}\text { No. of total users of } \\
\text { modern methods }\end{array}$ & 84.8 & 15.2 & 100.0 & 151 & 2.6 & 11.3 & 1.3 \\
\hline No. of condom users & 85.4 & 14.6 & 100.0 & 151 & 2.0 & 11.3 & 1.3 \\
\hline No. of total users of pills & 86.8 & 13.2 & 100.0 & 151 & 1.3 & 10.6 & 1.3 \\
\hline No. of injectable users & 83.4 & 16.6 & 100.0 & 151 & 3.3 & 10.6 & 2.6 \\
\hline No. of total users of IUD & 86.1 & 13.9 & 100.0 & 151 & 2.0 & 8.6 & 3.3 \\
\hline $\begin{array}{l}\text { No. of total users of female } \\
\text { sterilization }\end{array}$ & 84.8 & 15.2 & 100.0 & 151 & 2.6 & 7.9 & 4.6 \\
\hline $\begin{array}{l}\text { No. of total users of other } \\
\text { modern methods }\end{array}$ & 58.9 & 41.1 & 100.0 & 151 & 19.9 & 10.6 & 10.6 \\
\hline $\begin{array}{l}\text { No. of total users of } \\
\text { traditional methods }\end{array}$ & 85.4 & 14.6 & 100.0 & 151 & 1.3 & 9.3 & 4.0 \\
\hline $\begin{array}{l}\text { No. of couples referred to } \\
\text { health facility/FP center }\end{array}$ & 54.3 & 45.7 & 100.0 & 151 & 17.2 & 18.5 & 9.9 \\
\hline $\begin{array}{l}\text { No. of clients provided } \\
\text { condom }\end{array}$ & 51.7 & 48.3 & 100.0 & 151 & 22.5 & 16.6 & 9.3 \\
\hline No. of clients provided pills & 64.2 & 35.8 & 100.0 & 151 & 11.9 & 17.2 & 6.6 \\
\hline $\begin{array}{l}\text { No. of clients provided } \\
\text { injectables }\end{array}$ & 58.3 & 41.7 & 100.0 & 151 & 16.6 & 13.2 & 11.9 \\
\hline
\end{tabular}

\section{Data accuracy}

Figure 3.5 shows the components (correct, over and under reporting) of complete reporting, the most accurately reported indicator was the 'number of registered eligible couples' (50 percent). The proportion of correct reporting was lowest for two indicators; 'number of total users of modern methods' and 'number of current users given follow up' (13 percent and 5 percent respectively). The proportion of over reporting was higher than the proportion of under reporting for all the indicators that depict the number of current users of different family planning methods. 
Figure 3.5: Components of complete reporting (family planning indicators)

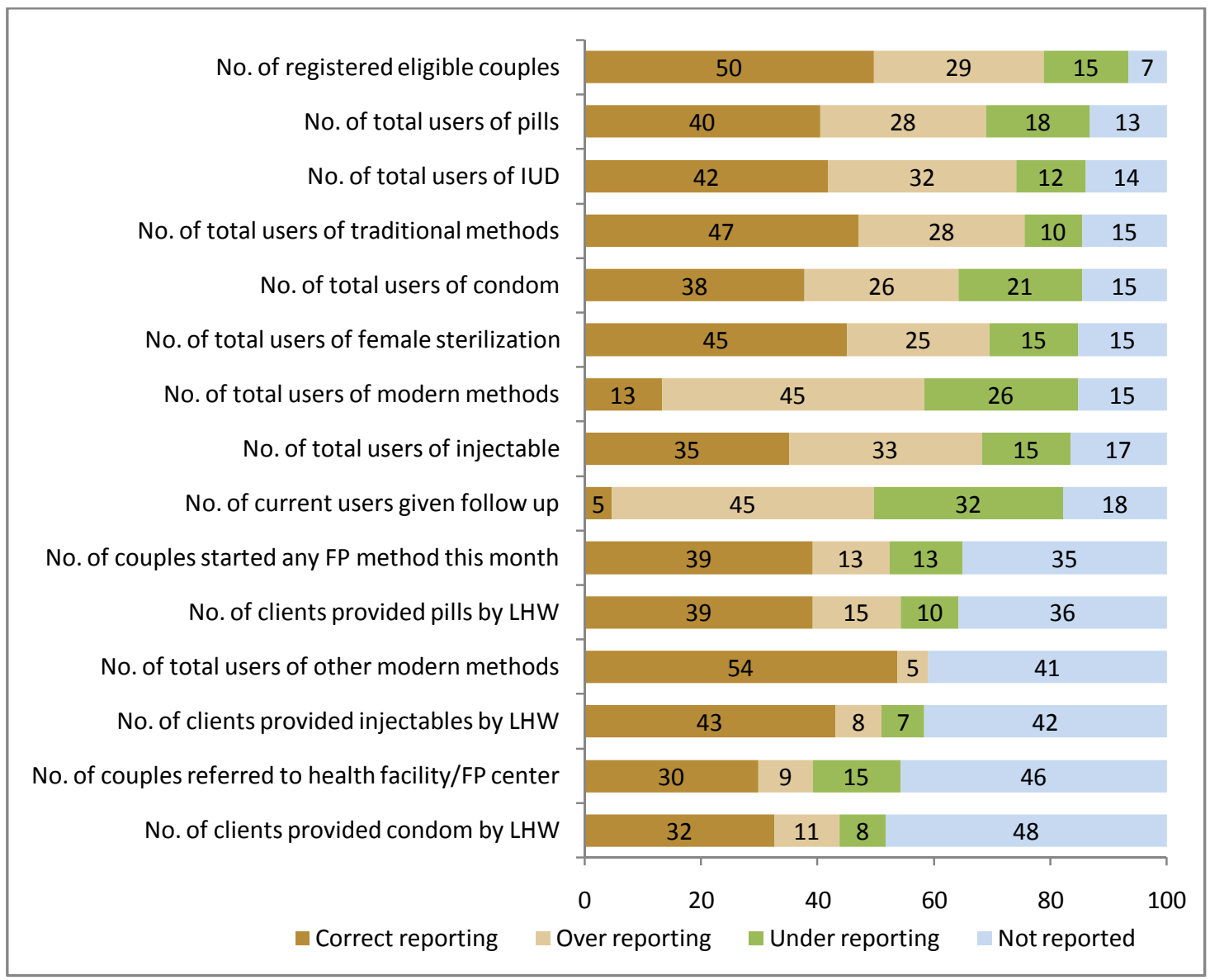

Table 3.6 depicts the accuracy of reported data for the family planning indicators. Our findings show that overall, none of the LHWs accurately reported all the 15 family planning indicators in monthly report. Results show a better data reporting in district D.G. Khan and Jhelum compared to Mardan and Sukkur districts. The median number of correctly reported family planning indicators was 8 for D.G. Khan and 7 for district Jhelum. On the other hand, the median number for correctly reported family planning indicators was 4 for Mardan and 2 for Sukkur. Moreover, in district Sukkur none of the LHWs reported more than 8 indicators correctly. 
Table 3.6: Percent distribution of LHWs with accurate reporting according to available record and monthly report (indicators $=15$ )

\begin{tabular}{|c|c|c|c|c|c|}
\hline Number of indicators & Jhelum & D.G. Khan & Mardan & Sukkur & Total \\
\hline $0-2$ & 8.5 & 11.5 & 33.4 & 54.5 & 25.2 \\
\hline 3-5 & 25.6 & 17.2 & 33.3 & 24.3 & 25.2 \\
\hline $6-8$ & 38.2 & 25.7 & 16.7 & 21.2 & 26.5 \\
\hline $9-11$ & 19.1 & 37.2 & 13.9 & 0.0 & 17.9 \\
\hline $12-14$ & 8.6 & 8.6 & 2.8 & 0.0 & 5.3 \\
\hline Total & 100.0 & 100.0 & 100.0 & 100.0 & 100.0 \\
\hline Median & 7 & 8 & 4 & 2 & 5 \\
\hline $\mathbf{N}$ & 47 & 35 & 36 & 33 & 151 \\
\hline
\end{tabular}

Figure 3.4 gives an overview about the extent of accurately reported data for the family planning indicators by district. Our results show that district Sukkur had the poorest accuracy of reported data for family planning indicators compared to other selected districts. The LHWs working in district D.G. Khan had the most accurate reported data for family planning indicators than other selected districts. However, for two indicators; 'number of total users of modern methods' and the 'number of current users given follow up' had a very small proportion of LHWs reported accurate data in all districts.

Figure 3.6: Percentage of LHWs Reported Correct Information from the Record for the Month of May 2011 in Selected BHUs, Family Planning Indicators

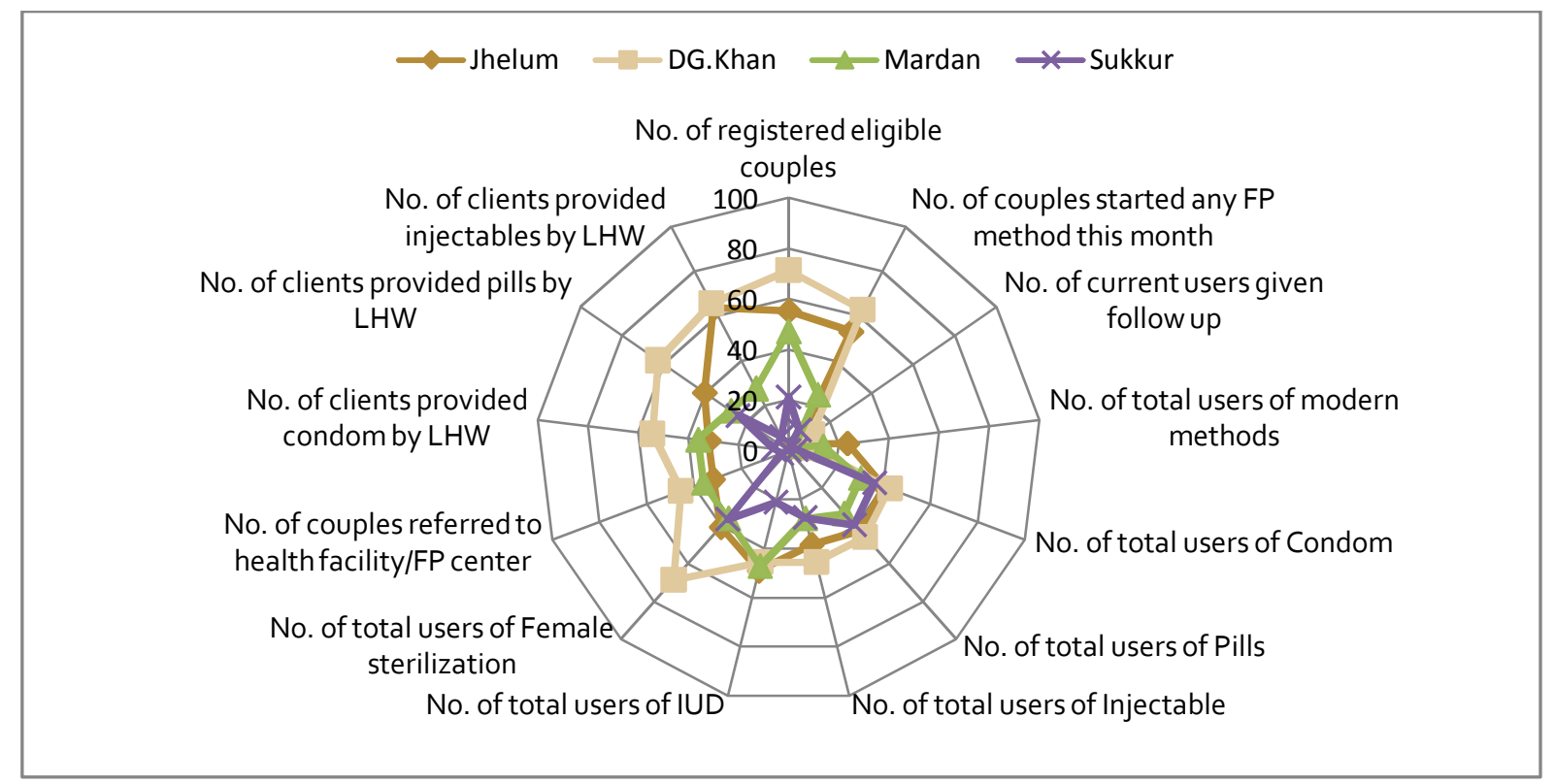




\section{Vital events (births and deaths)}

There are seven indicators related to the vital events in the LHW monthly report. Interestingly, data for births and deaths was complete in both records and monthly report of the LHW. LHW does not compile the number of deaths separately in her records; she only notes them down in the family register against the name of the person who died that month.

Figure 3.7 shows that most of the vital events indicators were correctly reported by the LHWs in all the selected districts. It is also noteworthy that the data was more accurate for the rare events; number of maternal, infant and child deaths. A higher proportion of LHWs over reported the births in their community than under reporting in all districts.

Figure 3.7: Components of complete reporting (vital events)

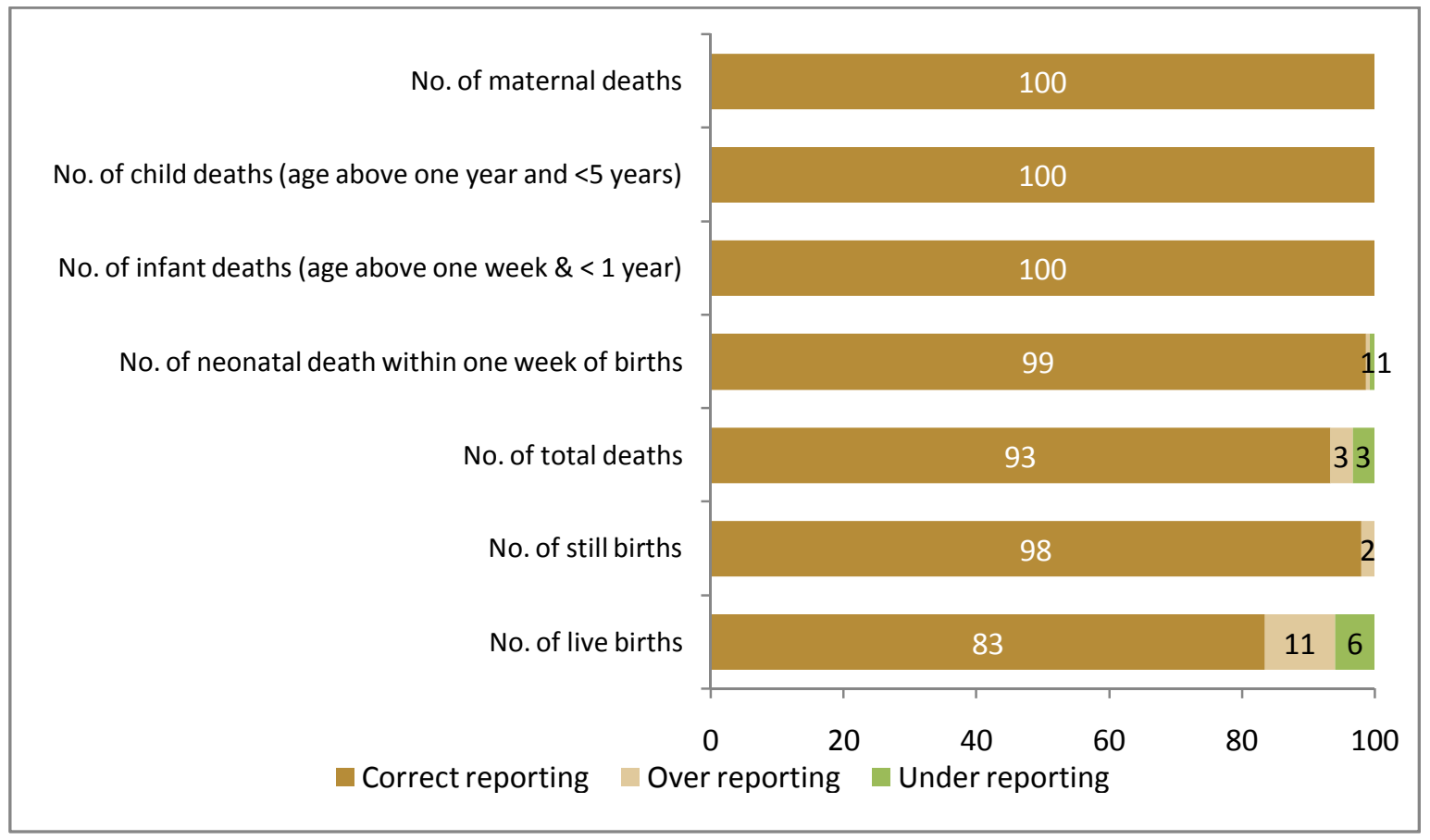

\section{Social relations}

There are three indicators related to the social relations in the LHW monthly report; 'number of meetings with village health committee ( $\mathrm{VHC})$ ', 'number of meetings with women health committee (WHC)' and 'number of health talks in local schools'. LHW conducts each of those meetings once in a month. Figure 3.8 below shows that most of the LHWs did complete reporting of those indicators, expect for only one third of LHWs reported incomplete data for the indicator 'number of health talks in local schools'. 
Figure 3.8: Percentage of LHWs with correct reporting according to available record and monthly report

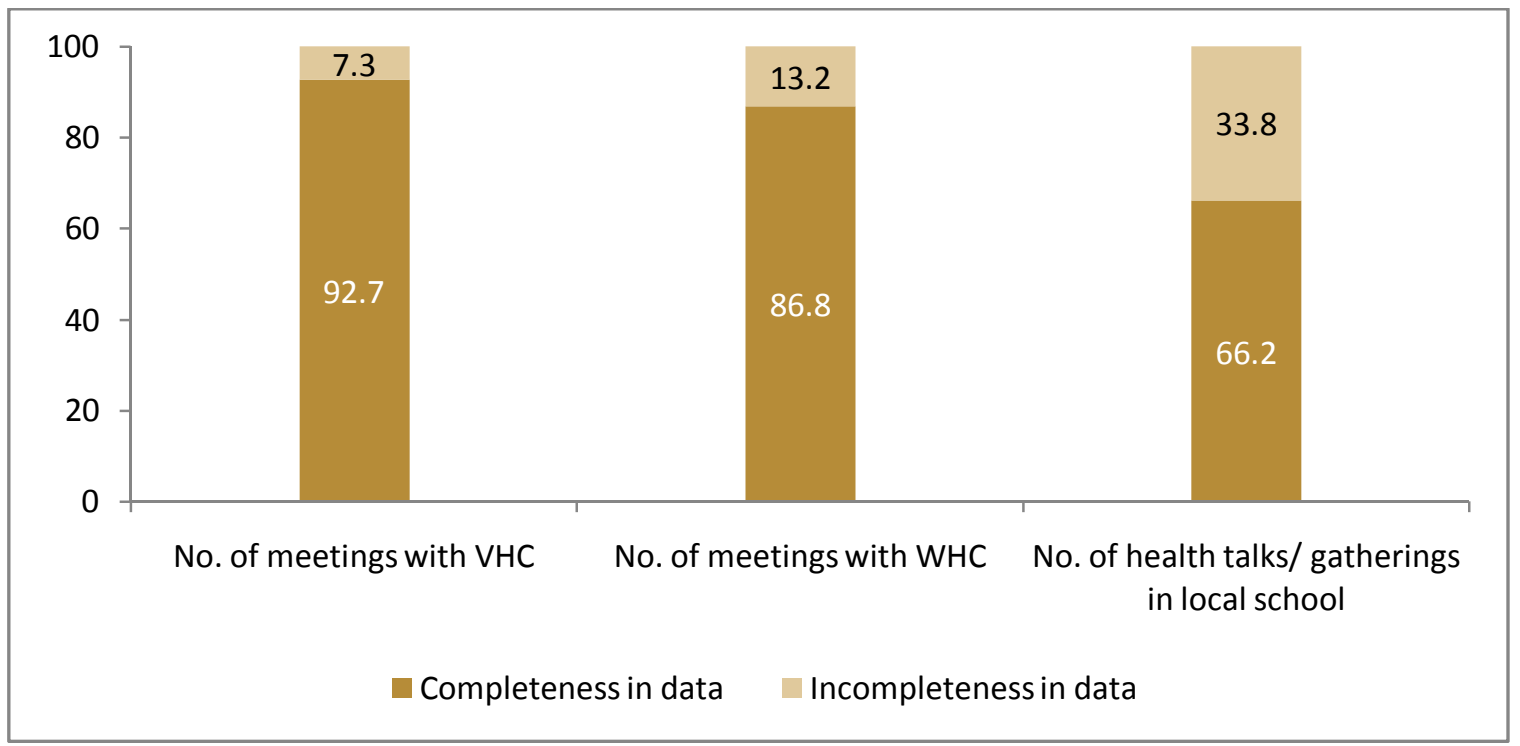

Figure 3.9 shows the level of accuracy in reported data for social events. Results show that in all the selected districts, a higher proportion of LHWs reported accurately the 'number of meetings with $\mathrm{VHC}^{\prime}$, followed by 'number of meetings with WHCs and no. of health talks in local schools'. Further, a higher proportion of the LHWs over reported all the social events indicators than under reporting.

Figure 3.9: Components of complete reporting (social events)

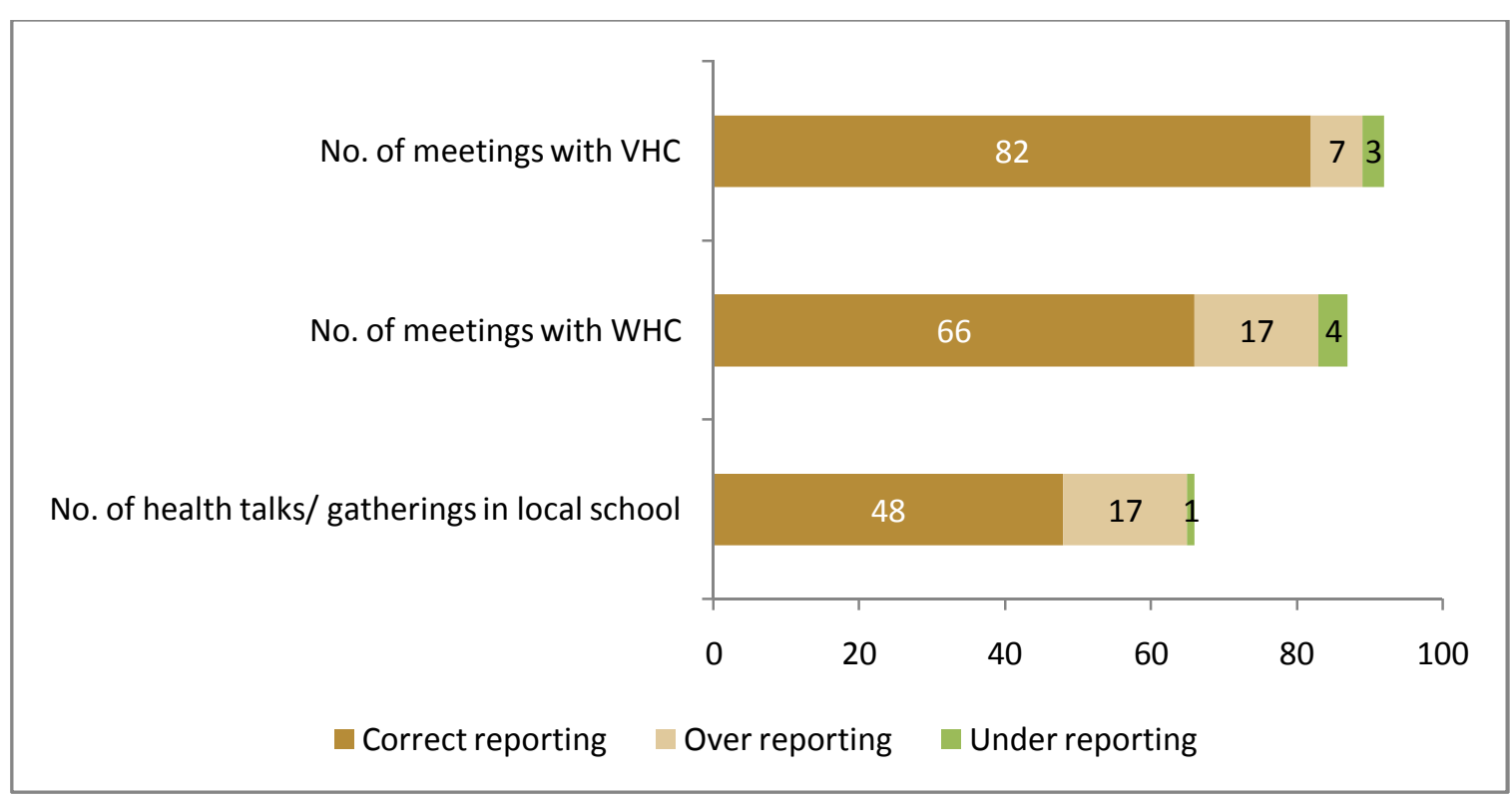




\section{All indicators}

Overall, each LHW reports few selected indicators for maternal and child health, family planning, births and deaths and social events that she conducts in her community and the information about the consumption of drugs and FP methods. In the current study, we analyzed the accuracy of a total of 43 indicators, excluding indicators related to consumption of drugs.

Table 3.7 shows the overall accuracy in reporting of all the selected 43 indicators from the LHW monthly report. Our findings show that none of the selected LHWs correctly reported all the indicators. The median number of correctly reported indicators was highest for the LHWs in district D.G. Khan, followed in district Jhelum (28 and 23 respectively). The LHWs in district Sukkur and Mardan reported the least number of correct indicators with median number of indicators as 14 and 18 respectively.

Table 3.7: Percentage distribution of number of correctly reported indicators by LHWs (Total variables = 43)

\begin{tabular}{|c|c|c|c|c|c|}
\hline No. of variables & Jhelum & D.G. Khan & Mardan & Sukkur & Total \\
\hline $1-5$ & 0.0 & 0.0 & 0.0 & 3.0 & 0.7 \\
\hline $6-10$ & 4.3 & 0.0 & 13.9 & 27.3 & 10.6 \\
\hline $11-15$ & 6.4 & 5.7 & 27.8 & 39.4 & 18.5 \\
\hline $16-20$ & 19.1 & 8.6 & 22.2 & 24.2 & 18.5 \\
\hline $21-25$ & 44.7 & 31.4 & 27.8 & 3.0 & 28.5 \\
\hline $26-30$ & 19.1 & 22.9 & 8.3 & 3.0 & 13.9 \\
\hline $31-35$ & 6.4 & 22.9 & 0.0 & 0.0 & 7.3 \\
\hline $36-43$ & 0.0 & 8.6 & 0.0 & 0.0 & 2.0 \\
\hline Total & 100.0 & 100.0 & 100.0 & 100.0 & 100.0 \\
\hline Median & 23 & 28 & 18 & 14 & 21 \\
\hline $\mathbf{N}$ & 47 & 35 & 36 & 33 & 151 \\
\hline
\end{tabular}


Figure 3.10: Percentage of correct indicators reported by the BHU

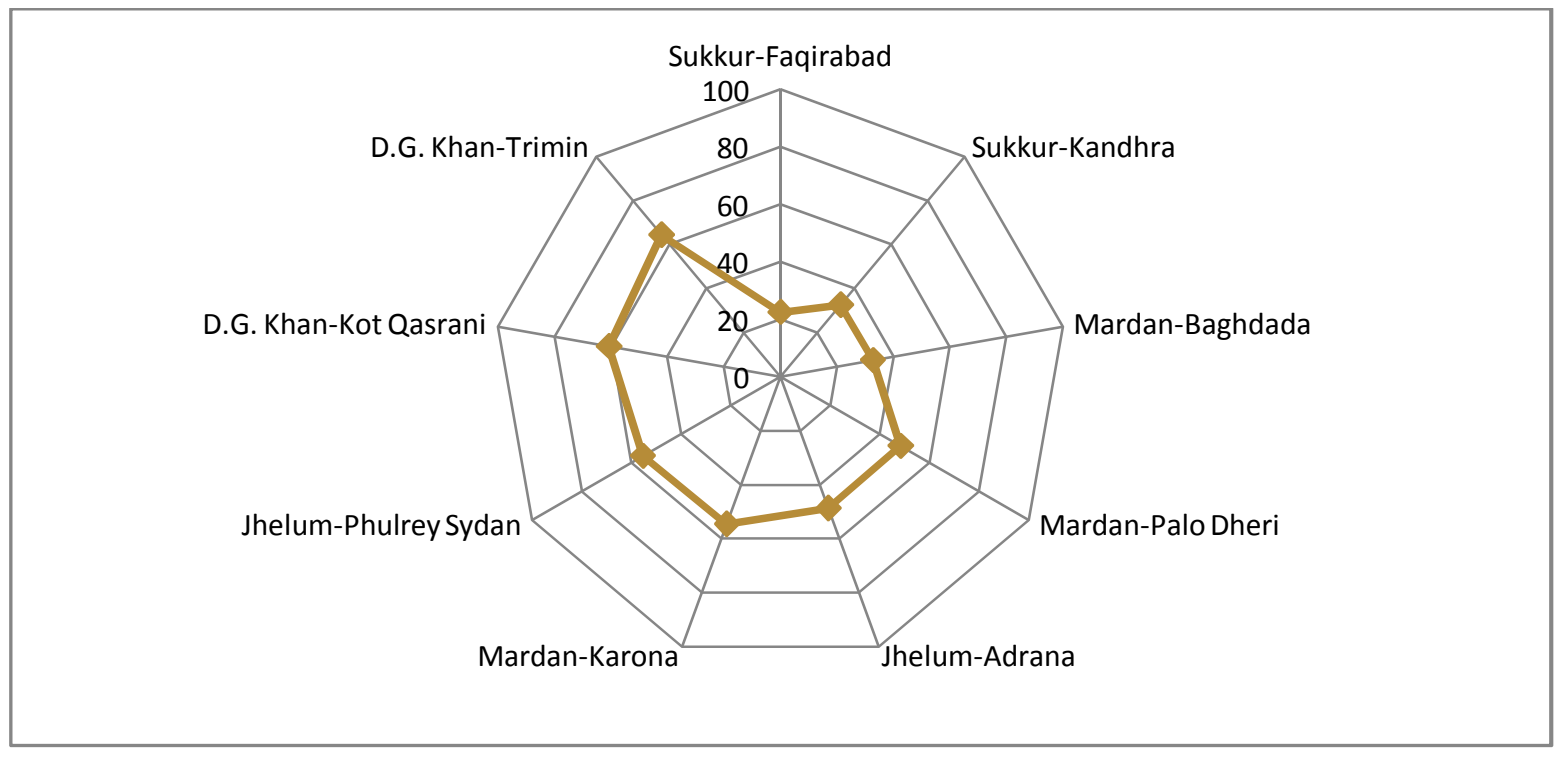

Figure 3.10 given below shows the percentage of correctly reported indicators by the LHWs at the facility level. The results show that facilities from the same district had almost similar percentages of correctly reported indicators by the districts except BHU Baghdada where the percentage was considerably lower than the other two facilities of Mardan. 


\section{Chapter 4 \\ Comparison of LHS report with LHWs' monthly report}

This chapter describes the discrepancies between the main indicators of the LHWs monthly report and the LHS report. LHS compiles her report on the basis of LHWs monthly reports working under her supervision. In this regard LHS's duty is to only copy the numbers from each LHW's monthly report and put them into a consolidated report that contains indicator wise information by each LHW under her supervision.

This data was explored for data completeness and data accuracy to examine the extent to which the data was completed at the two levels of reporting (LHW and LHS) and whether the same information against these indicators was matched at the two different levels of reporting. The under and over reporting of the data was determined on the basis of LHWs' monthly report, if for an indicator the LHS reported a higher number than what LHW reported for the same, this was considered as over reported. Therefore, the current chapter is mainly explaining the quality of LHS's report by comparing with LHWs report.

\section{Child Health}

\section{Data completeness}

Table 4.1 gives an overview of the data completeness in the reporting of child health indicators at the LHW and LHS level monthly reporting. The completeness of an indicator shows that both LHW and the LHS had reported that indicator, whereas the incomplete reporting shows that either or both of them had left that indicator empty. The most complete reporting was for indicators 'number of children aged 12-23 months', 'number of children aged < 3 years', and for 'number of children 12-23 months with complete vaccination'. The most incomplete reporting was in reporting the 'number of underweight neonates'.

Our findings show that, for all the child health indicators, a higher proportion of the selected LHWs in all the four districts did not provide information in their monthly reports than LHS report. 
It also tells that although some LHWs had not recorded the indicators, the LHS still had reported the numbers in their monthly reports against these indicators.

Table 4.1: Percent distribution of LHWs with incomplete reporting in either of the LHW report or the LHS report by each child health indicator

\begin{tabular}{|c|c|c|c|c|}
\hline Indicator & $\begin{array}{l}\text { Completeness } \\
\text { in data }\end{array}$ & $\begin{array}{l}\text { Incomplete } \\
\text { ness in data }\end{array}$ & Total & $\mathrm{N}$ \\
\hline $\begin{array}{l}\text { Number of neonates } \\
\text { weighted within one } \\
\text { week }\end{array}$ & 68.2 & 31.8 & 100.0 & 151 \\
\hline $\begin{array}{l}\text { Number of underweight } \\
\text { neonates }\end{array}$ & 56.3 & 43.7 & 100.0 & 151 \\
\hline $\begin{array}{l}\text { Number of neonates who } \\
\text { breastfed within } 24 \\
\text { hours of birth }\end{array}$ & 86.1 & 13.9 & 100.0 & 151 \\
\hline $\begin{array}{l}\text { Number of neonates who } \\
\text { were started vaccination }\end{array}$ & 80.8 & 19.2 & 100.0 & 151 \\
\hline $\begin{array}{l}\text { Number of children aged } \\
12-23 \text { months }\end{array}$ & 96.0 & 4.0 & 100.0 & 151 \\
\hline $\begin{array}{l}\text { Number of children } 12- \\
23 \text { months with } \\
\text { complete vaccination }\end{array}$ & 95.4 & 4.6 & 100.0 & 151 \\
\hline $\begin{array}{l}\text { Number of children aged } \\
<3 \text { years }\end{array}$ & 96.0 & 4.0 & 100.0 & 151 \\
\hline $\begin{array}{l}\text { Number of children }<3 \\
\text { yrs who were assessed } \\
\text { for their growth }\end{array}$ & 63.6 & 36.4 & 100.0 & 151 \\
\hline $\begin{array}{l}\text { Number of underweight } \\
\text { children }<3 \text { yrs }\end{array}$ & 60.9 & 39.1 & 100.0 & 151 \\
\hline
\end{tabular}

"No information" implies that the cells were empty in the register and/or report.

\begin{tabular}{|c|c|c|}
\hline \multicolumn{3}{|c|}{ Breakdown of incompleteness in data } \\
\hline $\begin{array}{c}\text { No } \\
\text { informatio } \\
\mathrm{n} \text { in LHW } \\
\text { report }\end{array}$ & $\begin{array}{c}\text { No } \\
\text { information } \\
\text { in LHS } \\
\text { report }\end{array}$ & $\begin{array}{c}\text { No } \\
\text { information } \\
\text { in both* }\end{array}$ \\
\hline 13.2 & 7.9 & 10.6 \\
\hline 19.9 & 10.6 & 13.2 \\
\hline 9.9 & 0.7 & 3.3 \\
\hline 15.9 & 0.7 & 2.6 \\
\hline 2.6 & 1.3 & 0.0 \\
\hline 4.0 & 0.0 & 0.7 \\
\hline 3.3 & 0.7 & 0.0 \\
\hline 16.6 & 4.6 & 15.2 \\
\hline 16.6 & 8.6 & 13.9 \\
\hline
\end{tabular}

*recording and reporting

\section{Data accuracy}

Figure 4.1 shows the accuracy and components (correct, over and under) of complete reporting. Our findings show that for most of the child health indicators in all the four districts, a higher proportion of the LHSs reported correct data, whereas the proportion of over and under reporting varies by the type of indicator. The proportion of correct reporting was lowest for the indicator 'number of children 12-23 months with complete vaccination', whereas it was highest for the indicator 'number of neonates who were breastfed within 24 hours'. The proportion of over and under reporting was almost similar for most of the child health indicators. 
Figure 4.1: Status of reporting

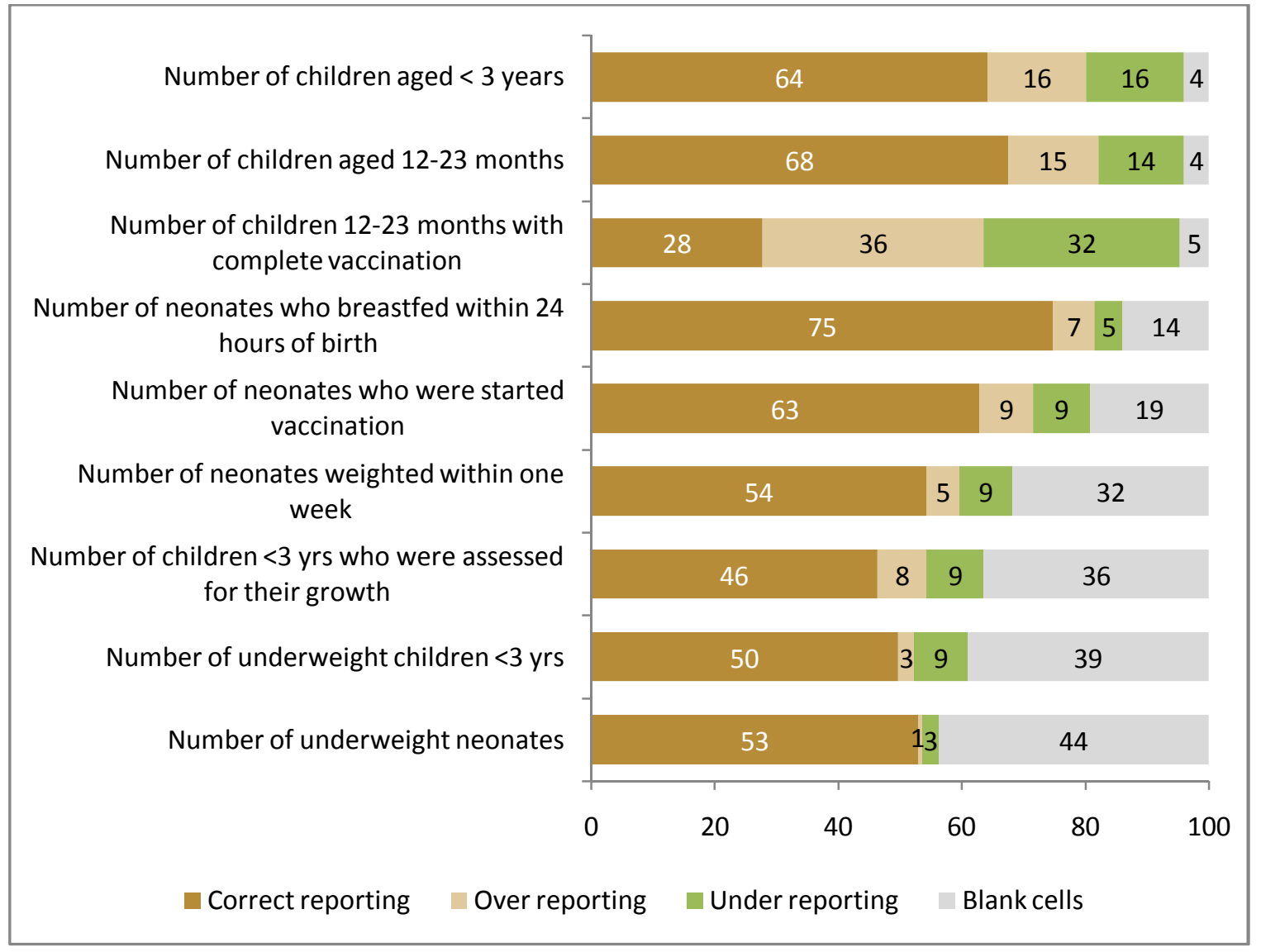

Table 4.2 shows the accuracy of LHSs reported data for child health indicators. Results show that overall only 9 percent of the 151 LHSs accurately reported all the nine child health indicators. Further, our findings show that LHSs working in Jhelum and D.G. Khan districts reported data more accurate compared to other two districts. The median number of correctly reported child health indicators in Jhelum and D.G. Khan was 8 and 6 indicators respectively, while it was 5 and only 2 indicators in Mardan and Sukkur respectively. 
Table 4.2: Percent distribution of LHSs with accurate reporting according to available record and monthly report (variables $=9$ )

\begin{tabular}{l|r|r|r|r|r}
\hline Number of indicators & Jhelum & D.G. Khan & Mardan & Sukkur & Total \\
\hline $\mathbf{0 - 2}$ & 8.5 & 17.2 & 13.9 & 54.5 & 21.9 \\
\hline $\mathbf{3 - 5}$ & 14.8 & 25.7 & 41.6 & 39.4 & 29.2 \\
\hline $\mathbf{6 - 8}$ & 49 & 54.3 & 44.4 & 6.1 & 39.7 \\
\hline $\mathbf{9}$ & 27.7 & 2.9 & 0 & 1 & 9.3 \\
\hline Total & 100.0 & 100.0 & 100.0 & 100.0 & 100.0 \\
\hline Median & 8 & 6 & 5 & 3 & 5 \\
\hline $\mathbf{N}$ & 47 & 35 & 36 & 33 & 151 \\
\hline
\end{tabular}

Figure 4.2 gives a snapshot of the accuracy of reported data for the child health indicators by district. Our findings show that amongst LHSs working in all the selected four districts, district Sukkur had the poorest accuracy of reported data for child health indicators, while district Jhelum had the most accurate data reported for child health indicators when compared to the other three districts. In district Mardan, the LHSs had one of the best reporting for four out of nine indicators while for rest of the indicators their accuracy level was lower than Jhelum and D.G. Khan. Figure 4.2 shows that for one indicator; 'number of children 12-23 months with complete vaccination' the proportion of accurate reporting by LHS was lower in all the four districts.

Figure 4.2: Percentage of LHSs reported Correct Information from the Record for the Month of May 2011 in Selected BHUs, Child Health Indicators

No. of underweight children
$<3$ yrs
No. of neonates weighted
within one week
breastfed within 24
months with complete
noccination




\section{Maternal Health}

\section{Data completeness}

Table 4.3 gives an overview of the data completeness in the LHS level reporting of the maternal health indicators in all the four districts. The most complete data was for indicators 'number of registered pregnant women' and the 'number of pregnant women checked' (95 and 97 percent respectively). On the other hand, the most incomplete data was for indicators 'number of pregnant women provided iron tablets' and the 'number of abortions' (33 percent and 22 percent respectively).

Our results show that a higher proportion of LHWs did not provide information in recording of the indicators as compared to the LHSs in all the four districts. It also tells that although some LHWs had not recorded the indicators, the LHS still had reported the numbers in their monthly reports against these indicators.

Table 4.3: Percent distribution of LHWs with incomplete reporting in either of the LHW report or the LHS report by each maternal health indicator

\begin{tabular}{|c|c|c|c|c|}
\hline Indicator & $\begin{array}{l}\text { Completenes } \\
\mathrm{s} \text { in data }\end{array}$ & $\begin{array}{l}\text { Incompletene } \\
\text { ss in data }\end{array}$ & Total & $\mathrm{N}$ \\
\hline $\begin{array}{l}\text { Number of pregnant } \\
\text { women registered this } \\
\text { month }\end{array}$ & 87.4 & 12.6 & 100 & 151 \\
\hline $\begin{array}{l}\text { Number of total registered } \\
\text { pregnant women }\end{array}$ & 96.7 & 3.3 & 100 & 151 \\
\hline $\begin{array}{l}\text { Number of total pregnant } \\
\text { women checked }\end{array}$ & 94.7 & 5.3 & 100 & 151 \\
\hline $\begin{array}{l}\text { Number of pregnant } \\
\text { women provided iron } \\
\text { tablets }\end{array}$ & 78.1 & 21.9 & 100 & 151 \\
\hline $\begin{array}{l}\text { Number of abortions } \\
\text { (within } 7 \text { months of } \\
\text { pregnancy) }\end{array}$ & 66.9 & 33.1 & 100 & 151 \\
\hline $\begin{array}{l}\text { Number of women who } \\
\text { visited } 4 />4 \text { times to } \\
\text { skilled provider }\end{array}$ & 84.1 & 15.9 & 100 & 151 \\
\hline $\begin{array}{l}\text { Number of women who } \\
\text { completed } \Pi \pi \text { vaccine } \\
\text { before delivery }\end{array}$ & 84.1 & 15.9 & 100 & 151 \\
\hline $\begin{array}{l}\text { Number of deliveries } \\
\text { assisted by SBA }\end{array}$ & 80.1 & 19.9 & 100 & 151 \\
\hline $\begin{array}{l}\text { Number of women } \\
\text { checked up within } 24 \\
\text { hours of delivery }\end{array}$ & 80.8 & 19.2 & 100 & 151 \\
\hline
\end{tabular}

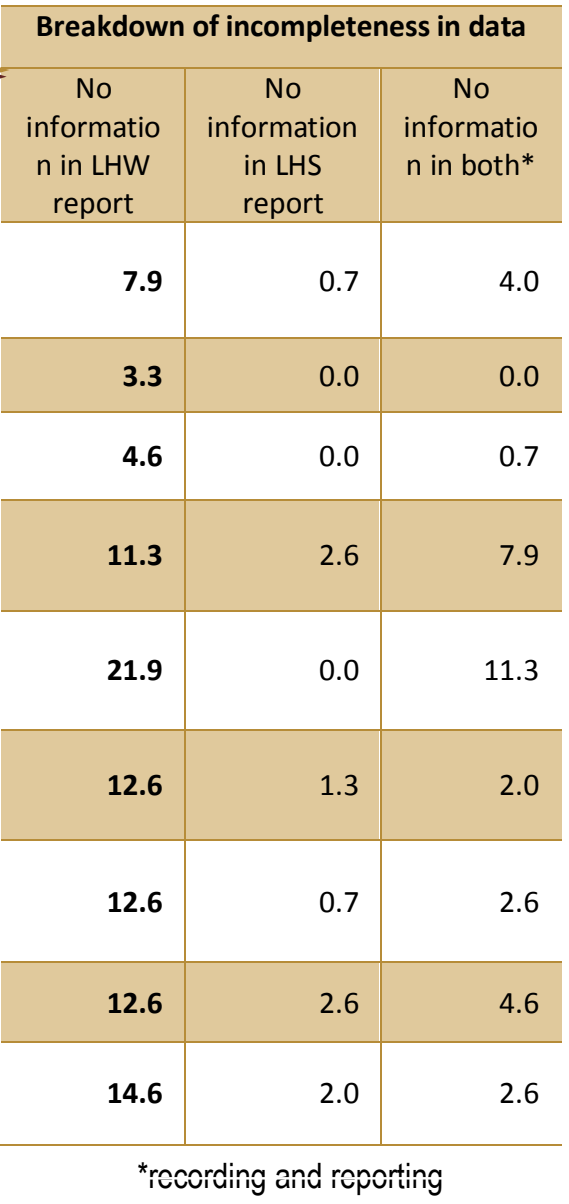




\section{Data accuracy}

Figure 4.3 shows the components of complete reporting and accuracy of reported data. It shows that for most of the maternal health indicators a higher proportion of the LHSs reported correct data, whereas the proportion of over and under reporting varies by the type of indicator. The proportion of correct reporting was lowest for the indicator 'number of pregnant women provided iron tablets', whereas it was highest for the indicator 'number of pregnant women registered this month'.

The proportion of under reporting was higher for the indicator 'number of total registered pregnant women' whereas the proportion of over reporting was higher for the indicator 'number of total pregnant women checked' followed by the indicator 'number pregnant women provided iron tablets' (16 percent and 15 percent respectively). This shows that the indicators that depict the performance of LHW are mostly over reported by the LHS.

\section{Figure 4.3: Components of complete reporting}

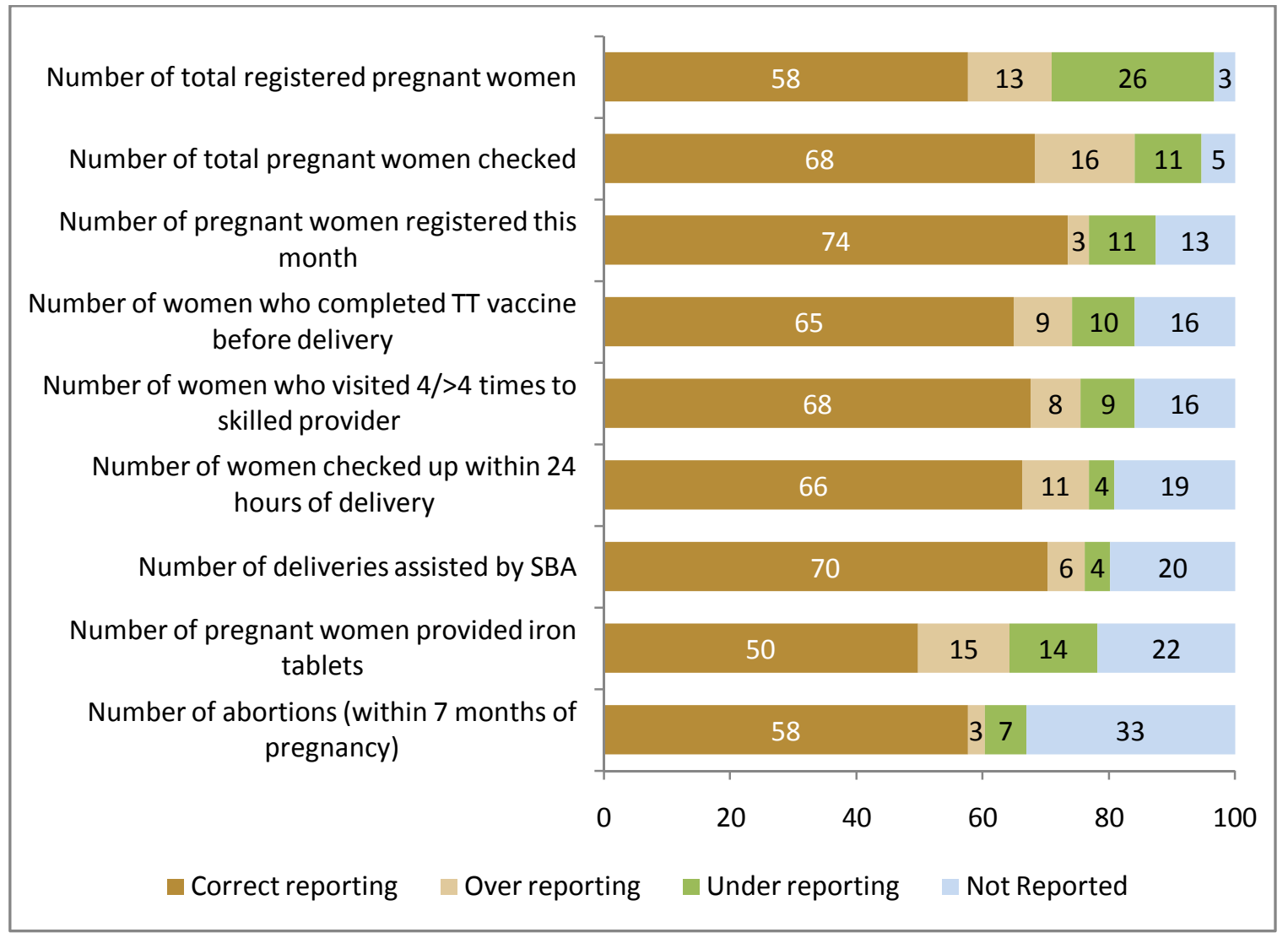

Table 4.4 shows the accuracy of reported data by LHSs for maternal health indicators. It shows that only 13 percent of the LHSs accurately reported all the nine maternal health. Results show 
LHSs reported more accurate data in district Mardan and Jhelum with a median of 8 correct indicators each. The median number of correctly reported indicators in district D.G. Khan was 6 whereas it was only two indicators for district Sukkur.

Table 4.4: Percent distribution of LHWs with accurate reporting according to available record and monthly report (indicators $=9$ )

\begin{tabular}{|c|c|c|c|c|c|}
\hline Number of indicators & Jhelum & D.G. Khan & Mardan & Sukkur & Total \\
\hline 0 & 2.1 & 2.9 & 2.8 & 24.2 & 7.3 \\
\hline $1-3$ & 14.8 & 14.3 & 5.6 & 33.4 & 16.6 \\
\hline 4-6 & 8.5 & 42.8 & 19.5 & 30.4 & 23.8 \\
\hline $7-8$ & 46.8 & 31.5 & 61.1 & 12.1 & 39.1 \\
\hline 9 & 27.7 & 8.6 & 11.1 & 0 & 13.2 \\
\hline Total & 100.0 & 100.0 & 100.0 & 100.0 & 100.0 \\
\hline Median & 8 & 6 & 8 & 2 & 7 \\
\hline $\mathbf{N}$ & 47 & 35 & 36 & 33 & 151 \\
\hline
\end{tabular}

Figure 4.4 gives an overview of the accuracy of reported data for maternal health indicators by district. It shows that overall in this section, LHSs of district Jhelum and Mardan performed very well. Apart from one indicator, 'number of total registered pregnant women' the LHSs working in district D.G. Khan reported data more accurate compared to LHSs working in Jhelum and Mardan. Proportion of accuracy is again poorest in district Sukkur. 
Figure 4.4: Percentage of LHSs reported Correct Information from the Record for the Month of May 2011 in Selected BHUs, Maternal Health Indicators

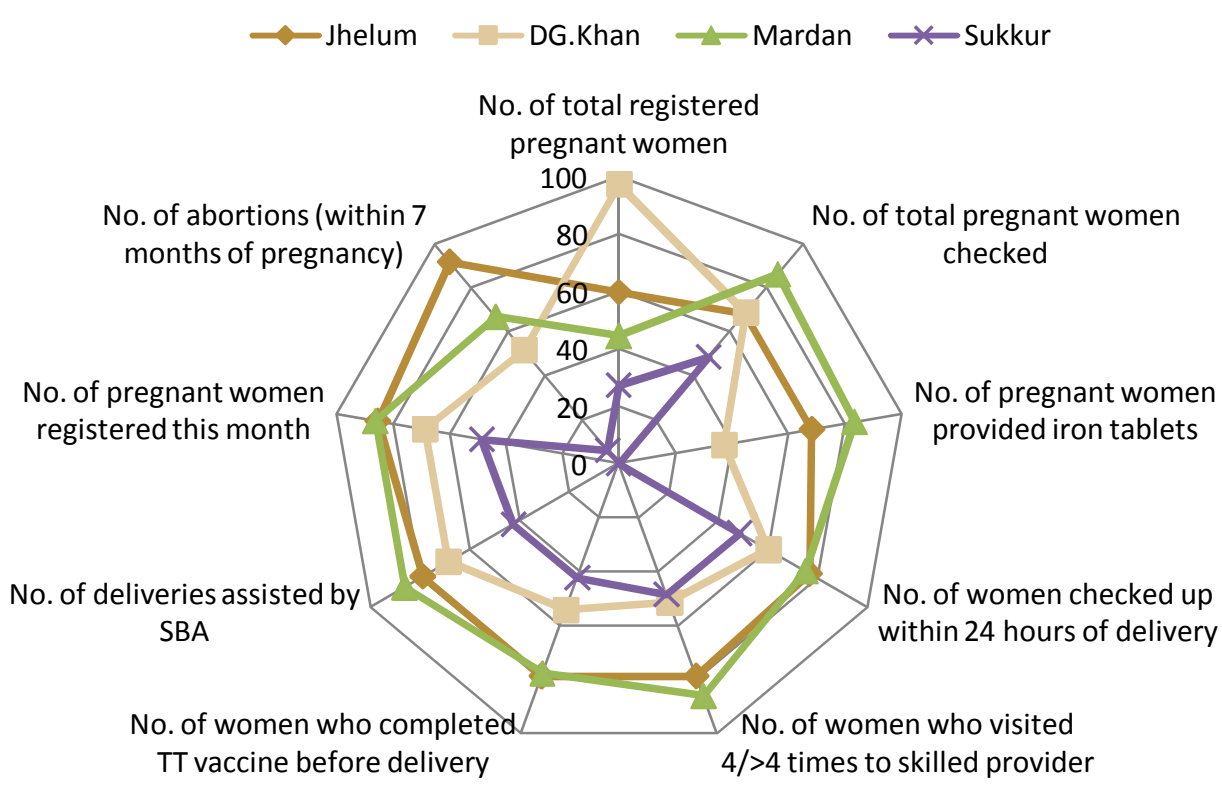




\section{Family Planning}

\section{Data completeness}

Table 4.5 gives an overview of the data completeness in the LHS level reporting of family planning indicators. For most of the family planning indicators, the proportion of completeness was high in all the four districts. However for four indicators, around a quarter of LHSs in all the four districts reported data incompletely, which shows that LHS does not give importance to these indicators.

Our findings show that for all the family planning indicators, a higher proportion of LHWs did not provide information in recording of the indicators as compared to the LHSs in all the four districts. It also shows that although some LHWs had not recorded the indicators, the LHS still had reported the numbers in their monthly reports against these indicators.

Table 4.5: Percent distribution of LHWs with incomplete reporting in either of the LHW report or the LHS report by each family planning related indicators

\begin{tabular}{|c|c|c|c|c|c|c|c|}
\hline \multirow[b]{2}{*}{ Indicator } & \multirow[b]{2}{*}{$\begin{array}{l}\text { Completenes } \\
\text { s in data }\end{array}$} & \multirow[b]{2}{*}{$\begin{array}{l}\text { Incomplete- } \\
\text { ness in data }\end{array}$} & \multirow[b]{2}{*}{ Total } & \multirow[b]{2}{*}{$\mathrm{N}$} & \multicolumn{3}{|c|}{ Breakdown of incompleteness in data } \\
\hline & & & & & $\begin{array}{c}\text { No } \\
\text { information in } \\
\text { LHW report }\end{array}$ & $\begin{array}{c}\text { No } \\
\text { information in } \\
\text { LHS report }\end{array}$ & $\begin{array}{c}\text { No } \\
\text { information } \\
\text { in both* }\end{array}$ \\
\hline Registered eligible couples & 97.4 & 2.6 & 100 & 151 & 2.0 & 0.7 & 0.0 \\
\hline $\begin{array}{l}\text { Couples started any FP } \\
\text { method this month }\end{array}$ & 68.9 & 31.1 & 100 & 151 & 16.6 & 3.3 & 11.3 \\
\hline Current users given follow up & 91.4 & 8.6 & 100 & 151 & 7.9 & 0.7 & 0.0 \\
\hline Users of modern methods & 95.4 & 4.6 & 100 & 151 & 3.3 & 0.0 & 1.3 \\
\hline Condom users & 96.0 & 4.0 & 100 & 151 & 3.3 & 0.7 & 0.0 \\
\hline Pill users & 96.7 & 3.3 & 100 & 151 & 2.6 & 0.7 & 0.0 \\
\hline Injectable users & 93.4 & 6.6 & 100 & 151 & 6.0 & 0.7 & 0.0 \\
\hline IUD users & 94.0 & 6.0 & 100 & 151 & 4.6 & 0.7 & 0.7 \\
\hline Users of Female sterilization & 91.4 & 8.6 & 100 & 151 & 6.0 & 1.3 & 1.3 \\
\hline $\begin{array}{l}\text { Users of Other modern } \\
\text { methods }\end{array}$ & 64.9 & 35.1 & 100 & 151 & 16.6 & 4.6 & 13.9 \\
\hline Users of traditional methods & 94.0 & 6.0 & 100 & 151 & 3.3 & 0.7 & 2.0 \\
\hline $\begin{array}{l}\text { Couples referred to health } \\
\text { facility/FP center }\end{array}$ & 69.5 & 30.5 & 100 & 151 & 16.6 & 3.3 & 10.6 \\
\hline $\begin{array}{l}\text { Clients provided condom by } \\
\text { LHW }\end{array}$ & 65.6 & 34.4 & 100 & 151 & 18.5 & 2.6 & 13.2 \\
\hline Clients provided pills by LHW & 80.1 & 19.9 & 100 & 151 & 15.9 & 1.3 & 2.6 \\
\hline $\begin{array}{l}\text { Clients provided injectables } \\
\text { by LHW }\end{array}$ & 68.2 & 31.8 & 100 & 151 & 14.6 & 3.3 & 13.9 \\
\hline
\end{tabular}

*recording and reporting 


\section{Data accuracy}

Figure 4.5 shows the components of complete reporting, it shows that for most of the family planning indicators, a higher proportion of the LHSs reported correct data in all the four districts, whereas the proportion of over and under reporting varies by the type of indicator. The proportion of over reporting was highest for indicators 'number of total users of modern methods' and 'number of current users given follow up' (21 percent each).

Figure 4.5: Components of complete reporting

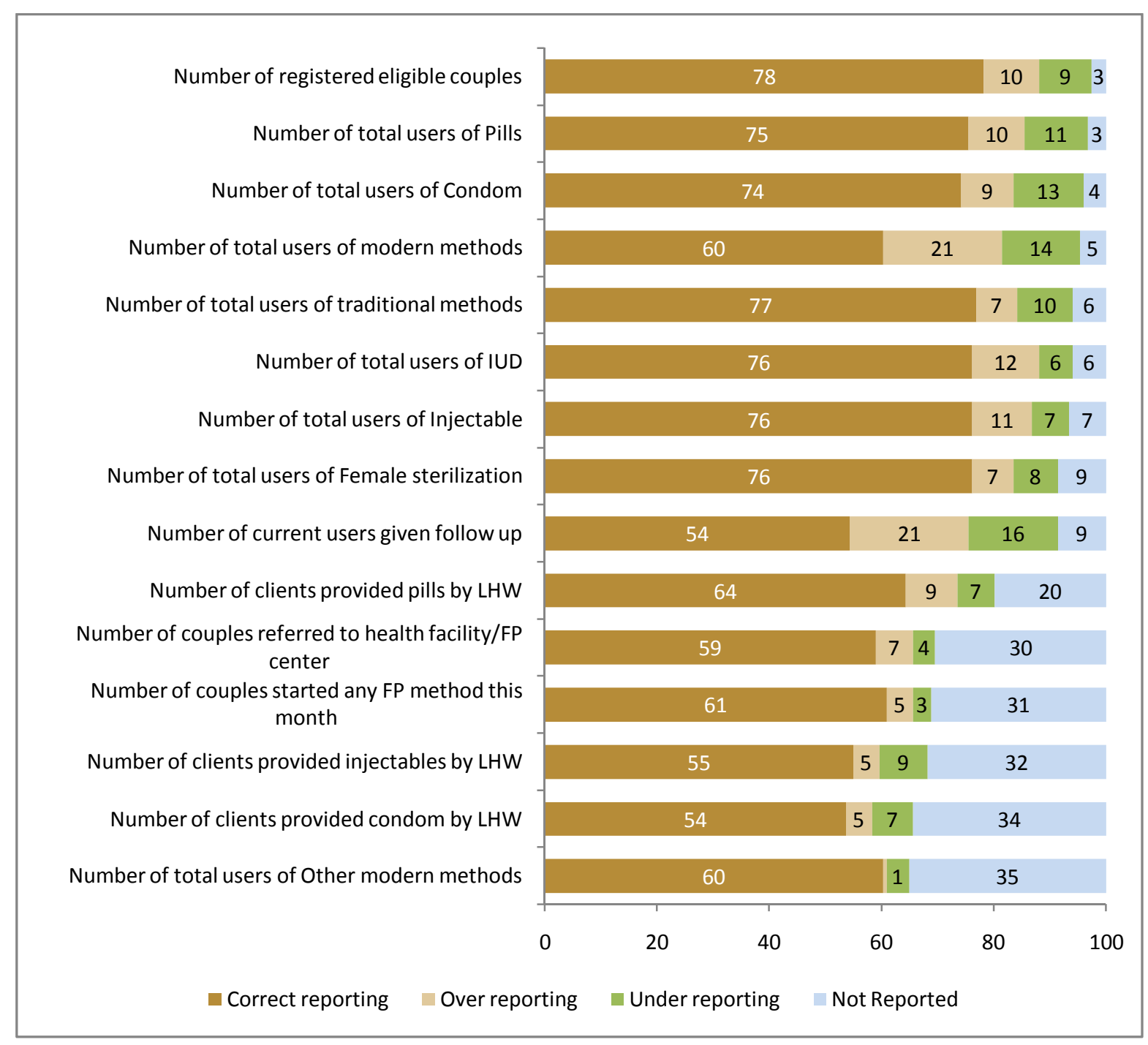


Table 4.6 shows the accuracy of reported data by the LHSs for the family planning indicators. It shows that one-fifths of the LHSs correctly reported all the fifteen indicators. Among the four selected districts, results show that LHSs working in district Jhelum reported the most accurate data, followed by the LHSs working in Mardan and D.G. Khan (with a Median of 14, 12 and 11 indicators respectively). None of the LHSs in district Sukkur could report more than 11 correct indicators in this section.

Table 4.6: Percent distribution of LHWs with accurate reporting according to available record and monthly report (variables $=15$ )

\begin{tabular}{l|r|r|r|r|r}
\hline Number of indicators & Jhelum & D.G. Khan & Mardan & \multicolumn{1}{|c}{ Sukkur } & \multicolumn{1}{c}{ Total } \\
\hline $\mathbf{0}$ & 0.0 & 2.9 & 2.8 & 15.2 & 4.6 \\
\hline $\mathbf{1 - 3}$ & 4.2 & 2.9 & 0.0 & 21.2 & 6.6 \\
\hline $\mathbf{4 - 6}$ & 12.9 & 20.0 & 2.8 & 15.2 & 12.6 \\
\hline $\mathbf{7 - 9}$ & 4.2 & 11.5 & 16.7 & 36.3 & 15.8 \\
\hline $\mathbf{1 0 - 1 2}$ & 12.8 & 22.9 & 38.8 & 12.2 & 21.2 \\
\hline $\mathbf{1 3 - 1 4}$ & 25.6 & 28.6 & 25.0 & 0.0 & 20.5 \\
\hline $\mathbf{1 5}$ & 40.4 & 11.4 & 13.9 & 0.0 & 18.5 \\
\hline Total & $\mathbf{1 0 0 . 0}$ & $\mathbf{1 0 0 . 0}$ & $\mathbf{1 0 0 . 0}$ & $\mathbf{1 0 0 . 0}$ & $\mathbf{1 0 0 . 0}$ \\
\hline Median & $\mathbf{1 4}$ & $\mathbf{1 1}$ & $\mathbf{1 2}$ & $\mathbf{6}$ & $\mathbf{1 1}$ \\
\hline $\mathbf{N}$ & $\mathbf{4 7}$ & $\mathbf{3 5}$ & $\mathbf{3 6}$ & $\mathbf{3 3}$ & $\mathbf{1 5 1}$ \\
\hline
\end{tabular}

Figure 4.6 gives a snapshot of the accuracy of reported data by LHSs for the family planning indicators by district. It shows that for all of the family planning indicators, the LHSs in district Sukkur had the poorest accuracy of reporting data, except for the indicator 'number of registered eligible couples' which was correctly reported by the 73 percent of the LHSs and was better than district D.G. Khan.

Overall in all districts, for two indicators; the 'number of users of modern methods' and the 'number of current users given follow up', the proportion of correct reporting was relatively lower than rest of the indicators. 
Figure 4.6: Percentage of LHSs reported Correct Information from the monthly report of LHW for the Month of May 2011 in Selected BHUs, Family Planning Indicators

No. of total users of traditional
methods
No. of couples started any FP
method this month
injectables by LHW
No. of total users of Female total users of Pills
sterilization
No. of total users of Injectable

\section{Vital Events (births and deaths)}

\section{Data completeness}

Indicators pertaining births and deaths were complete in both the reporting levels of LHW and LHS. This shows that both LHWs and LHSs give these indicators more importance than the rest of indicators.

Figure 4.7 shows that all of the vital events indicators were correctly reported by the LHSs except the 'number of live births', which was correctly reported by more than 80 percent of the LHSs in all the districts except Sukkur. 
Figure 4.7: Percentage of LHSs reported Correct Information from the monthly report of LHW for the Month of May 2011 in Selected BHUs, vital events

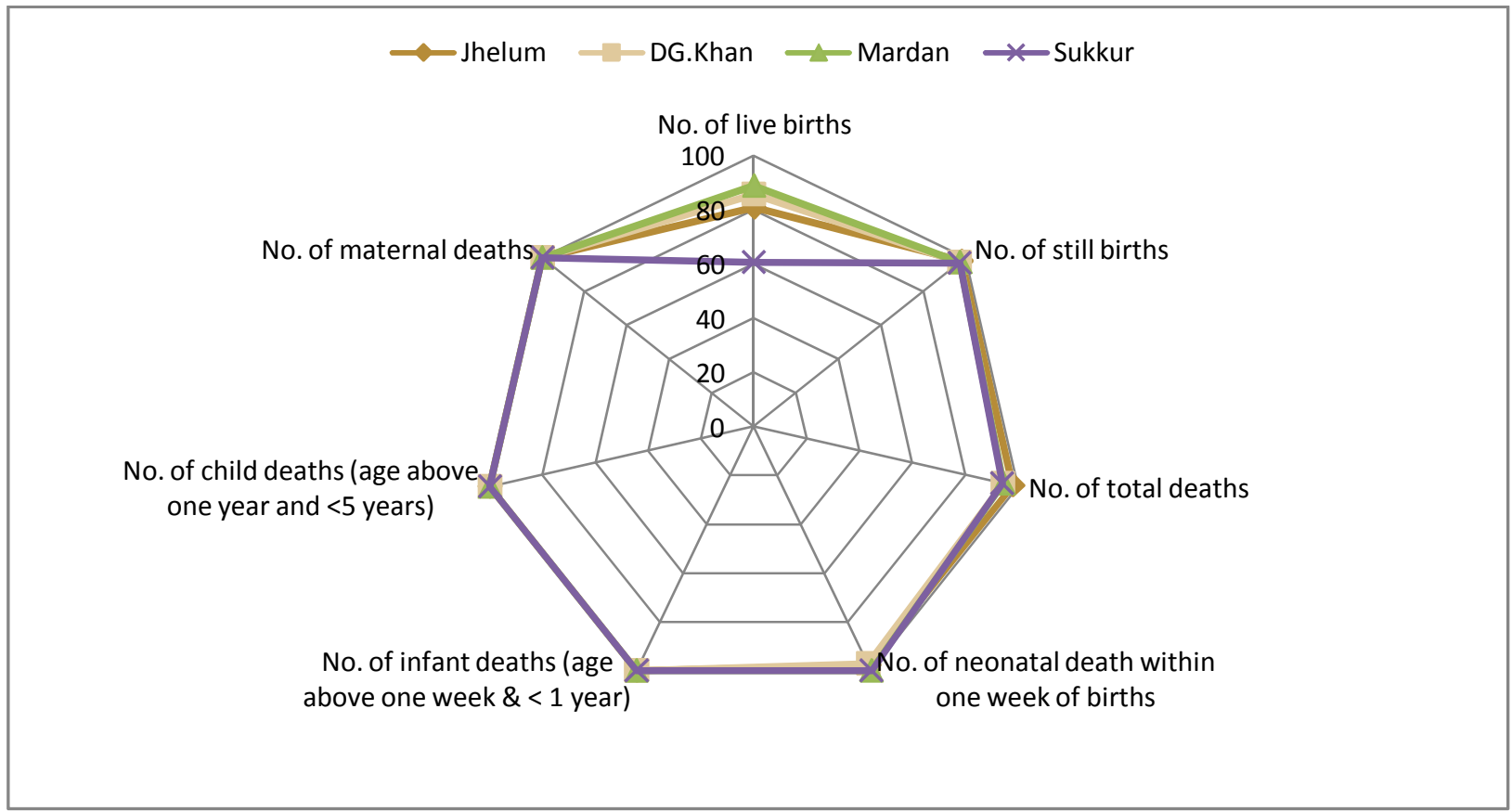

\section{Sociall Relations}

Figure 4.8 below shows that most of the social relations indicators were completed. Most incomplete data was reported for the indicator 'number of health talks in local schools' where data was incomplete for a quarter of times.

Figure 4.8: Percentage of LHSs with correct reporting according to available record and monthly report

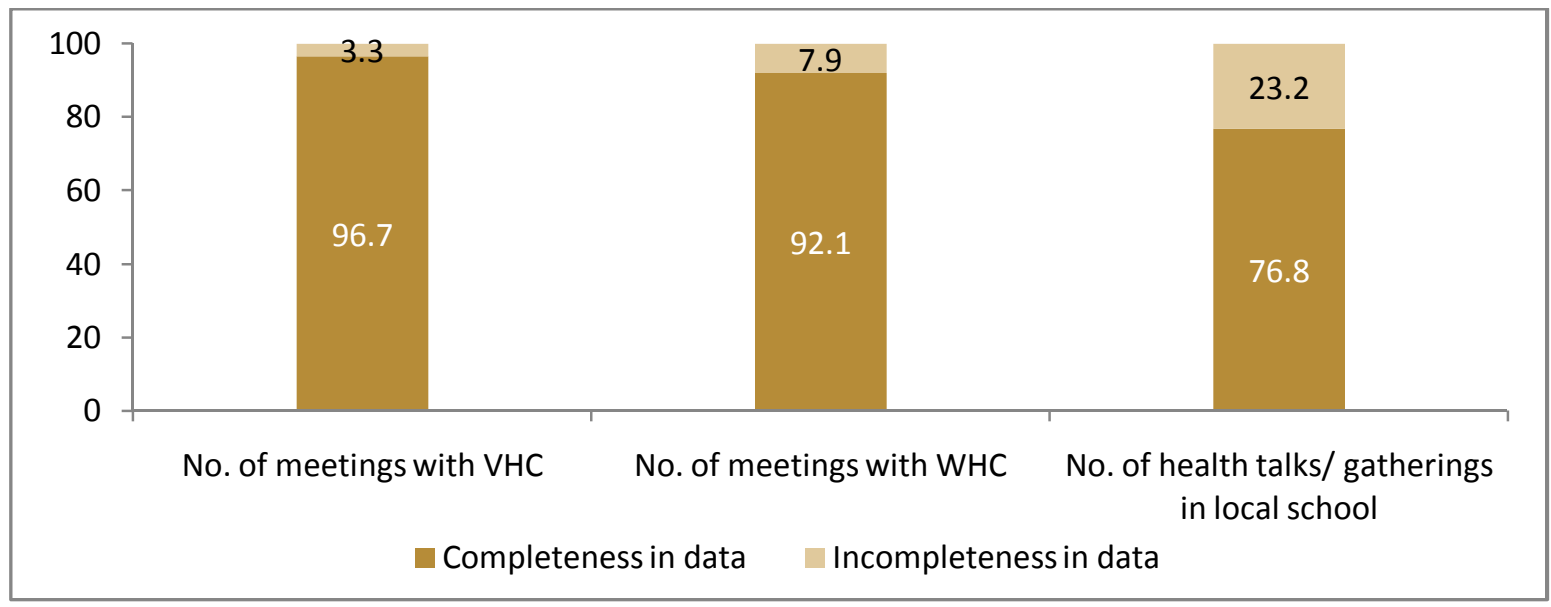


Figure 4.9 shows the level of accuracy in social events related data. Results show that for the indicator 'number of meetings with VHCs' was more accurately reported than for other two indicators. On the other hand, the proportion of over reporting was higher for the indicator 'number of meetings with WHC' compared to the other two indicators.

Figure 4.9: Components of complete reporting (social events)

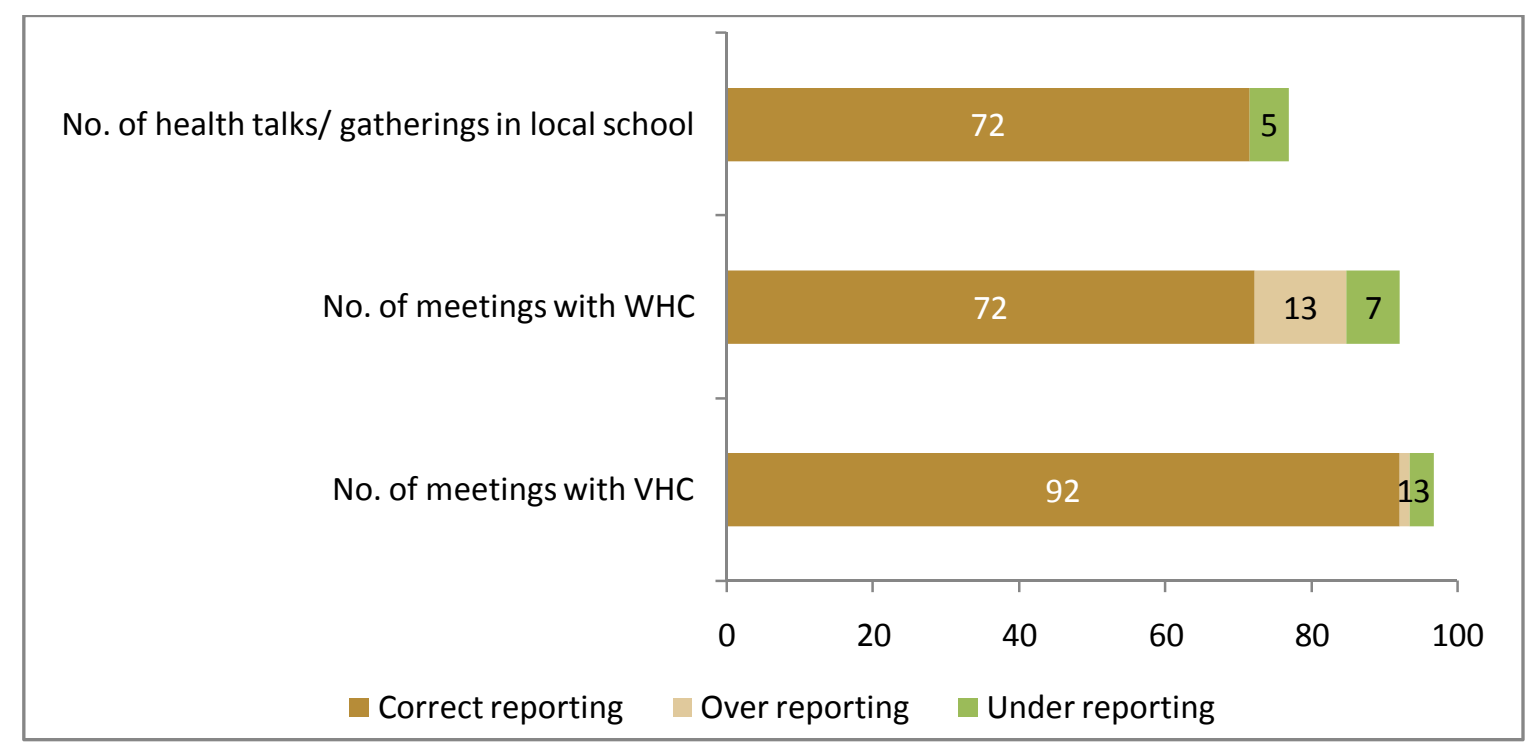

\section{All indicators}

Table 4.7 shows the overall accuracy of reported data for all the 43 selected indicators. It shows that none of the LHSs correctly reported all the indicators. The median number of correctly reported indicators was highest for the LHSs working in district Jhelum, followed by almost an equal median number in Mardan and D.G. Khan as 33 and 32 indicators respectively. The LHSs in district Sukkur reported the least number of correct indicators with median number of indicators as 22 . 
Table 4.7: Percentage distribution of number of correctly reported indicators by LHSs (Total variables = 43)

\begin{tabular}{|c|c|c|c|c|c|}
\hline Number of indicators & Jhelum & D.G. Khan & Mardan & Sukkur & Total \\
\hline $1-5$ & 0.0 & 0.0 & 2.8 & 6.1 & 2.0 \\
\hline $6-10$ & 0.0 & 0.0 & 0.0 & 12.1 & 2.6 \\
\hline $11-15$ & 8.5 & 5.7 & 2.8 & 15.2 & 7.9 \\
\hline $16-20$ & 6.4 & 11.4 & 0.0 & 15.2 & 7.9 \\
\hline 21-25 & 2.1 & 17.1 & 5.6 & 21.2 & 10.6 \\
\hline $26-30$ & 2.1 & 11.4 & 19.4 & 27.3 & 13.9 \\
\hline 31-35 & 12.8 & 20.0 & 33.3 & 3.0 & 17.2 \\
\hline $36-40$ & 31.9 & 28.6 & 30.6 & 0.0 & 23.8 \\
\hline $41+$ & 36.2 & 5.7 & 5.6 & 0.0 & 13.9 \\
\hline Total & 100.0 & 100.0 & 100.0 & 100.0 & 100.0 \\
\hline Median & 39 & 32 & 33 & 22 & 32 \\
\hline $\mathbf{N}$ & 47 & 35 & 36 & 33 & 151 \\
\hline
\end{tabular}

*Number of correct reported variables (Minimum $=4$, Maximum $=43$ )

Figure 4.10 given below shows the LHS level percentage of correctly reported indicators by the facility. The results show that the percentage of correctly reported indicators was lowest for BHU Faqirabad in Sukkur district whereas it was highest for RHC Palo Dheri in Mardan.

Figure 4.10: Percentage of correct indicators reported by the BHU

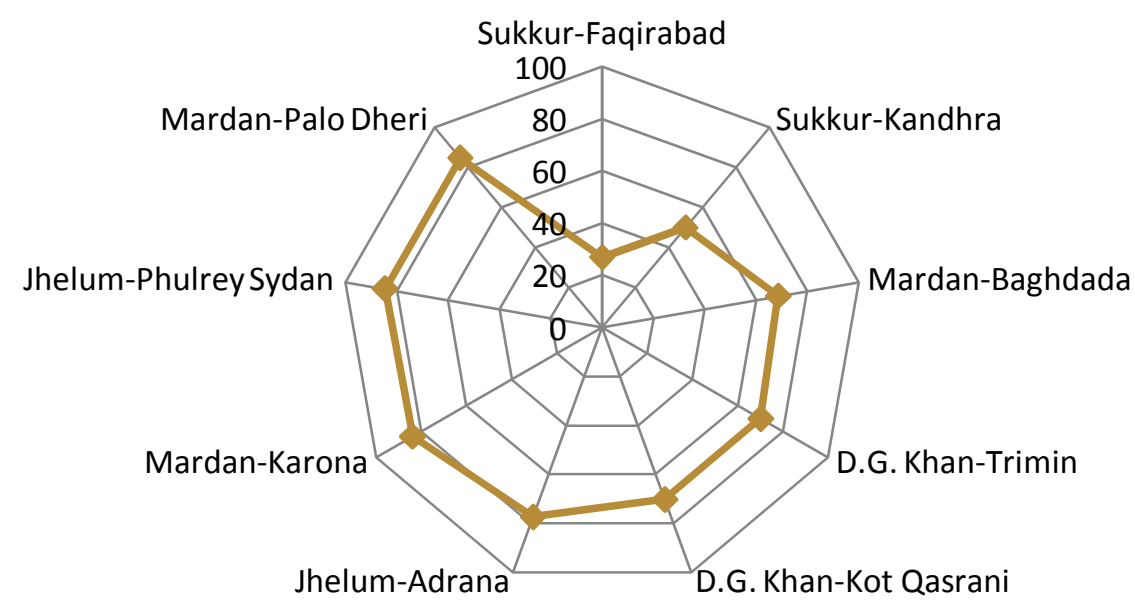




\section{Chapter 5 Validation of LHW Records}

The LHW visits all households of her community at least once in a month. During these visits she records information on several indicators. In order to provide necessary health services to her community it is important for LHW to maintain the updated health status especially of the women of reproductive age and children under three years of age. The failure in correct recording of these indicators would result in insufficient provision of necessary health services to the target groups in the LHW community.

This chapter addresses the second component of this assessment, which includes the validation of recording of pregnant women, mothers of less than 4 months old children, current users of contraception and the deaths in the catchment area of the LHWs.

\section{Current pregnancies}

The LHW is required to closely monitor the health status of the pregnant women. To achieve this objective, LHW is required to maintain and update the list of currently pregnant women in her community.

Out of the total 154 LHWs interviewed, 112 (73 percent) had correctly reported the current pregnancies in their community whereas 42 (27 percent) had under reported (one of the two or both pregnancies) that were selected for validation (Table 5.1). The term under reported used here mean that at least one of the two

Table 5.1: Validation of the current pregnancies

\begin{tabular}{l|r|r}
\hline Pregnancy status & Frequency & Percent \\
\hline Correct reporting & 112 & 72.7 \\
\hline Under reporting & 42 & 27.3 \\
\hline Total & 154 & 100.0 \\
\hline
\end{tabular}
women interviewed were currently pregnant whereas the LHW had recorded them as non pregnant. These 27 percent LHWs are those who either did not have the diary (12 percent of LHWs) or they had not updated the list of pregnant women in their community. These results show the irregular visits by the LHWs in their community.

Since many of the women remain unsure about their pregnancy until after the one or two months of the pregnancy, it might be possible that the woman was unsure when LHW visited her the last 
time but when the survey team interviewed her she was sure about her pregnancy. However, this statement would only be valid for those women who were in their first trimester of pregnancy at the time of interview.

\section{Births during past four months}

After recording all the pregnant women in her community the LHW records the outcome of those registered pregnancies and other related information to child birth. She is also required to visit the delivered woman for her postnatal check up within 24 hours of delivery. During postnatal checkup within 1 week after delivery, each LHW measures and records the weight of the baby.

To evaluate if the LHW properly maintains the record of the births in her community, two women whose children were under 4 months of age were interviewed from each LHW's covered area. Along with asking women if they had received antenatal care and TT shots during last pregnancy, the survey team (female interviewers) also asked them about the birth attendant and if LHW visited them within 24 hours of the birth and that if the child was weighted within a week of birth by the LHW. The information collected from the women

Table 5.2: Validation of the births pregnancies

\begin{tabular}{l|l|l}
\hline Child birth & Frequency & Percent \\
\hline Correct reporting & 126 & 81.8 \\
\hline Under reporting & 28 & 18.2 \\
\hline Total & $\mathbf{1 5 4}$ & $\mathbf{1 0 0 . 0}$ \\
\hline
\end{tabular}
was then validated from the LHW's records.

The results show that a substantial majority of LHWs, 126 LHWs (82 percent), had correctly recorded the births in their community whereas 28 LHWs (18 percent) had not reported (under reported) at least one birth in their catchment area.

\section{Antenatal Care}

The selected women whose children were under four months of age were also asked if

Figure 5.1: Validation of antenatal care

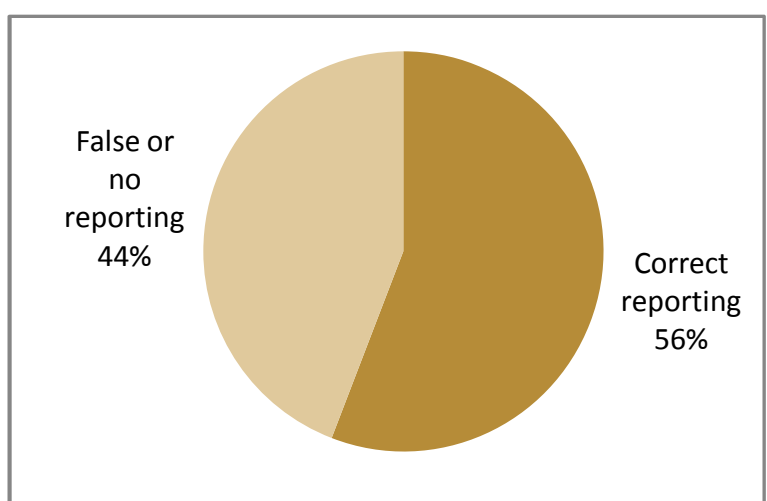
they had received antenatal care checkups during their last pregnancy. On validating their responses with the LHW records, it was observed that only 56 percent of the LHWs had correctly reported the status of antenatal checkup of those pregnant women.

Sixty-eight LHWs (44 percent) had either not reported at all or falsely reported the ANC checkup status of the women. Out of 68 LHWs, 13 LHWs (8 percent) under reported the ANC visits 
whereas 10 LHWs (7 percent) over reported those visits. Forty-seven LHWs (31 percent) had not recorded any information about ANC visits of at least one selected woman in their register.

It is important to mention here that some of the LHWs were using old format of the registers, where the column that includes information about the antenatal checkups of the pregnant women was not given. So these 31 percent LHWs who did not report antenatal care status include such LHWs as well.

\section{TT shots}

One hundered and seven LHWs (69 percent) had correctly reported whether the women in their community had received TT shots during their last pregnancy or not, while 31 percent of the LHWs had either false or no reporting of the TT shots.

Out of those 47 LHWs, 8 LHWs (5 percent) under reported the status of TT shots for selected women, whereas 9 LHWs ( 6 percent) over reported their status. Thirty-one LHWs (20 percent) had not recorded information about the status of $T T$ shots during their last pregnancy of the selected women.

\section{Birth attendant}

If a child is born in the LHW covered area, the LHW is required to visit the mother and the
Figure 5.2: Validation of TT shots

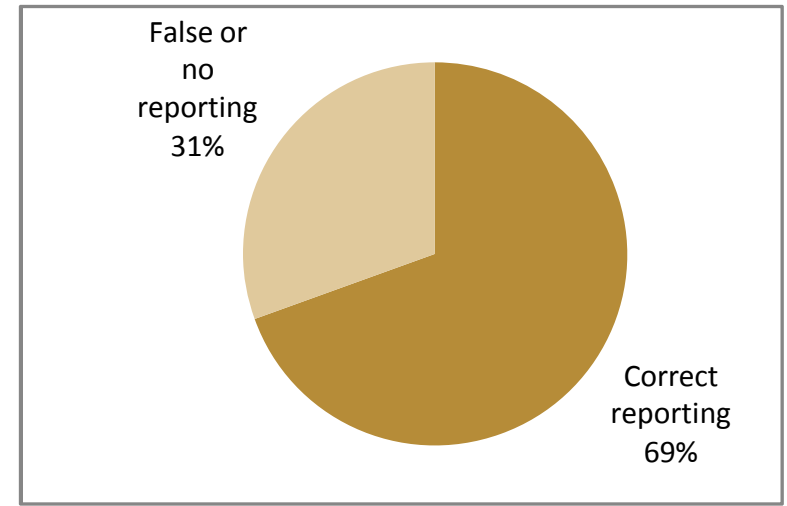

Figure 5.3: Validation of birth attendant

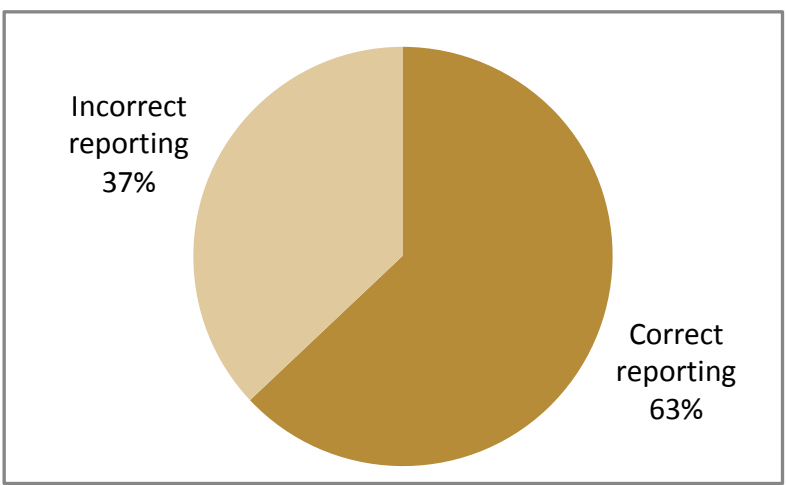
newborn within 24 hours of the birth. LHW is required to conduct a checkup of both (mother and baby) to identify any complication and to provide them appropriate advice or take necessary action. After paying this visit, LHW records the type of birth attendant, sex and name of the baby in her diary. If the LHW is not visiting the newborns and their mothers, she will not be able to provide necessary advice to them.

Majority of LHWs, ninety-seven LHWs (63 percent), had correctly reported the birth attendant of the women who delivered at least four months preceding the current assessment. On the other hand, slightly over one third of the LHWs reported a wrongly birth attendant for their last 
pregnancy, which wasn't matched with the statement of the selected women. This shows that LHWs are not regularly visiting their catchment areas at the childbirth.

\section{Contraceptive Use}

LHWs play a vital role in the motivation and provision of family planning methods/ contraceptives to the eligible couples in their catchment areas. In order to provide the correct information about the contraceptive methods to all women in her catchment area, LHW needs to have an updated list of the current contraceptive users. So the LHW could ensure timely supply of contraceptive methods (that she provides) to the currently users in her community. Also the list of current users will provide her an overall sense of the contraceptive prevalence in her community and the rest of the women whom she needs to motivate and facilitate for the contraceptive use.

In this assessment, two current contraceptive users (women) from each LHW's area were randomly selected and interviewed about their current contraceptive usage, type of method, duration of use and source of method. Later the LHW records were checked to validate this information. 


\section{Current users}

Ninety-nine LHWs (65 percent) had correctly reported whether the women in their community were current contraceptive users or not. Slightly over one third of the LHWs (35 percent) had either false or no reporting of the current contraceptive use of women.

Among those 35 percent LHWs who did not report or falsely report the contraceptive use, 17 LHWs (11 percent) under reported the status of current users whereas only one LHW (0.6 percent) over reported. Thirty-eight LHWs (25 percent) had not recorded any information about the current contraceptive status of the women in their catchment areas.

\section{Contraceptive method}

Among those current users whom the LHW correctly reported as current users, the type of method reported by the respondents (users) was also validated withLHW records. Almost threefifths of the LHWs (59 percent) had correctly reported the type of method that women in their community were using whereas more than a quarter of the LHWs had either did not report the current contraceptive users or missed to record her current method. Around 14 percent of the LHWs reported a different contraceptive method than what she was actually using.

\section{Duration of use}

The duration of current contraceptive used stated by the respondents was also validated with LHW's record. More than half of the LHWs (54 percent) had correctly reported the duration of
Figure 5.4: Validation of contraceptive use

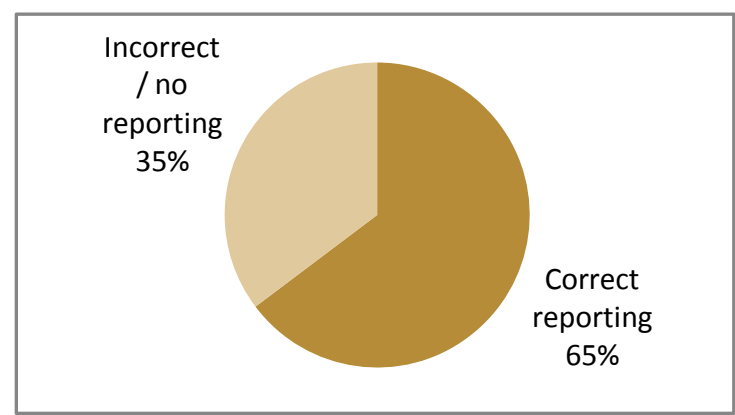

Figure 5.5: Validation of current contraceptive method

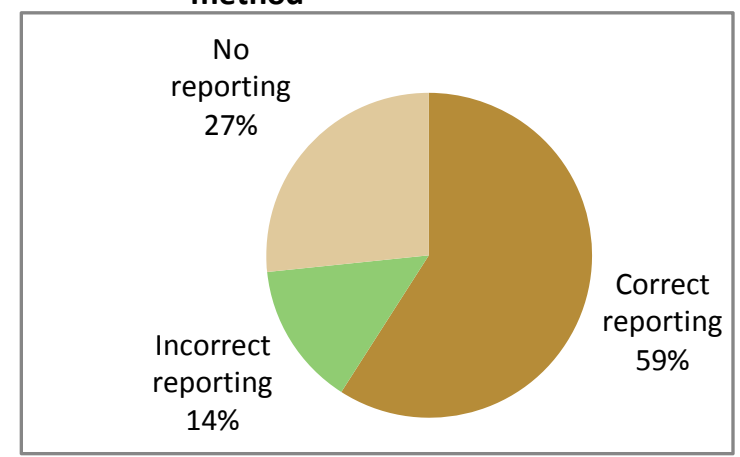

Figure 5.6: Validation of current contraceptive method

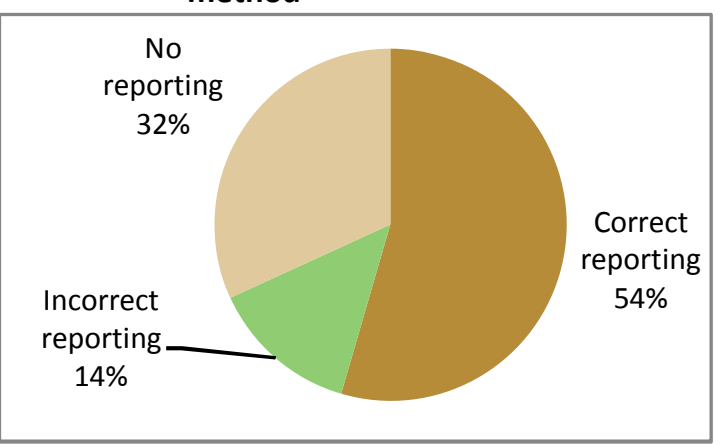

Figure 5.7: Validation of current contraceptive method

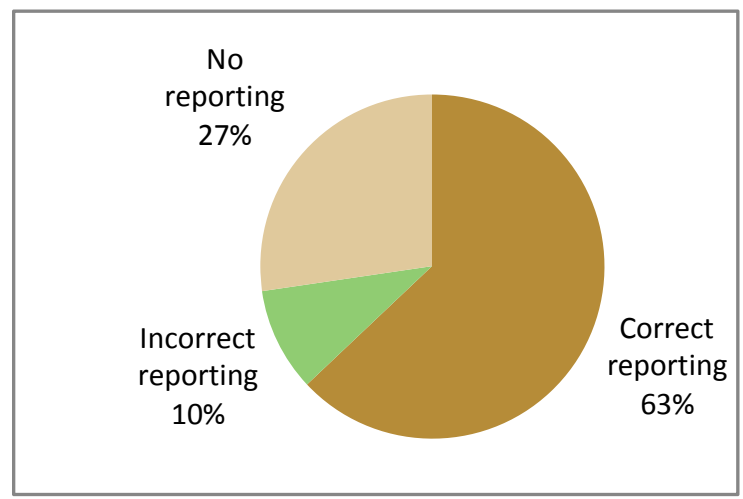


contraceptive use of the women in their community as reported by the respondents. Forteen percent of the LHWs had incorrect reporting of the durartion of use by the women whereas almost a third of the LHWs (32 percent) either did not report the current users or did not mention the duration of use.

\section{Source of method}

The source of contraceptive method reported by the respondents (women) was also validated with LHW record. The question was ask to the women 'where did they obtain the method last time?. Almost two thirds of the LHWs (63 percent) had correctly reported the source of method of the contraceptive users in their community. Ten percent of the LHWs had incorrect reporting of the source of the method whereas more than a quarter of the LHWs (27 percent) either did not report the current users or did not mention the source of method.

\section{Reporting of deaths}

The LHW records each and every vital event (including number of deaths and live births) in her catchment area. Each LHW is required to report name, age, sex and reason of death of the deceased person.

In order to validate the recorded information of LHWs, six households from each LHW's catchment area were selected to ask if any member of their household died within past six months. Our findings

Figure 5.8: Validation of deaths at household level

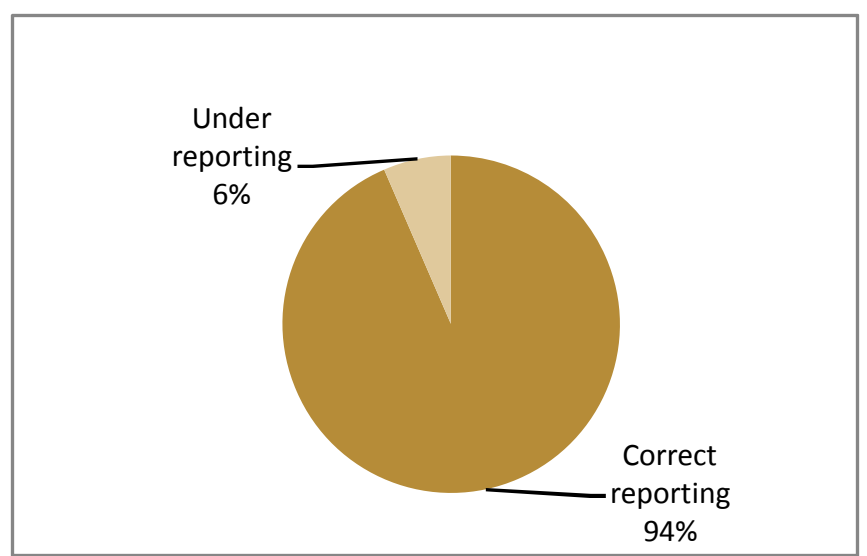
show that six percent of the LHWs had under reported the deaths in the past six months compared to what was reported by the respondents. 
The selected households were also asked if any death happened in their community at least a month prior to the survey/ assessment study. Figure 5.9 shows that 14 percent of the LHWs under reported the deaths that occurred in their catchment area. This reflects a lack of up-to-date recording and reporting by the LHWs on the deaths data.
Figure 5.9: Validation of deaths in the community

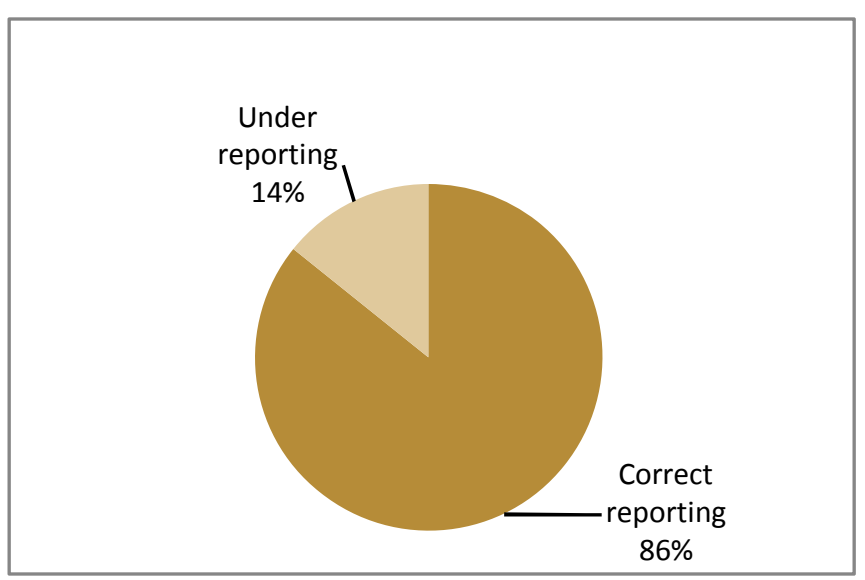




\section{Chapter 6 \\ Conclusions and Recommendations}

\section{Key observations from the field}

- Some of the LHWs who did not have the LHW material with them e.g. weighing machine, thermometer, scissors, syringe cutter etc.

- It was also observed that very few LHWs had the supply of child health cards, as an outcome majority of them were not assessing and keeping record of the growth of under 3 children in their community.

- Most of the LHWs complained that they are not supplied with the sufficient amount of the stationary that is required to maintain proper recording and reporting. They reported that most of the time they get the important forms (referral slips, $\mathrm{MCH}$ cards etc.) photocopied from their own pocket.

- LHWs who had the supply of $\mathrm{MCH}$ cards, complained that the women did not keep those cards safely. This is also one of the main reasons why LHWs cannot keep an accurate record on the indicators whose record she maintains on the $\mathrm{MCH}$ card. One suggestion in this regard could be that the LHW should keep these cards with her and fill them up every time she visits the pregnant woman or the child under three years to make a good use of this tool.

- Most of the LHWs reported that they didn't know how to maintain the data properly, they themselves admitted that they were confused by many indicators and did not know how to note down on the records and how to count them from the records for the monthly report.

- Most of the LHWs reported that they only memorize some of the indicators and at the end of the month report them in their monthly report by not keeping any record of them in other MIS tools.

- LHWs do not have a uniform clarity on how to report the number of traditional method users in their monthly reports. Some of them report the traditional method users in their registers (list of current users) but do not report them in the monthly report, while the others think it is not even important to record the traditional method users in their registers. 
- LHWs don't properly maintain the record on their registers; they rather more cautiously maintain their monthly reports. Thus when compared these two there were a lot of discrepancies and for many of the indicators there was no information in the LHW records.

\section{Recommendations}

- As findings show that quite a number of LHWs did not have the recording (LHW-MIS) tools to record the information. Therefore, it is recommended that the LHW program management should provide all necessary MIS tools to each LHW. If it is the printing issue that should be handled at high level by taking all measures including allocation of resources for printing and if it is management problem that should be ensured at EDO (Health)/District Coordinator(LHW) level. All immediate and long term measures are needed by according high priority as otherwise information cannot be collected if basic tools are not there .Partial information questions the data quality for which policy/ decision makers lack their confidence in data and remain hesitant to use it. In conclusion the absence of data tools affects both data quality data use.

- Likewise, many of the LHWs were not equipped with the basic equipment like weighing scales for babies, thermometers etc. Therefore, it is recommended that the LHW program management should provide all the equipment to each LHW. Management should look into the problem as a whole or case by case. These are minor equipment and do not demand huge amount of money but very important for measuring weight leading to identify the nutritional status of babies. In the absence advice cannot be provided to mothers for growth of children. Underweight babies may face deaths having adverse effect on the efforts of lowering child mortality.

- After provision of MIS tools and equipment, the LHW program management should encourage every LHW to complete all the MIS tools. A strong supervision is recommended to ensure complete recording of all the events in their catchment areas. Incomplete cells mean incomplete individual and aggregate reports. As stated above this affects quality of data and as a result use of data by wasting scarce resources of the Government. Basic purpose of any MIS is to provide evidence based decision making. This cannot be achieved if data collected is incomplete. Reports must be analyzed, feedback provided whose Reports are in complete upward and down ward. The concerned may be questioned in meetings /writing letters/ serving notices and issuing instructions/guidance where necessary. This will help resolve the problem. 
- LHW program management should provide all the material (including tools, stationary and equipment) well in time to get complete and accurate data. First supplies needs to be ensured at district level and then needs to ensure distribution down wards reaching ultimately LHWs without interruptions.

- After provision of all the MIS-tools to LHWs, in order to improve the completeness of data at LHW level, the LHW program management should provide trainings/refreshers on MIS tools to all the LHWs. As observed, some LHWs are not clear enough about the importance of the cells and how to fill the cells. As attrition and addition of LHWs is a ongoing phenomena, this calls for trainings. And refreshers have their own importance as human nature is likely to forget things especially when they are not in use. Refreshers allocating some time in routine meetings of LHWs/LHSs will be a practical solution without arranging and consuming additional resources.

- Similarly, to improve the completeness of data at LHS level, the LHW program management should provide refresher trainings on MIS tools to all the LHSs.(Repeat . May be deleted)

- In order to improve the completeness of data quality of data, the LHS should pay full attention on each LHW working under her supervision and check her report every month. Further, LHS should give clear instructions to all LHWs to complete all the cells of their reports before submission.LHS should be made responsible and answerable for completion of all cells specifically on Family Planning and she should receive instructions from higher up to this effect and also pass on to the LHWs working under her.

- In order to improve the quality of data at LHW level, LHS on her visit to each LHW, should compare LHW report with her recording tools. Whenever, LHS finds any discrepancy in reporting and recording, she should take/recommend necessary action against those LHWs.

- The facility staff/in-charge should also check and verify LHS report by comparing with LHW Reports before onward submission to determine the completeness and accuracy of data. Whenever, facility in-charge findings any discrepancy in LHS reporting with LHWs report, the in-charge should take necessary action against LHS.

- In order to improve the quality of data at LHS level, the facility in-charge should compare the LHS report with monthly reports of LHWs working under her supervision. Whenever, facility in-charge findings any discrepancy in LHS reporting with LHWs report, the in-charge should take necessary action against LHS.(May be deleted as merged above) 
- Further, to improve quality of data at LHW level, LHS periodically validate some of the recorded and reported events from her catchment area. A regular validation of LHW monthly report and recording tools should be the part of the LHW program's MIS. District Coordinator (LHW Program) needs to ensure implementation by his monitoring visits and random checking.

\section{Conclusions}

The findings of current assessment study of LHW MIS show that the selected LHWs working in district D.G. Khan have better data completeness and accuracy compared to LHWs working in other three selected districts. Further, at LHS level, our findings show that LHSs working in district Jhelum have reported more accurately than other LHSs working in other three districts. On the other hand, results from district Sukkur are not encouraging at all and immediate measures should be taken by the LHW program management to improve the quality of data in the district. If above given recommendations are implemented, will surely help improve the situation. 


\section{Annex}

Facility (BHU/RHC) wise performance of LHWs (percentage of correctly reported indicatorsFigure $A$ to Figure I):

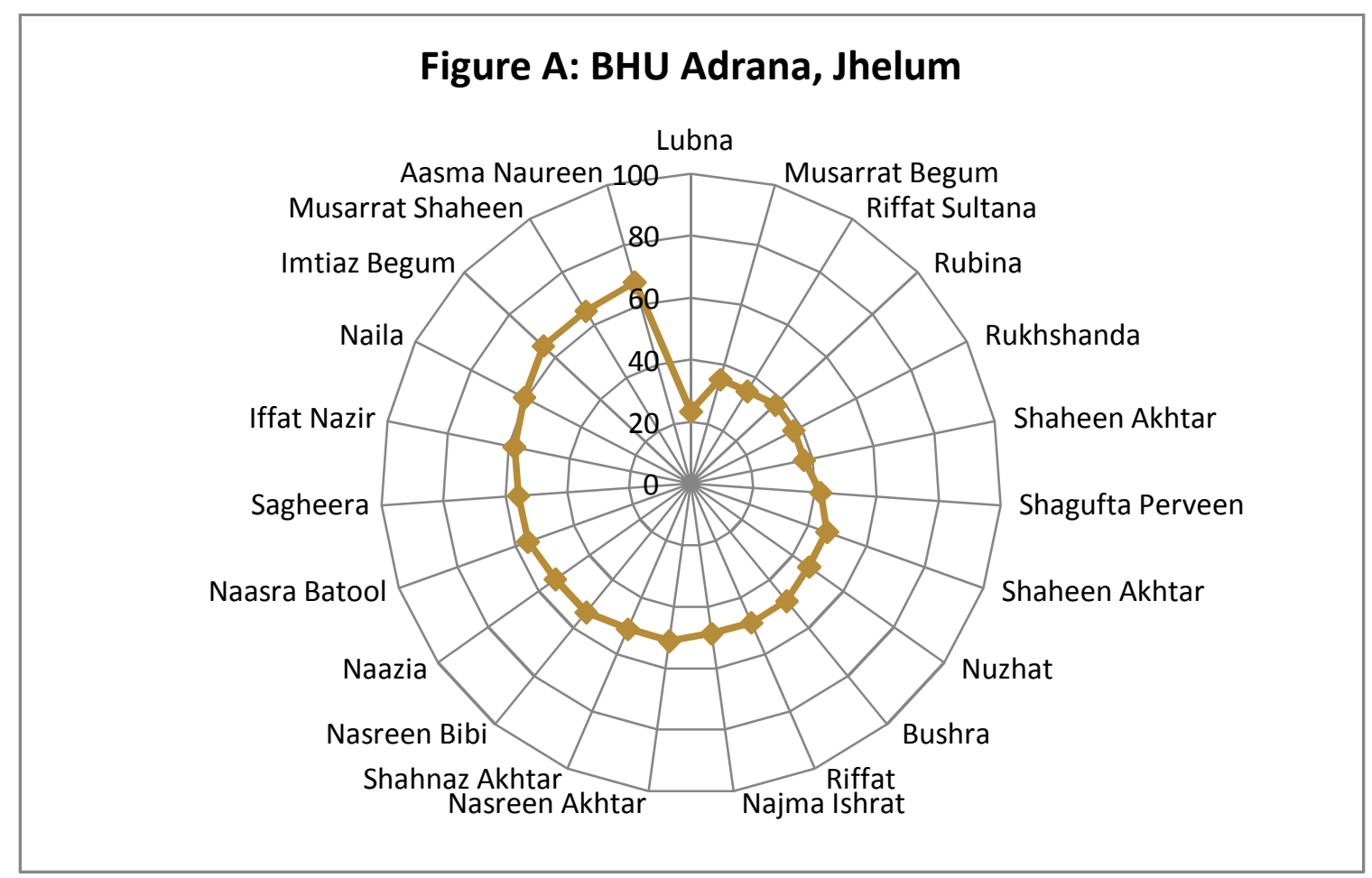


Figure B: BHU Phulrey Sydan, Jhelum

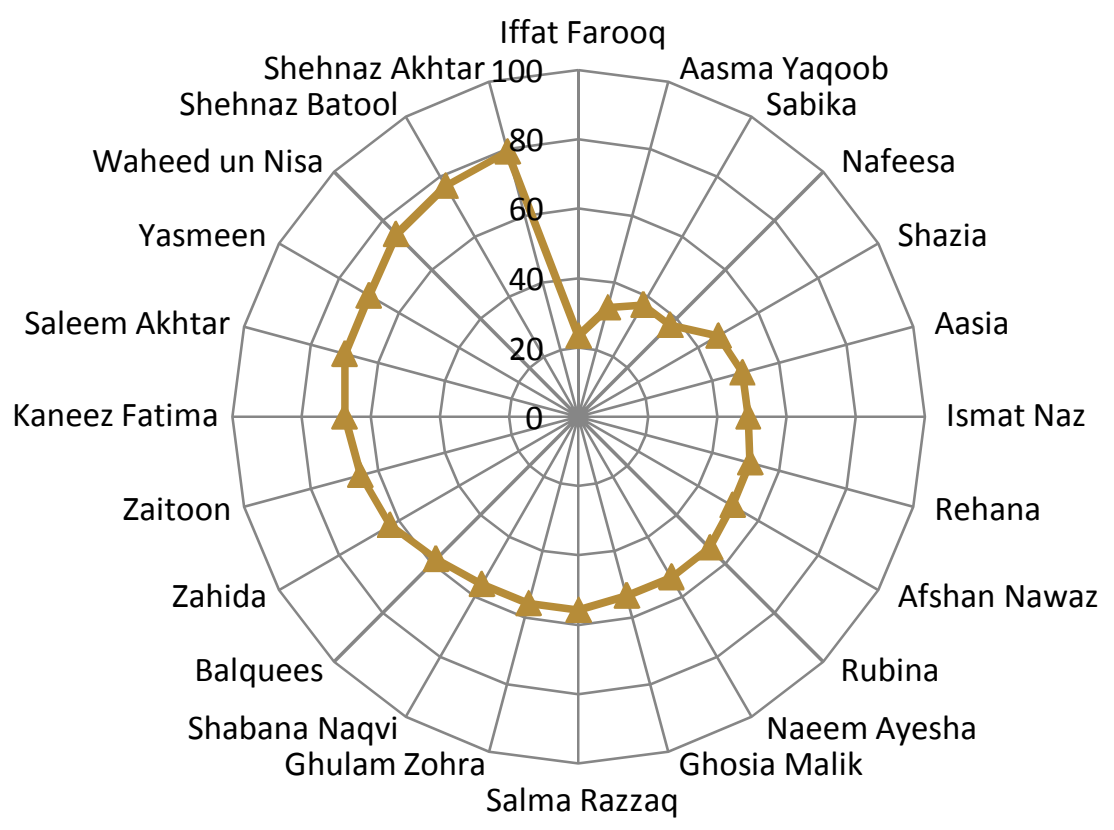

\section{Figure C: BHU Kot Qaisrani, D.G. Khan}

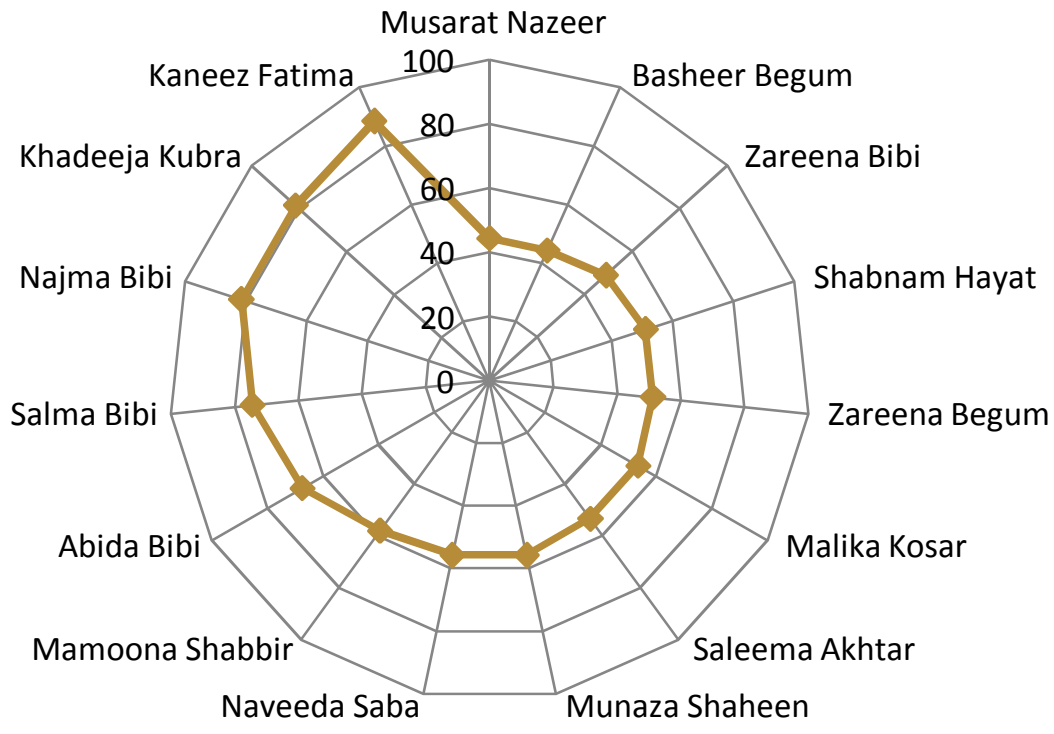




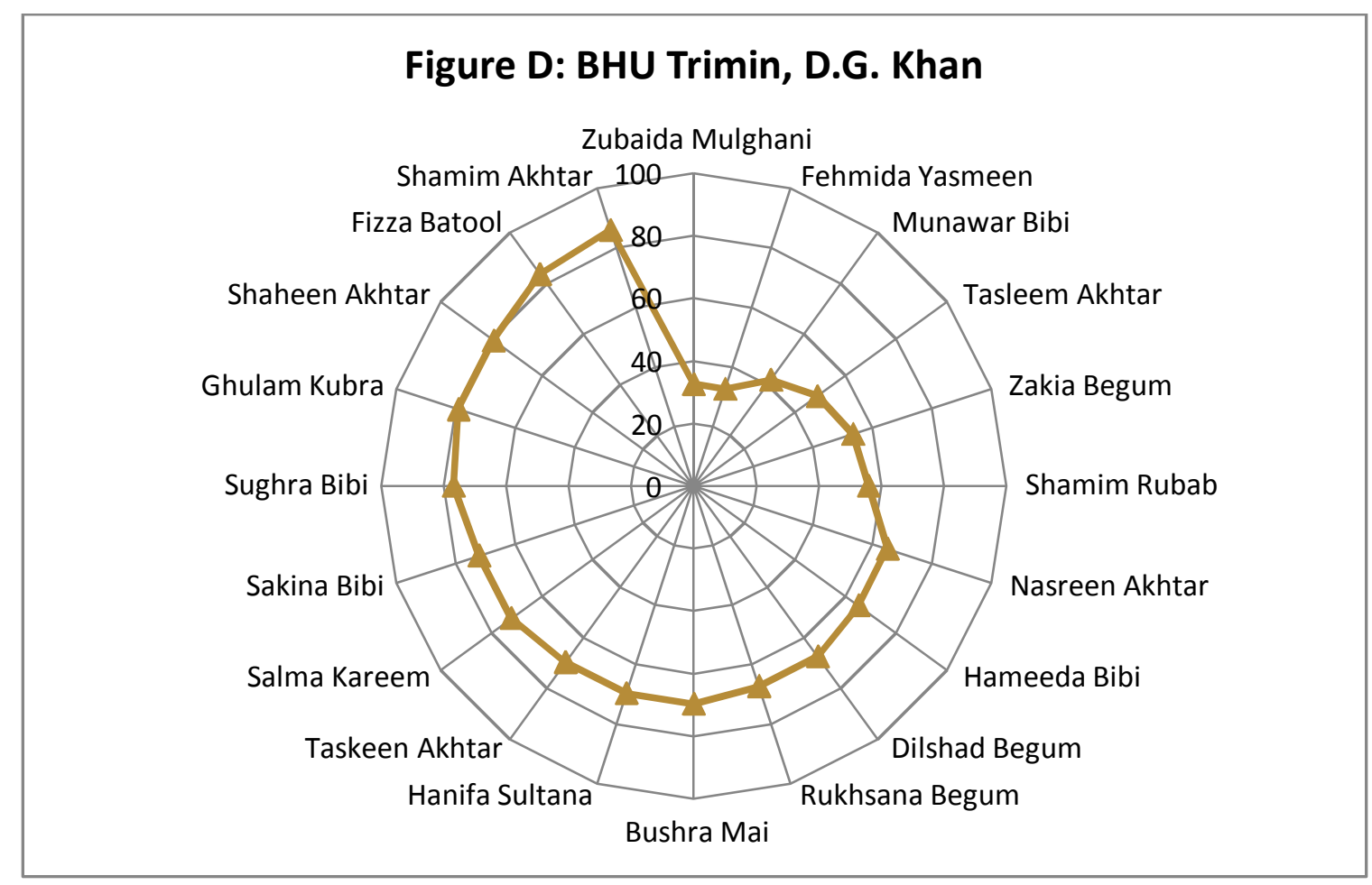

Figure E: BHU Faqirabad, Sukkur

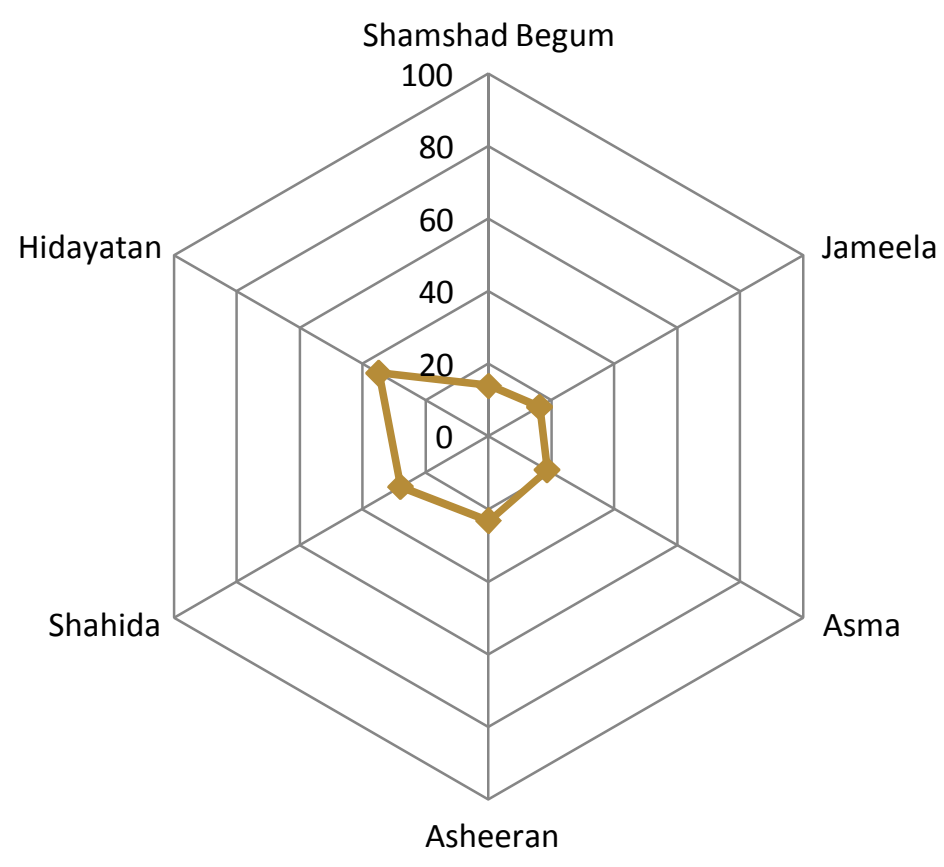




\section{Figure F: BHU Kandhra, Sukkur}

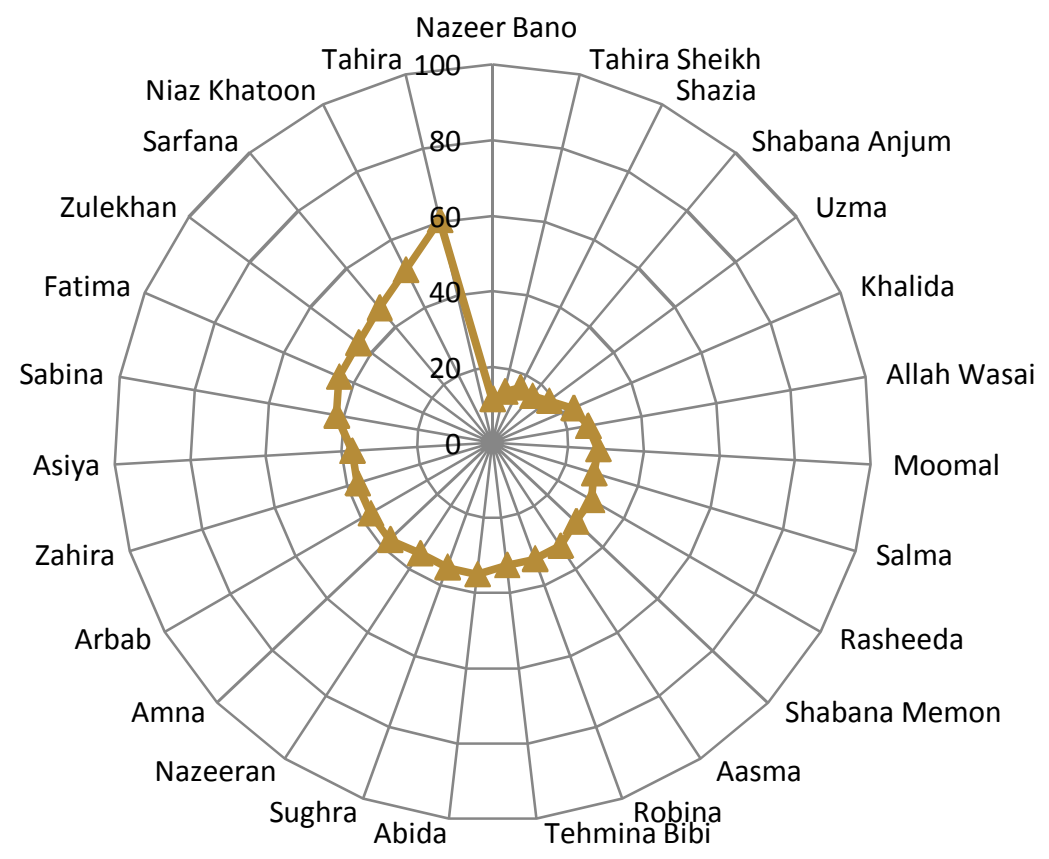


Figure G: BHU Koroona, Mardan

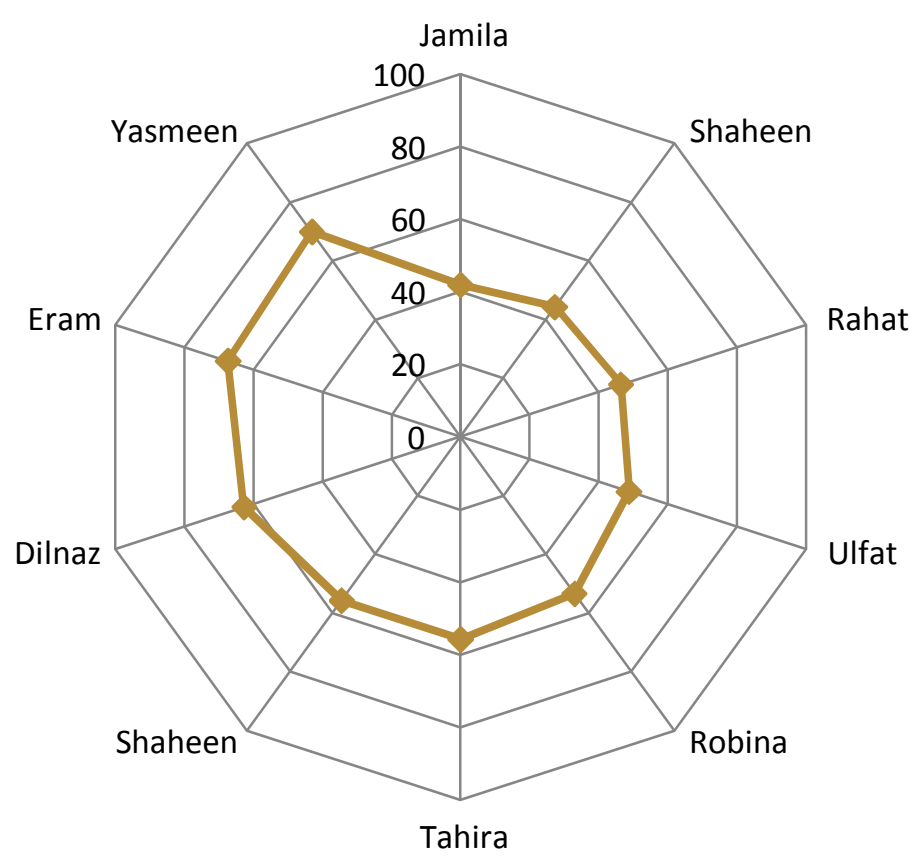

\section{Figure H: CD Baghdada, Mardan}

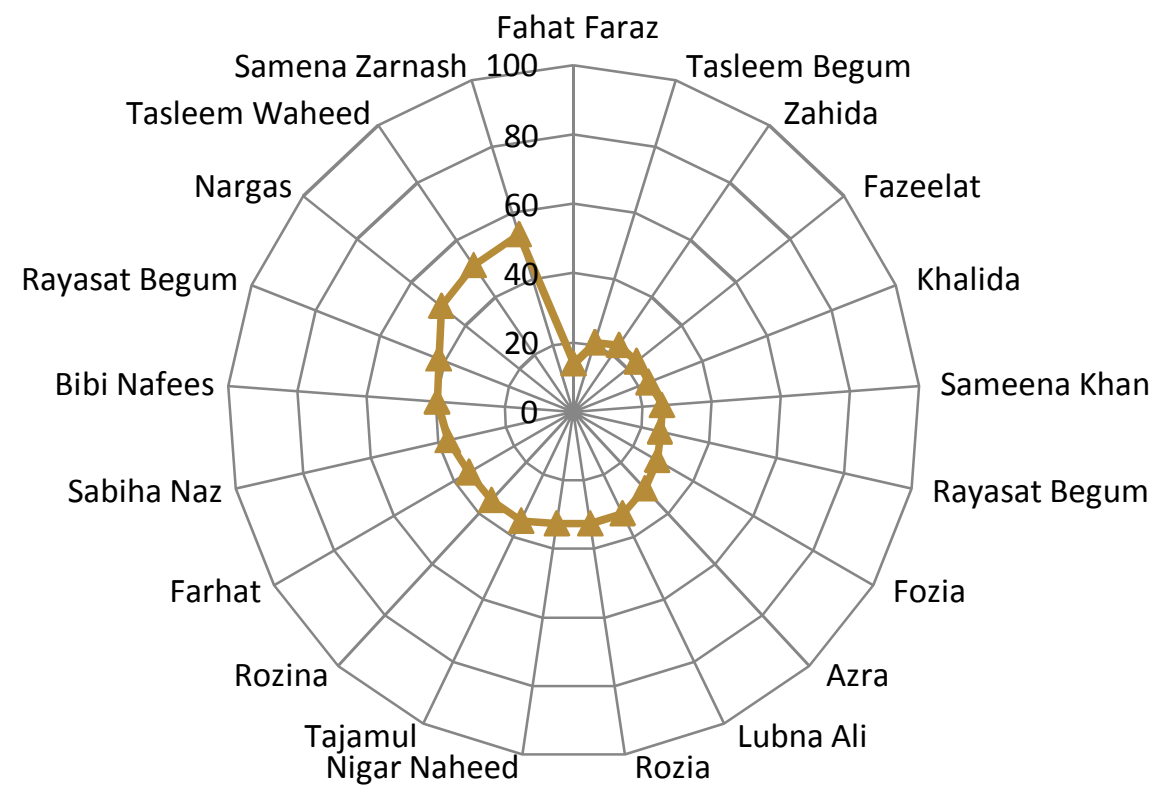


Figure I: RHC Palo Dheri, Mardan

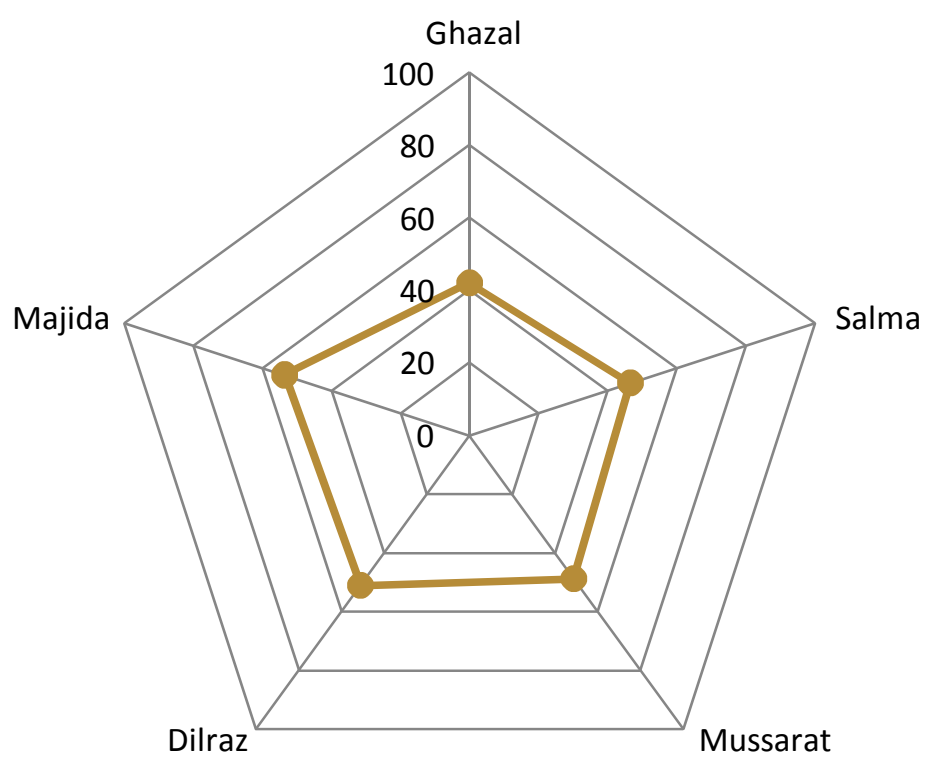

